\title{
Language and cultural identity: Perceptions of the role of language in the construction of Aboriginal identities
}

by

Claire Owen

A thesis submitted to the Faculty of Graduate and Postdoctoral Affairs in partial fulfillment of the requirements for the degree of

\section{Master of Arts}

in

Applied Linguistics and Discourse Studies

Carleton University

Ottawa, Ontario

(C) 2011

Claire Owen 
Library and Archives

Canada

Published Heritage

Branch

395 Wellington Street

Ottawa ON K1A ON4

Canada
Bibliothèque et

Archives Canada

Direction du

Patrimoine de l'édition

395, rue Wellington

Ottawa ON K1A 0N4

Canada
Your file Votre référence

ISBN: 978-0-494-83089-5

Our file Notre référence

ISBN: 978-0-494-83089-5
NOTICE:

The author has granted a nonexclusive license allowing Library and Archives Canada to reproduce, publish, archive, preserve, conserve, communicate to the public by telecommunication or on the Internet, loan, distribute and sell theses worldwide, for commercial or noncommercial purposes, in microform, paper, electronic and/or any other formats.

The author retains copyright ownership and moral rights in this thesis. Neither the thesis nor substantial extracts from it may be printed or otherwise reproduced without the author's permission.
AVIS:

L'auteur a accordé une licence non exclusive permettant à la Bibliothèque et Archives Canada de reproduire, publier, archiver, sauvegarder, conserver, transmettre au public par télécommunication ou par l'Internet, prêter, distribuer et vendre des thèses partout dans le monde, à des fins commerciales ou autres, sur support microforme, papier, électronique et/ou autres formats.

L'auteur conserve la propriété du droit d'auteur et des droits moraux qui protège cette thèse. $\mathrm{Ni}$ la thèse ni des extraits substantiels de celle-ci ne doivent être imprimés ou autrement reproduits sans son autorisation.
In compliance with the Canadian Privacy Act some supporting forms may have been removed from this thesis.

While these forms may be included in the document page count, their removal does not represent any loss of content from the thesis.
Conformément à la loi canadienne sur la protection de la vie privée, quelques formulaires secondaires ont été enlevés de cette thèse.

Bien que ces formulaires aient inclus dans la pagination, il n'y aura aucun contenu manquant.

\section{Canadä}




\begin{abstract}
The belief in an essential bond between traditional language and cultural identity is prominent in discourses promoting Indigenous languages. It is not always clear, however, to what extent this view corresponds to Aboriginal individuals' actual attitudes regarding their languages. Five semi-structured interviews constitute the primary source of data for this study, supported by a focus group discussion and participatory observation. A bottom-up qualitative approach, discourse analysis (DA), is employed to identify major emergent themes and specific discursive features revealing participants' language attitudes. Key themes include social mobility and cultural continuity, pride and shame, names and naming practices, and land. Findings illustrate that although there are other modes of identification, language remains a prominent manifestation of identity for most participants. An awareness of individual perceptions of the presumed language/identity link may have implications for conceptualising Aboriginality, for understanding the role of language in identity negotiation, and for undertaking language maintenance efforts.
\end{abstract}

Keywords: language attitudes, cultural identity, Aboriginal, Canada, discourse analysis 


\section{Acknowledgements}

This thesis could not have been completed without the greatly appreciated support and involvement of a significant number of people. My first debt of gratitude must be paid to the five Aboriginal women who volunteered their time and emotional energy as participants in this project: chi miigwetch (thank you) for your patience, your openness, your strength of character and most of all for sharing with me your own stories and your own truths. I am truly humbled.

I am also deeply indebted to local Aboriginal organisations and community members. Thank you to Mallory Whiteduck, Naomi Sarazin and Irvin Hill at CACE, and Patricia Reynolds and Leslie Cousins at AESP, for your invaluable input during the early stages of research. To the staff at Wabano Centre, Ottawa Inuit Children's Centre and Tungasuvvingat Inuit, qujannamiik for welcoming me and allowing me to participate in the wonderful activities and programmes you offer. Chi miigwetch to Elders Paul Skanks, Cle-alls (John Medicine Horse Kelly) and Willy Bruce for your patience, insight and guidance.

Thanks also go to a number of SLALS faculty and staff: my supervisor Jaffer Sheyholislami for your guidance, encouragement, and countless hours of diligent editing; Ellen Cray for your important insights during the writing phase; Devon Woods for the motivating pep talks; and Joan Grant for always having the answers to my many administrative questions.

Merci infiniment to my partner Shane for your unwavering support and for keeping me grounded, and to my family back home for believing in me. Finally, special thanks to my mother, not only for the constant reassurance from nearly $5,000 \mathrm{~km}$ away, but because it is thanks to your voice and your song that some of the earliest words I heard were in an Aboriginal language:

Hey, hey watenay

Hey, hey watenay

Hey, hey watenay

Kah-ni-ki-nah

Kah-ni-ki-nah

$\sim$ All my relations 


\section{Table of Contents}

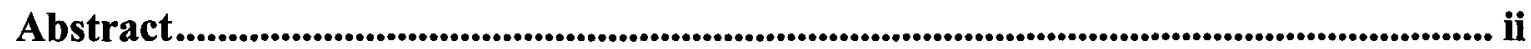

Acknowledgements.................................................................................................................. iii

List of Tables ...........................................................................................................................................vi

List of Appendices...................................................................................................................... vii

List of Abbreviations .......................................................................................... viii

Chapter 1: Introduction .............................................................................................................1

Chapter 2: Literature Review and Theoretical Framework......................................................7

2.1 Identity: Multiplicity, Sameness and Difference........................................................................8

2.2 Language and Identity ....................................................................................................................12

2.2.1 Language functions: instrumental and symbolic.........................................................12

2.2.2 The importance of "mother tongue" ............................................................................ 14

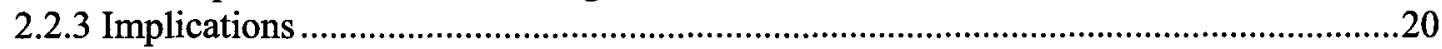

2.2.4 Cultural and bicultural identity ...............................................................................25

2.3 Language Attitudes...................................................................................................................28

2.4 Investigating Language (Attitudes) and Identity: Discourse Analysis ............................32

2.4.1 Studies on language and identity .................................................................................34

2.4.2 Thematic trends in language and identity studies ........................................................42

2.5 Language and Identity in an Aboriginal Context in Canada ............................................43

Chapter 3: Methodology..............................................................................................................57

3.1 Research Questions..........................................................................................................................57

3.2 Ethical Considerations ..............................................................................................................58

3.3 Research Site and Recruitment Process ..............................................................................58

3.4 Participants ..................................................................................................................................61

3.5 Data Collection.............................................................................................................................64

3.5.1 Participatory observation..................................................................................65

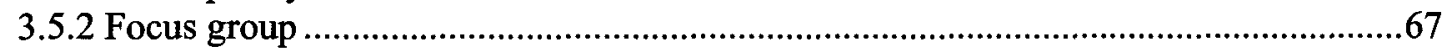

3.5.3 Individual interviews ..................................................................................68

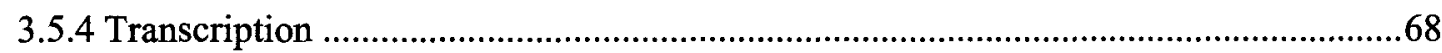

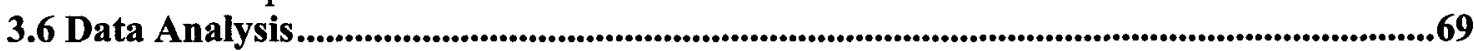

3.6.1 Thematic coding ……………………………………….....................................69

3.6.2 Linguistic analysis ...........................................................................................

3.7 Study Limitations..................................................................................................................................75

Chapter 4: Analysis and Findings .....................................................................................................77

4.1 Social Mobility and Cultural Continuity ................................................................................79

4.1.1 Usefulness: A discourse of social mobility ..............................................................79

4.1.2 Struggle: A discourse of cultural continuity ...............................................................82

4.2 Pride and Shame .......................................................................................................................................88

4.2.1 Pride and belonging...................................................................................................

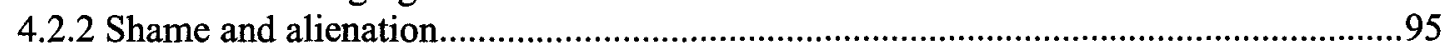

4.3 Names and Naming Practices ...................................................................................................101

4.4 Land ........................................................................................................................110

4.4.1 Language and land........................................................................................110

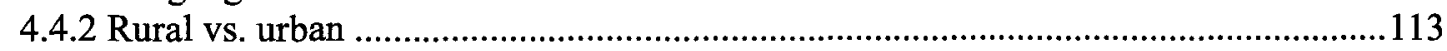




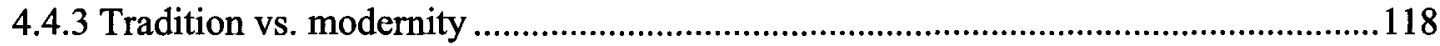

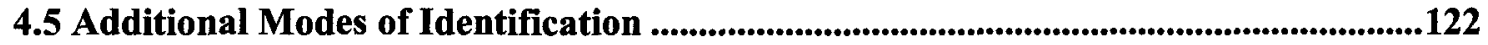

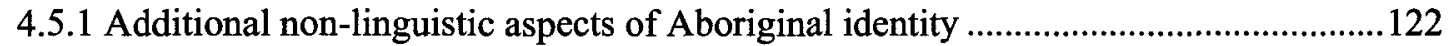

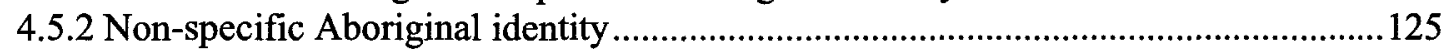

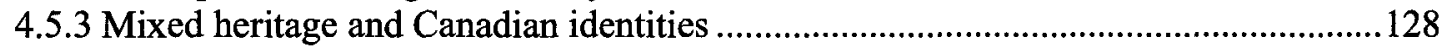

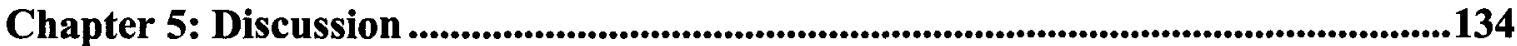

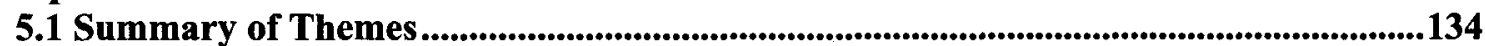

5.2 Summary and Discussion of Individual Attitudes ..................................................137

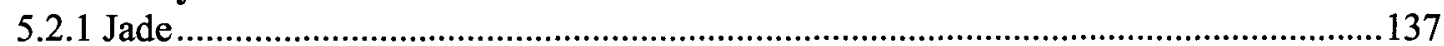

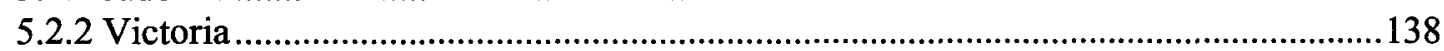

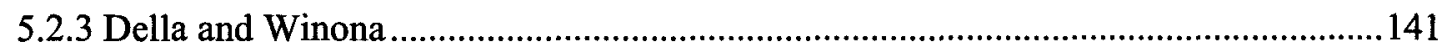

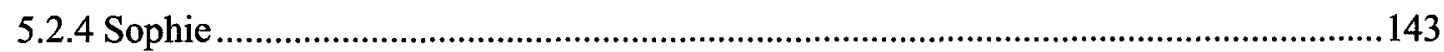

5.3 Beyond Instrumental and Symbolic: A Third Language Function? ..............................144

5.4 Pride and Shame: New Twists on Old Themes? ...............................................................146

5.5 Sketching Cultural Identities in Light of BII ......................................................................151

5.6 Return to the Research Questions............................................................................................154

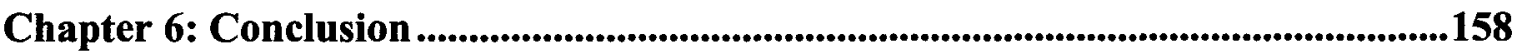

6.1 Further Research Directions...........................................................................................161

References ............................................................................................................... 165

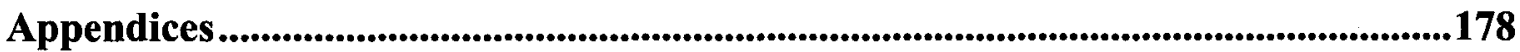




\section{List of Tables}

Table 1: Definitions of mother tongue ............................................. 15

Table 2: Participant data summary ..........................................6 62 


\section{List of Appendices}

Appendix A: Participant Biographies............................................. 179

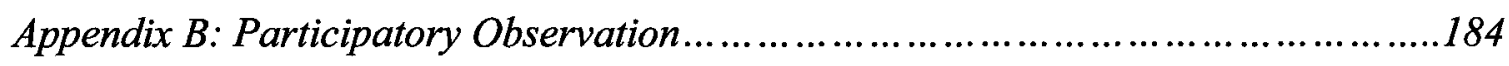

Appendix C: Focus Group Questions............................................185

Appendix D: Sample Interview Questions.......................................... 186 


\section{List of Abbreviations}

$\begin{array}{ll}\text { AESP } & \begin{array}{l}\text { Aboriginal Enriched Support Program } \\ \text { CACE }\end{array} \\ \text { FPHLCC } & \text { Centre for Aboriginal Culture and Education } \\ \text { ITK } & \text { Inuit Tapiriit Kanatami } \\ \text { NS } & \text { Nunavut Sivuniksavut } \\ \text { OICC } & \text { Ottawa Inuit Children's Centre } \\ \text { TEK } & \text { Traditional Ecological Knowledge } \\ \text { TFALC } & \text { Task Force on Aboriginal Language and Culture } \\ \text { TI } & \text { Tungasuvvingat Inuit }\end{array}$


Do not let propagandists of any stripe tell you the native languages are archaic relics of a bygone age, best forgotten. [...] We must continue to use the tongue of the grandfathers and imbibe the wisdom contained therein, for they are the only fixed point in a changing and confusing age, the anchor of identity and meaning.

(Bunge, 1992, p. 380) 


\section{Chapter 1: Introduction}

The dark soft languages are being silenced: Mothertongue Mothertongue Mothertongue falling one by one back into the moon (Atwood, 1995, p. 54)

This thesis is not about the silencing of these "dark soft languages" themselves. It is not about the rights and wrongs of language shift, or the efforts of Indigenous communities to maintain or revitalise their traditional languages. It is not even about Indigenous rights, although this is certainly an important concern underpinning this work. Rather, it is about a collection of lived experiences, of personal realities offering insight into the impact of these languages on individual identities. Specifically, it shares the pain, struggle, joy and hope of five Aboriginal women whose identity negotiation has been influenced in different ways by attitudes regarding their respective heritage languages.

Here, identity is understood to be plural, dynamic, non-fixed and socially constructed (e.g. Bucholtz \& Hall, 2004; Castells, 2004; Edwards, 2009; Lemke, 2008; May, 2008). ${ }^{1}$ Why focus on identity for a thesis in language studies? Because "identity is at the heart of the person, and the group, and the connective tissue that links them. People need psychosocial 'anchors': it is as simple as that" (Edwards, 2009, p. 2). And one such anchor, a very powerful one in fact, can be language. Indeed, as Joseph (2004) observes, any study of language needs to take consideration of identity if it is to be full and rich and meaningful, because identity is itself at the very heart of what language is about, how it operates, why and how it came into existence and evolved as it did, how it is learned and how it is used, every day, by every user, every time it is used. (p. 224)

The precise nature of this relationship between language and identity, however, is a contested topic. Some believe that a particular language is fundamental to a particular

\footnotetext{
${ }^{1}$ This is further explained in chapter 2 .
} 
ethnic or cultural identity, in part because it is thought to "encode" a cultural worldview and traditional forms of knowledge (Bunge, 1992; Fishman, 1991; Nettle \& Romaine, 2000; Skutnabb-Kangas \& Dunbar, 2010). Others find this characterisation too essentialist, and feel instead that language is a contingent marker of identity (Edwards, 2009; May, 2004, 2008), or even that it is simply a surface "behavioural" feature, so that a specific language is easily replaceable by another with no change to the underlying or "primordial" aspect of that identity (Eastman, 1984).

In the context of Aboriginal groups in Canada, as well as Indigenous people more generally, the former position (fundamentally linking language to identity) is quite widespread (e.g. First Peoples' Heritage, Language and Culture Council, 2010; Johnston, 1991; Task Force on Aboriginal Languages and Cultures, 2005; see also Patrick, 2007 for a review of the latter). This is connected to a broader overall mobilisation, particularly since the latter half of the twentieth century, in the pursuit of Indigenous rights concerning land claims and increased political autonomy, or self-determination. ${ }^{2}$ Overlapping with this movement is a growing international discourse of language endangerment in the face of the perceived "linguistic McDonaldization" that has accompanied globalisation (Heller \& Duchêne, 2007, p. 5); this discourse is also intertwined with arguments advocating minority language rights (e.g. Skutnabb-Kangas \& Bucak, 1995). Aboriginal languages figure prominently among those that are now in danger of disappearing, particularly as a result of past colonial assimilationist policies that interrupted or altogether stopped the intergenerational transmission of these languages. Consequently, in the public sphere the reclamation of Aboriginal languages has become symbolic of the struggle for self-determination; as Patrick (2007) observes, "language

\footnotetext{
${ }^{2}$ This concept is addressed in chapter 2 .
} 
endangerment is broadly conceived as political and cannot be factored out of the larger concerns of restitution of land, resources and autonomy" of Aboriginal peoples (p. 45).

Despite the prevalence of this discourse, however, it is not always clear to what extent it actually reflects the lived reality of Aboriginal individuals and the connection they may (or may not) feel with their traditional language - particularly for those communities in which the language is no longer spoken by a significant portion of the population. It is this concern regarding the individual experience that gave rise to the direction of my research. The main objective of the present study, then, is to investigate the ways in which an Aboriginal language is (or is not) experienced as a salient marker of an Aboriginal identity on an individual level. ${ }^{3}$ This is pursued in the form of the following three research questions:

1. Is heritage language a salient aspect of participants' respective Aboriginal identities?

2. If so, in what way(s) is this language experienced as salient by each individual? What similarities and differences exist among these individual experiences, and what social, political, geographical or other factors might account for them?

3. To what extent do these personal, individual experiences correspond to or diverge from theoretical perspectives on language and identity? Do participants emit essentialist discourses, or deny linguistic rootedness, or something in between?

Note that this enquiry is equally important to undertake for non-speakers, partial speakers, and fluent speakers of Aboriginal languages, because all individuals' identity construction - not just that of speakers - is influenced to some degree by particular ideologies, including linguistic ones.

To carry out this study, I use the interdisciplinary research approach of discourse analysis to examine the language attitudes of participants. Discourse analysis views

\footnotetext{
${ }^{3}$ Note that my use of the term Aboriginal here serves as a general "formula," but in practice I investigate the perceived link between Cree language and identity, between Inuktitut and Inuit identity, and so on.
} 
language as situated social practice, and holds that language use is ideological in the sense that the linguistic choices we make reflect certain underlying beliefs, attitudes and assumptions about the world (Fairclough, 2001; Gee, 2011; Wodak, 2006). Individual interviews and a focus group transcript are therefore analysed in order to identify thematic trends in the data, as well as specific linguistic features - such as metaphors, pronouns, presuppositions, and others ${ }^{4}$ - that are particularly revealing of participants' attitudes towards language and other potential indexes of identity. My approach to this analysis is grounded in a number of other studies - with a focus on Indigenous communities - that use qualitative ethnographic methods, including discourse analysis, to investigate the language/identity connection. These studies provide a theoretical framework for the kinds of themes I might expect to find in my own data, while still allowing for the possibility of new perspectives to be accounted for. Finally, my approach is further complemented by participatory observation and my ongoing involvement in Ottawa's Aboriginal community; Johnstone (2000) notes that this kind of engagement allows researchers to "focus an ethnographic eye on sociolinguistic phenomena" (p. 81). Some of this involvement has included consultations with Elders and other community members, whose teachings have provided me with additional insight into individual perceptions of language and identity.

Due to the small sample size and variables among participants, this study does not aim to find trends within a single Aboriginal nation. Indeed, as the premise of this research is a focus on individual experience, generalisation across participants or their respective communities is necessarily limited. Instead, this study is intended to contribute to an understanding of specific ways in which some individuals may (or may not) relate

\footnotetext{
${ }^{4}$ These are elaborated upon in chapter 3.
} 
to their traditional language, while considering the highly situated nature of these perceptions. That is, I take into account both macro-level factors (broad social, political, and historical contexts) and micro-level elements (cultural norms and personal experiences) within which participants negotiate the complexities of identity construction.

The results of the analysis show that heritage language is highly symbolic of the Aboriginal identities of three of the five participants, including non-speakers and a fluent speaker. A fourth participant (a partial speaker) exhibits contradictory attitudes towards her language but clearly does identify with it on some level, and as for the fifth (a nonspeaker), she appears to make no symbolic connection whatsoever between her Aboriginal language and identity. Overall the salience of language for cultural identity is manifested in a number of key “themes" arising in participants' discourse. These themes include social mobility and cultural continuity; pride and belonging; shame and alienation; names and naming practices; and the broad category of "land" which is further broken down into language and land, urban vs. rural, and tradition vs. modernity. While these themes indicate certain commonalities among participants, they are experienced quite differently depending on the individual. The significant variation among participants' views suggests that prominent Aboriginal discourse essentialising the link between language and cultural identity does not reflect the personal realities of all individuals and may not adequately account for the highly situated and complex nature of identity construction. Overall, I feel that this research serves as a kind of small, exploratory case study that may help to "lay the groundwork" for future research by drawing attention to individual identification processes in terms of heritage language.

Finally, the present thesis is organised as follows. Chapter 2 outlines the literature review and theoretical framework underpinning this study, including a discussion of the 
historical context of Aboriginal languages and identities in Canada. The methodology is described in chapter 3 , including recruitment procedures, participant profiles, data collection and data analysis. Ethical concerns and possible study limitations are also addressed here. Chapter 4 contains the principal study findings and is divided by thematic category based on the themes identified during data analysis. It is fairly lengthy, but this is required due to the nature of the individual analysis. Some discussion also necessarily takes place throughout the chapter, in which I account for some of the possible factors influencing the attitudes and beliefs displayed by participants in regards to language and identity. However, a broader discussion of the overall findings, and how they may relate back to my research questions and literature review, is presented in chapter 5 . There, the study's thematic findings are summarised, certain aspects of participants' discourse are revisited in light of my research questions and literature review, and some of what I believe to be the more novel findings are explored in greater detail. Finally, in the concluding chapter I offer a summary of the research process and findings as well as a brief discussion of limitations and possible avenues for future research. 


\section{Chapter 2: Literature Review and Theoretical Framework}

The following is an overview of the topics central to my study as they are discussed in the literature. Broadly, these include the nature and construction of identity; the functions of language and its relationship with identity; language attitudes; discourse analysis; and language and identity in the context of Aboriginal peoples in Canada. I also include illustrative examples of previous studies that investigate the language/identity relationship of specific communities. These studies serve to illuminate certain thematic trends that may appear in connection to language and identity; such themes help guide my own approach to the data collected for this study.

I will show that there is disagreement in the field regarding the degree of importance of language in the construction of identity. This debate is of particular concern due to rapid changes, propelled by the force of globalisation, currently affecting the world's linguistic make-up; many languages are disappearing or becoming endangered as a result of language contact and shift (e.g. Nettle \& Romaine, 2000; Skutnabb-Kangas, 2008). There is a spectrum of opinion among scholars regarding the implications of language shift for a particular speech community. At one end are those who believe that a group's worldview, traditional knowledge, and general way of life are encoded in its ancestral language, so losing that language would have disastrous consequences for that group's cultural vitality and hence identity (Bunge, 1992; Davis, 2009; Fishman, 1991; Nettle \& Romaine, 2000; Skutnabb-Kangas \& Dunbar, 2010). At the other end are those who claim that while language in general is a recognised element of human life and perhaps identity, it is of little import which language is used by a group; that is, their traditional language can be replaced by another with little or no 
change to their identity (e.g. Anderson, 1991 on national identity; and Eastman, 1984 on ethnic identity). I adopt a stance between the two polarities, which is in line with a third camp of scholars (Edwards, 2009; May, 2008). I examine some of the main arguments put forth in this debate, and with this literature review I hope to offer readers a better understanding of the issues at hand before presenting the methodology and findings of my own study.

\subsection{Identity: Multiplicity, Sameness and Difference}

The study of identity per se, as a field of inquiry in itself, is a relatively recent development from the latter half of the twentieth century (Edwards, 2009). Anderson (1991) and Hall (1996) note that pre-modern conceptions of individuality stemmed from age-old, rigid religious and social traditions that did not allow for flexibility or change. People were viewed in terms of their fixed, permanent place in greater society rather than as unique and complex entities, until the notion of the "sovereign individual" (Hall, 1996, p. 602) emerged prior to the eighteenth-century Enlightenment. Since then, more attention has indeed been paid the individual; however, identity was conceptualised as "the very core or essence of our being" with the notion of

the human person as a fully centered, unified individual [...] whose 'center' consisted of an inner core which first emerged when the subject was born, and unfolded with it, while remaining essentially the same continuous or 'identical' with itself - throughout the individual's existence. (Hall, 1996, p. 597)

Then with the growth of nationalism as we know it today - which likely originated with the French Revolution and (especially German) Romanticism (Anderson, 1991; Edwards, 2009) - any conceptions of identity usually became inextricably linked to ethnicity and 
nationality. This, too, remained a simplistic and essentialist formula that defined people according to discrete, pre-existing categories denoting absolutism and fixedness.

Now, however, postmodern discourse in the social sciences holds that individuals have a multifaceted and non-static identity based on affiliations such as gender, age, religion, social class, culture, ethnicity, nationality, kinship roles, sexual orientation and language (Bucholtz \& Hall, 2004; Castells, 2010; Edwards, 2009; Joseph, 2004; Lemke, 2008; May, 2008; Weaver, 2001). Different affiliations may be privileged at different times for a single individual, depending on the context. Indeed, it may even be more accurate to speak of identities, than of a single identity, for as Lemke (2008) observes:

we are always ourselves, but who we are, who we portray ourselves as being, who we are construed as being changes with interactants and settings, with age of life. Identities develop and change, they are at least multi-faceted if not in fact plural. Their consistency and continuity are our constructions, mandated by our cultural notions of the kinds of selves that are normal and abnormal in our community. (p. 19, emphasis added)

This notion of a multiplicity of identities is at the heart of hybridity theory, which is "entirely opposed to universalism, traditionalism and any idea of ethnic or cultural (or linguistic) rootedness" and as such, "is viewed as being able to subvert categorical oppositions and essentialist ideological movements - particularly ethnicity and nationalism" (May, 2008, pp. 38-39). Furthermore, Lemke's (2008) use of the term "construction" (see above) also reveals another crucial aspect of identity as it is understood today: that it is not something we inherently possess from birth, but rather is socially constructed. In fact, in the social-constructivist view, identity is a "fluctuating, contingent and sometimes quite unstable phenomenon: a process, rather than an entity" (Edwards, 2009, p. 23). 
While these two basic tenets - multiplicity and the constructed nature of identity do indeed ring true, one should however be cautious of extreme theoretical positions. Like Edwards (2009), I am wary of the "vigorous assertion of impermanence and contingency" (p. 23) put forth by postmodern hybridity theory. The denial of any and all historical, ethnic, cultural, or other kinds of bond may conflict with the lived experiences of certain groups or individuals for whom these affiliations are actually very salient (Edwards, 2009; May, 2008). Nor are identities constructed, deconstructed, or reconstructed overnight; these processes are complex and highly situated. Thus an extreme social-constructivist view may risk putting undue emphasis on fluctuation and change. ${ }^{5}$

Nevertheless, if we accept that identities are indeed constructed, the question then becomes: how does this process take place? Key to the construction of an identity are the complementary notions of Self and Other, or "sameness and difference" (Bucholtz \& Hall, 2004, p. 369; see also Rajagopalan, 2001). We would not be able to perceive - or even conceive of - our own identity without being faced with another, outside ourselves. Here it is useful to distinguish between personal identity and collective identity. Personal identity relates to the notion of personality: the sense of sameness and continuity that persists across time and space, the self-consciousness and awareness that assures us of "the fact that a person is oneself and not someone else" (Edwards, 2009, p. 19). In this sense, the Self is literally the individual, and everyone else is an Other. Collective identity, however, refers to a sense of group unity whereby one aligns oneself with specific individuals based on certain (perceived) shared characteristics, while

\footnotetext{
${ }^{5}$ Note that the two theoretical polarities of postmodernism and what are considered essentialist discourses are revisited in further detail, later in this chapter, in the context of language and identity.
} 
simultaneously distinguishing oneself from others who do not share these traits.

According to Bucholtz and Hall (2004),

social grouping is a process not merely of discovering or acknowledging a similarity that precedes and establishes identity but, more fundamentally, of inventing similarity by downplaying difference. [...] The perception of shared identity often requires as its foil a sense of alterity, of an Other who can be positioned against those socially constituted as the same. (p. 371, emphasis added)

Thus collective identity is very much a social construction, an "imagined community" as Anderson (1991) famously posits, as the concepts of sameness and difference are relatively fluid and can be manipulated in the service of a sense of "groupness."

This is not to imply that such manipulation is necessarily conscious or calculated, though this may well occur in some instances of nationalist discourse. Rather, one may experience such a strong affiliation in terms of a specific characteristic that it simply overrides points of difference along other traits. For example, a gay or lesbian youth might experience intense feelings of group unity within a GLBTQ ${ }^{6}$ student society despite major differences among its members in terms of ethnicity, nationality, religion, class, language, and so on; in that context, their collective identity is constructed along the lines of sexual orientation. This last notion is so crucial that it warrants repetition: this particular identity is constructed in that context. That is, due to the multiplicity of identities discussed above, manifestations of Self/Other constructions may appear on different levels at different times, or even simultaneously. Thus while I might strongly identify, as a woman, with a group of female peers, at the same time I could still position my identity in opposition to others within that same group based on affiliations of religion or nationality, for example. This point is particularly important to remember in order to

\footnotetext{
${ }^{6}$ Gay, Lesbian, Bisexual, Trans-gendered, Queer.
} 
avoid the same pitfalls of over-generalisations and essentialism that dominated past conceptualisations of identity: that no group is entirely homogenous on all fronts, regardless of the strength and/or number of their apparent similarities (Edwards, 2009; Joseph, 2004; May, 2008).

Having established the plural nature of identity as it is currently theorised, as well as the Self/Other paradigm within which identification processes occur (albeit to varying degrees and along various group affiliations), I turn now to the connection between identity and language, two constructs which are "ultimately inseparable" (Joseph, 2004, p. 13).

\subsection{Language and Identity}

2.2.1 Language functions: instrumental and symbolic

Just as the notion of identity can be fluid and malleable, so too, in many ways, is the definition of language. First, there is the issue of languages versus dialects, a distinction which is largely political - generally bestowing the higher-status title of "language" to speech varieties with large numbers of speakers, high social or economic prestige, official state recognition and/or a standardised oral and written form - and has very little to do with actual characteristics inherent in the speech varieties themselves (Fishman, 1972; Rajagopalan, 2001; Romaine, 2000; Wee, 2011). Some so-called "dialects" are in fact mutually unintelligible, such as Sorani Kurdish and Kurmanji Kurdish (Sheyholislami, 2011), whereas in other cases what are officially considered distinct languages bear remarkable similarities, such as Norwegian, Swedish and Danish (May, 2006; see also Joseph, 2006). With language-dialect boundaries unclear and often 
blurred in this way, experts can only guess at the total number of languages currently in use worldwide; estimates range from six to seven thousand (Davis, 2009; Lewis, 2009). Secondly, language is extremely versatile and permeates all spheres of life, both private and public. As Lakota scholar Bunge (1992) notes, "language is not just another thing we do as humans - it is the thing we do. It is a total environment: we live in language as a fish lives in water" (p. 376). Arriving at a clear, concise and accurate definition that would truly account for the innumerable subtle roles played by this allpervading phenomenon seems a near-impossible task, and not one that I hold myself prepared to attempt. Suffice it to say that language is generally theorised in terms of two main functions: instrumental and symbolic (e.g. Edwards, 1984, 2009; Joseph, 2004; Rubio-Marín, 2003; Sheyholislami 2010). The former refers to language as a means of communication (the ability to understand, and to make oneself understood by, other individuals), which is arguably its most obvious and taken-for-granted function. The latter refers to the representational meanings it carries, particularly as a marker of culture and identity. In its symbolic role, language acts "as an emblem of groupness, a symbol, a psychosocial rallying point" (Edwards, 2009, p. 55). As such, it may be representative of ethnic or cultural traits - such as the Maori language, as opposed to English, in New Zealand - or of other kinds of groupings (such as regional, religious, social class, and so on) within the same language, distinguished by vocabulary, accent or pronunciation. Not only does this apply within a group - that is, emphasising linguistic sameness in the service of collective identity - but also between groups, as a linguistic community positions itself in opposition to the proverbial "Other" whose symbols do not match their own. 
Given that these functions of language (instrumental and symbolic) are so deeply embedded in everything we do, creating that "total environment" (Bunge, 1992, p. 376) in which identities are constructed, projected and interpreted on many levels, the overall language/identity relationship may appear overwhelmingly complex. It is therefore usually approached in terms of more manageable components: the symbolic function of language, and one kind of identity, such as ethnic or national (e.g. Edwards, 2009).

\subsubsection{The importance of "mother tongue"}

It is thus generally accepted in the field that language, in its symbolic role just described, is indeed related to identity; however, its degree of importance is very much subject to debate. Scholars do not agree on whether language in general (as a social practice and means of constructing social identities) is the significant factor, or whether it is a particular language that both shapes and reflects a particular (ethnic, national) identity - such as the Welsh language being an imperative aspect of a Welsh identity. A specific language that is associated with a specific group might be called, among others, a heritage language, a traditional language, an ancestral language, or a mother tongue. The latter term is of particular interest because it is widely recognised and used, yet rarely defined and this despite a large body of literature on mother tongue literacy and education. As it may have implications for identity, I briefly discuss the concept here.

The majority of authors seem to equate the notion of mother tongue with the first language learned and/or the language used in the home (e.g. Gagné 1979; Pennycook, 2002; Spolsky, 2004; Wee, 2011), and this would surely correspond to the way that many people conceive of the term. One notable exception is Skutnabb-Kangas (2008), who 
problematises and "unpacks" the concept in detail and identifies four possible definition criteria, namely origin, identification, competence, and function (p. 86):

Table 1 Definitions of mother tongue

\begin{tabular}{|l|l|}
\hline CRITERION & DEFINITION \\
\hline ORIGIN & the language one learned first \\
\hline $\begin{array}{l}\text { IDENTIFICATION } \\
\text { a. internal }\end{array}$ & $\begin{array}{l}\text { a. the language one identifies with } \\
\text { b. external }\end{array}$ \\
\hline COMPETENCE & the language one is identified as a native speaker of by others \\
\hline FUNCTION & the language one uses most \\
\hline
\end{tabular}

These definitions may apply in various combinations depending on the context. Generally for linguistic majorities all four criteria operate simultaneously, as in the case of Francophones in Québec, for example. However, Skutnabb-Kangas goes on to show that the definitions by competence and function may not be appropriate for linguistic minorities who live, work and/or receive submersion education ${ }^{7}$ in the majority language. In these situations, it is most "fair" identification. However, there are exceptions even to this, as in the case of "forcibly assimilated Indigenous" (p. 87) individuals whose traditional language was never passed down to them from a parent or grandparent generation; in this case it is not their first language, however, it may well be their mother tongue by virtue of internal identification. Thus for Skutnabb-Kangas, "it is possible to have a mother tongue that one does not have (any or 'full') competence in" (p. 88). She also posits that one can have two or more mother tongues, and that the mother tongue can change during a person's lifetime according to all definitions except that of origin (Skutnabb-Kangas \& Bucak, 1995).

\footnotetext{
${ }^{7}$ Submersion education is a "sink-or-swim" model whereby the child is fully immersed in the dominant language with no first language (L1) instruction or support. Research has shown this model to be ineffective and in fact mentally, socially, cognitively and psychologically harmful to students (Fox, 2005; Romaine, 2000; Skutnabb-Kangas, in press; Skutnabb-Kangas \& Dunbar, 2010).

${ }^{8}$ The author notes that "the expression 'not fair' here means that the definition does not respect linguistic human rights, and here especially the right to choose freely what one's mother tongue is" (pp. 86-87).
} 
Given that identification is one of the very criteria (and in fact, the most universally and "fairly" applicable one) that she presents for defining mother tongue, it should come as no surprise that in the scholarly debate mentioned earlier, SkutnabbKangas takes the position that a group's ethnic identity is indeed fundamentally linked to its particular language. Bunge (1992), Davis (2009), and Nettle and Romaine (2000) hold similar views, as does Fishman $(1991,1997)$, who believes that the mother tongue - what he calls "the beloved language" (1997, p. 334) - is imperative to ethnocultural identity. Rubio-Marín (2003) also links culture to a specific heritage language, advocating language rights that "aim at ensuring a person's capacity to enjoy a secure linguistic environment in her/his mother tongue and a linguistic group's fair chance of cultural selfreproduction" (p. 56, emphasis added).

These beliefs are founded in part on the notion of linguistic relativity, also known as the Sapir-Whorf Hypothesis, whereby the language we speak affects our way of thinking and our perception of the world around us (May, 2008, p. 133). This may be interpreted to varying degrees of intensity; some claim that our language actually determines our interpretation of reality, but most take a more conservative stance, which posits that our language merely influences those perceptions. As an example, consider both French and Plains Cree. French grammar assigns masculine and feminine gender to all nouns; the Plains Cree language does not make this distinction, but does incorporate another classification system (Rosen, 2008). Nouns are indexed as being animate or inanimate, but the way these categories are applied may surprise speakers of a European language: objects such as trees and rocks are considered animate, reflecting the Plains Cree cultural belief that elements of the natural world are endowed with a spirit or life 
force. ${ }^{9}$ Thus French speakers and Plains Cree speakers are thought to perceive their environments differently due to the way their languages are structured. The same is thought to be true in reverse; the perceptions and cultural beliefs or values of a society are encoded in the language itself. For Fishman (1991),

that language which has traditionally been linked with a given ethnoculture is, at any time during which that linkage is still intact, best able to name the artifacts and to formulate or express the interests, values and worldviews of that culture. (p. 20)

Similarly, Bunge (1992) believes that "a nation's language is a system of thought and expression peculiar to that nation and is the outward expression and manifestation of that nation's view of the universe" (p. 377). ${ }^{10}$ This intimate link conceived between a specific language and specific culture thus implies that ethnic identity is somehow rooted in the language traditionally associated with that group.

Others find, not without reason, that these arguments are absolutist, essentialist and incompatible with the non-fixed and multifaceted nature of identity. SkutnabbKangas and Dunbar (2010) note that they are "accused of romanticising the importance of languages and especially MTs [mother tongues]" (p. 38); and indeed, May (2008) explains that postmodernist proponents of hybridity "reject any forms of 'rooted' identity based on ethnicity, nationality and (one must also assume) language" as these "are branded with the negative characteristics of essentialism, closure and conflict" (p. 39). Similarly, in criticising strong proponents of linguistic rights and mother tongue education such as Skutnabb-Kangas, Stroud (2001) argues that:

\footnotetext{
${ }^{9}$ For a similar description of animacy in Anishinaabemowin, consult Spielmann (2009, pp. 110-111).

${ }^{10}$ Note that the author's use of the term "nation" here does not (necessarily) reflect its common modern usage referring to countries or nation-states, but rather is synonymous with a sense of peoplehood that corresponds to Fishman's (1991) "ethnoculture" just cited.
} 
What the notion of language rights does is to extend the assumption of language as a fully developed autonomous system from the individual to the collective, resulting in the mother tongue becoming essentialized as $a$ part of the group's ethnolinguistic identity. (as cited in Wee, 2011, p. 130, emphasis added)

Furthermore, scholars such as Eastman (1984) and Anderson (1991) hold that, while language may indeed be an important symbol of collective identity, it does not matter in the end which language is used or associated with which group. Eastman (1984) distinguishes between "primordial" and "behavioural" aspects of ethnic identity and claims that language use is just one surface form of ethnic behaviour or performance; that it doesn't impact the fundamental nature of that identity. As such, "when we stop using the language of our ethnic group, only the language use aspect of our ethnic identity changes; the primordial sense of who we are and what group we think we belong to for the remainder remains intact" (p. 261). In terms of national identity, Anderson (1991) famously refers to nations ${ }^{11}$ as "imagined communities" that come about largely through the presence and implementation of a common print-language uniting individuals in a sense of camaraderie and belonging - and yet, he clearly states that:

Nothing suggests that Ghanaian nationalism is any less real than Indonesian simply because its national language is English rather than Ashanti. It is always a mistake to treat languages in the way that certain nationalist ideologues treat them - as emblems of nation-ness, like flags, costumes, folk-dances, and the rest. [...] Print-language is what invents nationalism, not $a$ particular language per se. (pp. 133-134, emphasis in original)

For scholars on this side of the debate, then, language is seen as a surface feature of identity and any notion of rootedness in a particular language is rejected. While they are right to question the essentialism of those in the other camp, ironically, I find this

\footnotetext{
${ }^{11}$ The author notes that "my point of departure is that nationality, or, as one might prefer to put it in view of that word's multiple significations, nation-ness, as well as nationalism, are cultural artefacts of a particular kind" (p. 4).
} 
camp equally guilty of making generalisations by denying any and all possibility of such "rootedness." That is, while the nature of identity is undoubtedly multiple, dynamic, and socially constructed, none of this should preclude the existence of "roots." Ethnic and cultural identities do not exist in a void; they are constructed in terms of continuity with the past and are highly situated - the products of specific social, political, and historical factors, including "differential power relations" (May, 2008, p. 13). Thus different features (such as language) traditionally associated with a group may vary in salience for collective identity, depending on these contextual factors, and so neither kind of generalisation - essentialist or hybrid - is appropriate. And in fact, rootedness and hybridity need not be perceived as mutually exclusive; I do not believe the language/identity link can be adequately characterised in such black-and-white terms. As Joseph (2004) notes, our goal instead should be "to strive for the intellectual rigour of essentialist analysis without falling into the trap of believing in the absoluteness of its categories, and to maintain the dynamic and individualistic focus of constructionism while avoiding the trap of empty relativism" (p. 90).

This is in keeping with the views of other scholars who seem to adopt a more middle-of-the-road approach, acknowledging that language as a cultural marker may be experienced to varying degrees among different groups (Edwards, 2009; May, 2004, 2008). For example, Edwards (2009) posits that the maintenance of collective identity is not necessarily dependent on "the continuation of a particular, traditional or ancestral language" but is quick to add, "this is not to say that, where such a language has been sustained, it is not an obvious and powerful pillar of identity" (p. 205, emphasis added). Similarly, May $(2004,2008)$ agrees with constructivists that "there is no inevitable correspondence between language and ethnicity" (2008, p. 129), but nevertheless asserts: 
Particular languages clearly are for many people an important and constitutive factor of their individual, and at times, collective identities. In theory then, language may well be just one of many markers of identity. In practice, it is often much more than that. (2004, p. 43, emphasis in original)

These scholars thus espouse a more nuanced interpretation of the language/identity link, emphasising the salience of language inasmuch as it may be experienced by members of a community. To my sense this is a much more balanced approach, however, more specific analyses of differing perceptions of language is still required. Edwards' (2009) discussion remains very theoretical with no in-depth case studies and while May (2008) does examine in some detail the socio-political history of language groups such as Irish, Welsh, Québécois, and Maori, he focusses more on language shift, language policy and minority language rights than the actual ways in which community members do (or do not) identify with their heritage language. I believe much can be learned from a more micro-analytic study of individual perceptions of the language/identity link, and this is ultimately what I focus on in the present thesis. A number of studies that do investigate such perceptions, mainly in the form of ethnographic interviews, are discussed later in this chapter and inform my own approach. At the moment, however, it is important to examine the broader implications of these differing views on language and identity.

\subsubsection{Implications}

After reviewing these arguments debating the degree to which a specific language - that is, a traditional mother tongue - may or may not be fundamentally tied to a specific identity, we are still left with a simple yet glaring question: why should it matter? What are the implications of such a connection, if one exists? Is it not enough to say that people simply conceive of language and identity in different ways? The answer is to be found in 
the phenomenon of language shift - or, in more graphic terms, language death. ${ }^{12}$ This is occurring around the globe at a rate previously unsurpassed; more than half of the world's languages are in danger of disappearing by the end of this century (Nettle \& Romaine, 2000; Skutnabb-Kangas, 2008). If mother tongue is indeed crucial to identity, what then does this mean for those groups whose ancestral language is lost? What might be the impacts on their individual and collective identities? In short, what else may be lost along with the language?

If we follow those who see language as a contingent aspect of identity, language shift is not necessarily cause for concern at all. Eastman (1984), for example, does not subscribe to a fundamental connection between language and culture:

The question of preserving ethnic identity in the face of language change is moot. Language shift or change can only affect one aspect of our ethnic identity - the language use aspect, which is a very low level manifestation of our cultural belief system. [...] There is no need to worry about preserving ethnic identity, so long as the only change being made is in what language we use. (p. 275, emphasis added)

For his part, May (2008) observes that some groups, such as Irish, may abandon their traditional language "while continuing without difficulty to maintain their own distinct ethnic (and national) identities" (p. 129). Certainly, in many situations language shift takes place for reasons of social mobility, where a speech community - often, though not necessarily, a minority group - adopts another language in order to better function within another (usually more powerful) group, improve social standing and prestige, obtain better jobs, earn more money, and so forth (Bonvillain, 2003; Wee, 2011). As May (2006) explains, dominant languages are often associated with progress and modernity while minority languages are seen as archaic and obsolete; in fact, the latter are even seen as

\footnotetext{
${ }^{12}$ Some such as Skutnabb-Kangas and Bucak (1995) and Skutnabb-Kangas and Dunbar (2010) even use the term linguistic genocide, claiming that languages do not die - they are killed.
} 
"obstacles to social mobility" leading to the "ghettoization" of their speakers (p. 263).

Thus switching to a majority language (at the expense of one's first language) is

considered a sensible move towards progress and mobility; some see this as voluntary

language abandonment and as such, can only be helpful, not harmful, to the identities of

those who willingly give it up. However, as Nettle and Romaine (2000) point out, such a

characterisation "puts the blame squarely on the victim" (p. 6). They further note that

many instances of language shift and death occur under duress and stressful social circumstances, where there is no realistic choice but to give in. Many people stop speaking their languages out of self-defense as a survival strategy. (p. 6)

In other situations language is regulated by the state or other institutional authority - a phenomenon known as linguistic imperialism (Phillipson, 1992) - and is thus a more blatantly controlled aspect of society. ${ }^{13}$ Regardless of the cause of language shift, those who do not believe in a fundamental bond between ethnic identity and mother tongue believe that identity can be maintained in other, non-linguistic ways.

The other school of thought holds that with language loss comes cultural loss (e.g. Harrison 2007; McCarty, Romero \& Zepeda, 2006; Nettle \& Romaine, 2000). Fishman (1991) notes that "language shift generally and basically involves [...] quite devastating and profound culture change" (p. 16). For one thing, that unique worldview that accompanies a particular language, according to the notion of linguistic relativity, would be at risk. To return to the example offered earlier, if the Plains Cree language that encodes perceptions of animacy were to fall completely out of use, might those actual beliefs about animacy eventually fade away as well? If languages represent cultures, and

\footnotetext{
${ }^{13}$ See, for example, the oppression of the Kurdish language in Turkey, Iran and Syria (Hassanpour, 2000; Sheyholislami, 2010, 2011; Skutnabb-Kangas \& Bucak, 1995), the Speak-Mandarin campaigns aiming to eliminate other dialects in China (Wee, 2011), and the prohibition of Aboriginal languages in most Indian Residential Schools in Canada (Miller, 1996).
} 
"every culture is by definition a branch of our family tree, a repository of knowledge and experience" (Davis, 2009, p. 5), then the loss of a language is a loss for all humanity, as it means that a part of that collective knowledge and experience has disappeared. Linguistic encoding has also been linked to the natural world and what is known as Traditional Ecological Knowledge (TEK). Skutnabb-Kangas and Dunbar (2010) explain that traditional ecological knowledge and practices often make indigenous/ tribal peoples, minorities, and local communities highly skilled and respectful stewards of the ecosystems in greatest need of protection. Local, minority, and indigenous languages are repositories and means of transmission of this knowledge and the related social behaviors, practices, and innovations. (p. 75, emphasis added)

The authors also offer a concrete example of such linguistic encoding. In Finland, biologists studying salmon reproduction patterns suddenly "discovered" that even very shallow, small streams could be used for spawning. As it later turned out, the traditional names for these streams in the local Indigenous Saami language incorporated the word for "salmon spawning-bed" (p. 77) - hence that knowledge had been there all along. This is just one example of how linguistic and cultural diversity is being linked more and more to biodiversity and ecology (see also Davis, 2009; Nettle \& Romaine, 2000).

Those who adhere to this fundamental link between mother tongue and ethnic or cultural identity (that is, identity in terms of cultural practices, values, beliefs and knowledge) view assimilation and linguistic imperialism as a human rights abuse. Education is one of the main concerns here, as it is often considered to be the principal vehicle of said assimilation. Skutnabb-Kangas is a champion of linguistic rights, along with others such as Fishman (1991), Phillipson (1992, 2000), Hassanpour (2000), Cummins (2000), Rubio-Marín, (2003), and Kymlicka and Patten (2003). Language rights activists advocate for mother tongue education of minority children, especially in 
the early years and for an extended period of time (usually 6-8 years from first entering school) before transitioning to the dominant language of their region. This has been shown to improve students' mental, social, cognitive and psychological abilities (Fox, 2005; Skutnabb-Kangas, in press; Skutnabb-Kangas \& Dunbar, 2010). Fox (2005) discusses a successful mother tongue education initiative in a small island nation where curricular reform was achieved on a massive scale, establishing students' first language, Creole, as the initial medium of school instruction to be followed by a gradual transition to English - as opposed to the previous English submersion model. Over time, this shift showed impressive results, including improved literacy levels (in both languages), math skills, and critical thinking in primary students. This illustrates "the dependency of second-language acquisition on the development of children's mother tongues" (Alidou, 2004, as cited in Fox, 2005, p. 267).

Another argument, though less common, for the maintenance of language diversity through mother tongue education is economical. Skutnabb-Kangas and Dunbar (2010) state that such education models can create high-level multilingualism, which enhances creativity and thus leads to innovation, followed by investment. They claim:

Assimilation leads to homogenisation, and homogenisation, also in education, kills creativity. MLE [multilingual education] works against homogenisation; it maintains diversity and fosters creativity. Creativity is the main asset, the main cultural capital that is needed in knowledge/ information/networking societies. Homogenisation is bad economics. Human survival depends on creative solutions to the serious global and local problems of our own making. (Skutnabb-Kangas \& Dunbar, 2010, p. 75 , emphasis added)

Thus a variety of arguments - unique worldviews and cultural practices, biodiversity and TEK, education, and even economics - are put forth in support of the position that the loss of mother tongues and consequent linguistic assimilation can have disastrous 
consequences, both for the particular group in question (hence, their ethnocultural identity) and for humanity at large. While I remain wary, as noted above, of their essentialist tones, such views do raise important concerns for those communities and individuals who, because of specific social, political and historical factors, may perceive their heritage language to be a key part of their identity. If a specific language is thought to be a vessel of specific cultural knowledge or traditions (regardless of whether it actually is, "objectively" speaking), then surely the loss of that language has an impact on the cultural identities of group members. Arguments such as these, then, may provide a background or framework for understanding individuals' perceptions of the importance of a traditional language for their cultural identity.

\subsubsection{Cultural and bicultural identity}

Before moving on to the next section addressing language attitudes, it is important to clarify my use of certain terminology. I would now draw attention to the term "cultural identity" just mentioned, which I have thus far used synonymously with the "ethnic" or "ethnocultural" identity more commonly found in the literature. However, I do not find the term "ethnic" to be entirely suitable for the present study. First, I am uncomfortable with this label as it can carry implications of race, which in terms of biology is a "widely acknowledged scientific falsity (there are no such thing as 'races')" (Fenton \& May, 2002, p. 2). This could therefore be particularly problematic for the identities of those with mixed ancestry. Second, the terms "ethnic group" and "ethnic minority" are most often used for immigrant populations (May, 2006), which is inappropriate for Indigenous peoples who are the original habitants of the country known as Canada; furthermore, they 
imply a power dynamic whereby "ethnic" is conceptualised as subordinate to a dominant, normative, and somehow non-ethnic majority (May, 2008).

Instead, I find the concept of cultural identity to be more inclusive of all peoples who group themselves around a "shared cultural heritage" (Joseph, 2004, p. 163). In addition, "cultural" is more evocative of the kinds of changes feared to result from language loss by those who believe that a specific mother tongue is indeed crucial to a specific identity (as discussed in the preceding paragraphs). As one scholar points out, "the speaker's attachment to his variety and his language is symptomatic of the cultural load his language carries for him" (Pandit, 1975, as cited in Rajagopalan, 2001, p. 25, emphasis added). Geertz (1973) defines culture as:

an historically transmitted pattern of meanings embodied in symbols, a system of inherited conceptions expressed in symbolic forms by means of which men communicate, perpetuate, and develop their knowledge about and attitudes towards life. (p. 89)

The notion of culture thus implies common values, epistemologies, and behaviours - in other words, the ways of life of a community (Giddens, 1993). Similarly, Indigenous scholar Weaver (2001) uses the term cultural identity "as reflected in the values, beliefs, and worldviews of [I]ndigenous people" (p. 240). In the present study, it is understood as referring to each individual's Aboriginal affiliation - that is, Cree identity, Inuit identity, and so forth - without necessarily imposing a framework of "ethnicity" on participants.

This being said, it is important to recognise that study participants cannot be assumed to have just one cultural identity. Given the fact that these particular individuals live in and interact with Canadian society, and happen to be of mixed ancestry (this is addressed in chapter 3), they may experience other cultural identities besides their Aboriginal affiliations. While their Aboriginal identities remain the focus of my study, 
and a detailed examination of additional cultural affiliations would prove beyond its scope, nevertheless I do take the latter into account by considering bicultural identity integration (BII). Huynh, Nguyen and Benet-Martínez (2011) provide a useful and thorough explanation of the BII construct, a framework for investigating the identification patterns of "people who have internalized at least two cultures" (p. 828). ${ }^{14}$ Briefly, they perceive two separate components of bicultural identity: blendedness (vs. compartmentalisation), and harmony (vs. conflict). The former reflects the degree to which an individual sees her identity as mixed (e.g. Japanese-Canadian, as opposed to Japanese in Canada), while the latter refers to the perceived level of cultural compatibility or strain (e.g. feeling caught, or not, between cultures). In other words, "BII blendedness captures the organization and structure of one's two cultural orientations, whereas BII harmony indexes the feelings and attitudes toward those cultures" (p. 832). Significantly, the authors stress the subjectivity of BII, similar to my earlier emphasis on the importance of individual perceptions of language and identity, rather than any theoretically inherent qualities thereof (be they essentialist or hybrid).

While the preceding admittedly constitutes only a very brief description of the BII construct, it is an important concept to keep in mind - if only in a general sense - as a framework within which to understand participants' orientations towards their cultural identities (which will be more fully explored in the analysis and discussion chapters). For the moment, however, we return to the issue of the language/identity connection in terms of how it can be investigated in the first place: by examining language attitudes.

\footnotetext{
${ }^{14}$ Note that not all individuals who might "objectively" be seen to have two cultures necessarily identify as such. While biculturalism is indeed one kind of acculturation strategy, others include assimilation (identification with the dominant culture only), separation (identification with the "ethnic," or in this case Aboriginal, culture only), and marginalisation (identification with neither culture) (Huynh et al., 2011). This, too, is kept in mind when considering participants' cultural identities.
} 


\subsection{Language Attitudes}

Language attitudes are merely one kind of attitude, and as such must first be situated within the broader context of general attitude theory. Baker (1992) emphasises the importance of the concept of attitudes, particularly in education and psychology, calling it "an important explanatory variable" that "for over sixty years [...] has repeatedly proven a valuable construct in theory and research, policy and practice" (p. 10). Rosenberg and Hovland (1960) put forth the original tripartite attitudes model that has since become widely accepted and utilised. This model identifies three attitudinal components - cognitive, affective and behavioural - which merge together and operate in response to the object (real or symbolic) in question. ${ }^{15}$ Garrett, Coupland, and Williams (2003) offer concrete examples of these three aspects:

[Attitudes] are cognitive in that they contain or comprise beliefs about the world (for example, that learning the Welsh language will help me get a better job in Wales). They are affective in that they involve feelings about an attitude object (for example, enthusiasm for poetry written in the Welsh language). And they are systematically linked to behaviour, because they predispose us to act in a certain way (for example, to learn Welsh). (p. 3)

The authors go on to explain, however, that the behavioural aspect can be somewhat problematic. A common assumption holds that attitudes can be accurately inferred based on behaviour, and conversely, that behaviour can be consistently predicted according to known attitudes; however, studies show there is often a lack of cohesion between an individual's stated attitudes and his/her actual behaviour. While the cognitive and affective aspects of attitude (that is, one's thoughts and feelings) may remain private within the individual, outward behaviour is often constrained by the social context in

\footnotetext{
${ }^{15}$ For an alternative model of attitude structure, see Martin and White (2005) who, in their study of the language of evaluation, identify the three attitudinal components affect, judgement and appreciation. They consider affect (emotion) to be at the heart of this triad and view judgement and appreciation as "institutionalised feelings" (p. 45), that is, affect as it is influenced or manipulated by socio-cultural norms.
} 
which it occurs. As Baker (1992) points out, it is important to consider the relative specificity of the attitude and behaviour. That is, studying a general attitude (such as a non-Irish speaker's attitude towards the Irish language) is not likely to allow us to accurately predict a far more specific behaviour (such as whether s/he will enroll in an Irish language class). In this sense, then, attitudes are perhaps better conceptualised as a "mental construct" (Garrett, 2007, p. 116) with emphasis on cognition and emotion. Attitude can also be seen as both "input" and "output" (Baker, 1992; Garrett, 2010), a view that arises from educational research. Acting as input, an attitude (positive or negative) towards an activity or skill may contribute to one's respective success or failure in that skill. Conversely, as output, a specific attitude towards an activity may develop as a result of engaging in that activity, such as a language class. In this way, attitudes both influence and are influenced by social context and experiences; they are "a fundamental part of what is learned through human socialization" and are both "sociallystructured and socially-structuring phenomena" (Garrett et al., 2003, pp. 4-5). Similarly, Garrett $(2007,2010)$ notes that attitudes are learned rather than inherent. This conceptualisation of attitudes is reminiscent of the notion of identity, which as established earlier is also a learned social construct that both influences, and is influenced by, the world around us.

Another important term, often used interchangeably with attitudes, is ideology. For Baker (1992), “ideology tends to refer to codifications of group norms and values. At an individual level, ideology tends to refer to broad perspectives on society - a philosophy of life. In this sense, ideology may be a global attitude" (p. 15, emphasis added). In general, then, I understand and use the term attitude to refer to individuals' beliefs and feelings, and ideology in the broader context of the values of a social or 
cultural group. Garrett (2010) holds a similar view: "language attitudes research can arguably be seen $[\ldots]$ as one set of methodological options for studying language ideologies" (p. 35).

In terms of languages, then, the study of attitudes can be an extremely useful tool, particularly in the context of language shift. Bradley (2002) feels that "the crucial factor in language maintenance is the attitudes of the speech community concerning their language" (p. 1); and of course it follows that it is equally important to investigate what factors influence those language attitudes. Baker (1992) states:

The status, value and importance of a language is most often and mostly easily (though imperfectly) measured by attitudes to that language. Such attitudes may be measured at an individual level, or the common attitudes of a group or community may be elicited. (p. 10)

Knowledge of individual and group attitudes towards a traditional language, and thus its perceived "status, value and importance," is key to understanding how any proposed language policy and planning initiatives will play out. The attitudes and beliefs of community members must be taken into account in order for revitalisation projects, bilingual education programmes, and other endeavours to succeed. Baker (1992) goes on to identify several specific domains within language attitudes research, including but not limited to: attitude to language variation, dialect and speech style; attitude to a specific minority language; attitude to language groups, communities and minorities; attitude to language lessons; and attitude to the uses of a specific language (p. 29). By studying these kinds of attitudes, we are also indirectly studying identity; the emotional aspect of attitude is an intricate part of "the concept of the individual self - hence of identity. There is a widespread tendency to locate who one is - one's subjective self - in one's individual feelings" (Joseph, 2004, p. 17). Thus language attitudes can reveal important aspects of 
identity, particularly when we study an individual's attitude towards his/her own ancestral language.

The study of language attitudes is generally approached via one of three different methods, namely the societal treatment approach, the indirect approach and the direct approach (Baker, 1992; Garrett, 2007, 2010). The first is based principally on observational data and public-domain language sources (such as media advertisements, government publications, television shows, etc.); the second usually involves a degree of subtlety or deception, as participants are generally not aware of what, specifically, is being investigated. ${ }^{16}$ The direct approach, however, is characterised by the self-reporting of attitudes on the part of participants, usually in the form of questionnaires and/or interviews. Garrett (2007) notes that the use of (arguably artificial) speech recordings and fixed attitude-measurement scales is a growing concern in the field, and that some are calling for more qualitative methods instead, such as interviews and discourse analysis. It is within a similar framework that I have undertaken the present study on the language attitudes of Aboriginal individuals. In the next section I present a brief overview of the method of discourse analysis, followed by a review of specific studies using interviews and/or discourse analysis in order to investigate language attitudes and, in particular, language and identity. Special attention is paid to research in Indigenous communities.

\footnotetext{
${ }^{16}$ The most common indirect method is the matched-guise technique (MGT), developed by Lambert, Hodgson, Gardner and Fillenbaum (1960), whereby participants listen to speech recordings and are asked to evaluate the speakers by filling out attitude-rating scales. They are told that they are listening to different people, but in reality it is one speaker reproducing different speech styles. According to Garrett (2007), "the rationale is that all speech features apart from the one under investigation (accent) are controlled out, so that any differences in listener evaluations must be because they judge accents differently" (p. 117).
} 


\subsection{Investigating Language (Attitudes) and Identity: Discourse Analysis}

Discourse analysis (DA) emerged in the 1960s (Bhatia, Flowerdew \& Jones, 2008 ) and is an umbrella term that in fact covers a wide variety of methods and can involve working with quite different types of data sets, both written and spoken, formal and informal, and drawn from any and all genres. In DA, language is viewed as a social behaviour, and all linguistic interactions are thus situated and contextual. Sheyholislami (2010) notes that "discourse is a social practice; it is simultaneously constitutive of and constituted by social structures, relations and identities" (p. 294; see also Weiss \& Wodak, 2003). Because language and discourse permeate all areas of life - and indeed, DA is quite simply "the analysis of language in its social context" (McCarthy, Matthiessen \& Slade, 2002, p. 57) - they have become an object of study in several different academic domains. As a result of this interdisciplinary nature of DA, a number of approaches have developed within the field. These include, but are not limited to, corpus linguistics, ethnography, genre analysis, conversation analysis, and critical discourse analysis (CDA) (for detailed overviews see Bhatia et al., 2008; Johnstone, 2003, 2008; and McCarthy et al., 2002).

Wodak (2006) identifies a useful set of characteristics and guiding principles for CDA, which actually constitute an excellent framework for DA in general. Among these properties are interdisciplinarity, orientation to social problems rather than specific linguistic items, incorporation of ethnography, a continuous movement back and forth between theory and data, and the importance of context. To elaborate on the latter point in particular, despite the fact that different approaches to DA abound, they do share the central notion that language and discourse are intertwined with social phenomena such as gender, class, power relations, institutional genres, beliefs, attitudes, ideology, and so on. 
In this way, DA becomes a useful and appropriate tool for acknowledging the multiplicity of identity as it is constructed in different contexts; as Gee (2011) notes, "in language, there are important connections among saying (informing), doing (action), and being (identity)" (p. 2).

Similarly, Eggins (2004) notes that "whatever genre we are involved in, and whatever the register of the situation, our use of language will also be influenced by our ideological positions: the values we hold (consciously or unconsciously), the biases and perspectives we adopt" (p. 10). In other words, the way we choose to construct our discourses and narratives is not random or meaningless; rather, there are reasons - often unconscious ones - that we use particular lexical items or grammatical structures, such as active or passive voice, verb modality, pronouns, or metaphors. These choices can thus offer clues to our attitudes, worldviews, and even identities. To offer a brief example, consider the following two simple sentences (invented for illustrative purposes):

(a) I speak my language regularly in my community.

(b) Algonquin is spoken regularly in the community.

While the surface meaning of these two statements remains the same, the linguistic choices illustrate important differences in terms of emotion and identity. In (a) the speaker twice uses the possessive pronoun "my" to indicate a strong sense of attachment or belonging to a particular group, as well as expressing ownership of the language as if it is a possession. Furthermore, the active voice ("I speak") represents agency and personal involvement - and perhaps pride as well - on the part of the speaker. By contrast, the use of the passive voice in (b) could symbolise the speaker's detachment or removal from both the language and the community, as if s/he were an objective or ambivalent observer 
simply reporting a fact. Both of these sentences therefore contain linguistic features that offer important clues to their social meaning.

Thus DA can be used to analyse a spoken or written text on two levels: content and structure (Gee, 2011). Some approaches employ a general or "holistic" interpretation of textual meaning (as in some ethnographic interviews), while others make greater use of systematic linguistic analysis in order to arrive at their interpretations of a text. Conversation analysis, for example, usually entails a detailed examination of talk-ininteraction, including pauses and silences, turn-taking, word choice and the grammatical features of participants' speech (Bhatia et al., 2008, pp. 4-5). Given the preceding discussion suggesting that language choice is revealing of speakers' attitudes and ideologies (e.g. Eggins, 2004), I find such systematic linguistic analysis to provide richer and more valid insights into a text than holistic interpretation alone. In the section that follows I briefly review some sample studies that use different methods to investigate questions of language (attitudes) and identity in a variety of contexts.

\subsubsection{Studies on language and identity}

Various theoretical positions regarding the importance of a heritage language for a specific cultural identity were discussed previously in this chapter. I noted that while I generally concur with the more nuanced and context-sensitive views of May $(2004,2008)$ and Edwards (2009), their arguments lack detailed empirical evidence of the ways in which community members do or do not identify with their ancestral language. The following studies do offer valuable insight into such perceptions of the language/identity link, although they too are rather limited in terms of accounting for detailed individual participant "trajectories" - a point to which I return in the next subsection. 
Welsh

Williams (2009) describes a study in the coastal town of Caernarfon, northwest Wales, which has an unusually high percentage of Welsh speakers $-87.6 \%$ as opposed to the $20.5 \%$ average in Wales as a whole. He uses both indirect and direct measures by examining behaviours (in the form of three recent language-related and well-publicised incidents) and by undertaking interviews with six participants, and presents his findings in terms of the three attitudinal components - belief, feeling, and action (behaviour). He finds that territory emerges as a very salient theme, as interviewees consider Caernarfon to be a Welsh-speaking district and feel that it should remain that way; several emphasise the fact that they were born and raised there, as were their ancestors before them, "implying a claim of territorial privilege legitimised through ethnicity" (p. 77). The author also looks at the ways participants differentiate between the categories "Welsh" and "English" and examines the attitudes associated with these labels. He notes the use of linguistic features such as the pronouns "we" and "they" to establish in-group and outgroup membership, respectively, and informs readers that "Welsh is a language where second-person singular/plural pronouns and corresponding verb forms may be marked for solidarity and power" (p. 81). In the end, Williams (2009) concludes that "attitudes towards identity and the role of the language are equivocal. While no Welsh speakers [among his participants] see competence in Welsh as a necessary condition of an individual's 'being Welsh', they nonetheless see it as an important factor" (p. 86).

\section{Inuktitut I}

The abovementioned theme of territory, or land, is also very important for the identities of other groups. As one example, Searles' (2010) findings, based on his 
ethnographic and anthropological fieldwork in the Canadian Arctic during the mid-1990s and early 2000 s, have significant implications for conceptualising Inuit identities. He describes a polarisation of urban and rural in Inuit perceptions of "Inuitness" (p. 153). Living on the land, and the traditional knowledge and skills that accompany such a lifestyle (including hunting, fishing, seal-skinning, speaking the Inuktitut language, and so on) have come to symbolise what it means to be a true or "authentic" Inuk. ${ }^{17}$ By contrast, towns and other permanent settlements are negatively associated with loss of Inuit culture and the dominance of White, Euro-Canadian culture and power. Thus, despite the increasing number of Inuit now living in towns, the notion that an urban Inuit identity (a) exists, and (b) could be just as valid as the traditional, on-the-land conceptualisation of Inuitness, has not yet been accepted by most Northerners (Inuit and Qallunaat ${ }^{18}$ alike). While Searles' central focus is actually the link between identity and land, it turns out that language may play an important role as well:

Authenticity has become an index used to measure the relative Inuitness of people, places, and activities [...] Those Inuit persons, places, and activities that best exemplify (or represent) life before the arrival of Qallunaat qualify as being most genuinely Inuit. An elder who speaks very little English and who is familiar with life before the advent of modern towns and villages is considered to be authentically Inuit. By contrast, those Inuit who have little knowledge of the past, or who do not speak Inuktitut $[\ldots]$ are not considered to be authentically Inuit." (pp. 154-155, emphasis added)

Hence Inuktitut language proficiency emerges as a salient marker of "true" Inuit identity, though not necessarily the most important one. Interestingly, the term Inuktitut is literally translated as "the way of an Inuit person" (Searles, 2010, p. 162) and applies not only to

\footnotetext{
${ }^{17}$ Inuk is the singular form of Inuit.

${ }^{18}$ The original meaning of Qallunaat, and its most common meaning today, is "white people" (Searles, 2010 , p. 152). However, according to anecdotal evidence it is also increasingly being used to refer simply to non-Inuit (Alia, 2007; D. Nakoolak, personal communication, January 29, 2011).
} 
language but also to the traditional social and cultural practices of Inuit such as those mentioned above. This implies a strong link between language and cultural identity, as the ability to speak Inuktitut is equated with the ability to follow the path (that is, to assume the authentic identity) of an Inuk. The other important concept in this discussion is the notion of authenticity, which suggests that there are degrees of Inuitness and that one may be perceived as being relatively more or less Inuit. It is not difficult to see how such a framework could be problematic for the identities of urbanised Inuit who do not fit the traditional criteria of what it means to be Inuit. Thus according to Searles' findings, language, land and authenticity have important implications for Inuit identity.

\section{Inuktitut II}

Patrick (2008; based partly on 2003 findings) has conducted extensive qualitative ethnographic research both in Arctic communities and among Southern urban Inuit in Ottawa, focussing particularly on language, territoriality and identity in light of local, national, and global processes that help shape conceptions of Indigeneity and Inuitness. For example, Aboriginal political mobilisation (especially since the 1970s) regarding territorial rights allowed for the land claim agreements that have effectively redefined traditional Inuit land bases into the four regions of Inuvialuit, Nunavut, Nunavik and Nunatsiavut. International discourse surrounding the rights of Indigenous peoples, including the preservation of heritage languages, has also played an important role in shaping notions of Inuitness.

Like Searles (2010), Patrick (2008) acknowledges an association of Inuktitut and traditional cultural practices with an "authentic" Northern Inuit identity, but notes that variations of such features can still persist in new (Southern) urban settings in the form of 
traditional naming practices, informal economies for the sharing of "country food," and the maintenance of a symbolic connection to the North, particularly in terms of the four Inuit land bases. In this and a related article (Patrick and Tomiak, 2008), she also demonstrates how the emergence of local Inuit organisations, such as Tungasuvvingat Inuit (TI) and the Ottawa Inuit Children's Centre (OICC), allow for a non-geographicallybounded sense of "community" to arise along social networks, cultural programming, and

support systems. This symbolic “"reterritorialization' of their 'deterritorialized' identities" (Patrick, 2008, p. 102) is an example of dynamic and hybrid processes giving rise to new definitions of Inuitness. In terms of language, rather than focussing solely on Inuktitut, she asserts that key to understanding this modern Inuitness is the recognition of bilingual and plurilingual identities for both Northern and Southern Inuit: "Inuktitut, English, and French are all important linguistic markers of what it means to be an Inuk in the twentyfirst century" (Patrick, 2008, p. 104). By considering both macro and micro elements that is, broader socio-political, historical processes as well as the situated, daily realities of linguistic and social attitudes and interactions - she offers a nuanced and contextualised account of the need to reconceptualise notions of Inuit identity in ways that reflect the vibrant, lived experiences of contemporary Inuit.

\section{Navajo}

In another study, McCarty et al. (2006) describe their in-depth ethnographic approach - including participant observation, questionnaires, interviews, and collection of school achievement data - to investigating language and identity among Navajo youth in a small bilingual community of the southwestern United States. Their position is that "by illuminating language attitudes and ideologies," they are able to better understand "the 
role of Indigenous languages within their [participants'] lives, their aspirations, and their senses of self' (p. 31). Focussing mainly on the interview data, they identify the following salient themes: pride, shame, caring, the hegemony of English, and the iconic bonding of English with Whiteness.

The first three are interrelated in the sense that "for these youth, a critical factor capable of transforming self-hate into self-empowerment [that is, shame into pride] was the presence of caring adults" (p. 39). While most participants value the Navajo language and consider it integral to their identities, they also discuss feelings of shame in the face of "racialized discourses that symbolically and concretely link Navajo and Navajo-ness to 'tradition' and English and whiteness to the 'modern' world" (p. 40). ${ }^{19}$ This brings us to the latter two themes, which together create a formula where English is associated with power, Whiteness and modernity. One respondent observes that "the older people will encourage English so [youth] can make it in the Whiteman's world" (p. 39). And indeed, another, older informant explains his decision not to teach Navajo to his children or students: "the world speaks English [...] I think [children] need more English because... when they go off the reservation, they get jobs off the reservation, ... they will be more exposed to English type of culture" (p. 40). Thus the issue of social mobility arises, as the importance and value of the ancestral language is placed in competition with the perceived economic and social benefits of learning English, the dominant language.

Overall the authors' findings imply that a fundamental link is perceived between Navaho language and Navaho identity. When discussing parents who do not pass on the language to their children, one young man emphatically states, "Navajo is supposed to be

\footnotetext{
${ }^{19}$ Such discourses, according to youth in the study, characterise the Indigenous language as "stupid" (p. 39), "dirty," "backward," or "the way of the devil" (p. 43).
} 
spoken at all times in the house, no matter what. [...] I mean, they're Navajo, and they should be speaking Navajo" (p. 35). Another feels that the language "helps me not get too far in, not to lose the identity of who I am, of where I come from" (p. 35).

\section{Niitsitapi}

Lombard (2011) approaches the language/identity link in the context of personal names and socio-cultural naming practices among the Niitsitapi (Blackfoot) on the Kainai (Blood) Indian Reserve in southern Alberta. While many people now have both English and Niitsitapi names, and usually go by their English names in everyday interactions, they refer to their Niitsitapi names - always expressed in the traditional language, Niitsi'powahsin - as their "real names" (p. 43). The author analyses a series of ethnographic interviews in which she explores the functions and importance of these names in Niitsitapi culture. Beyond their perhaps obvious function as markers of individual identity, she finds that they are also fundamental to the transmission of cultural knowledge and, further, are considered to possess strong spiritual power.

Cultural knowledge is passed on in the form of akáitapiitsinikssiistsi, or "stories of the past people/ancestors" (p. 44) which are associated with each name and which serve to transmit beliefs, values and cultural expectations. Knowing a name's history, she argues, "gives people a sense of knowing where they come from. This, in turn, helps people to shape their perceptions of who they are as individuals, as well as in terms of belonging to the larger sociocultural group" (p. 49). And indeed, Niitsitapi identity seems to be constructed in accordance with their traditional philosophy in which

[...] the personal growth and development of individual people is always aimed towards the welfare of the community as a whole. Although each person has their own individual identity as a unique human being, they are 
simultaneously part of a wider social construct in which they are expected to play an active and contributory role. (p. 47)

People are expected to live up to their Niitsitapi name and to act in accordance with the teachings associated with it, thus simultaneously linking names to a tradition of oral history and setting up a system of accountability towards others in the community. These naming practices are also imbued with a deep sense of spirituality. As Lombard explains,

names themselves are sacred entities which possess spiritual power and are thus able to connect humans (mortals) to the spirit world. This notion is grounded in the belief that language, particularly the spoken form of language, contains the power to bring things to life; to speak things into being. (p. 48)

This notion is not unique to the Niitsitapi - many other Indigenous groups see their ancestral language as a gift from the Creator and/or a link to the spirit world (Alia, 2005; McCarty et al., 2006; Pecos \& Blum-Martinez, 2001). It follows, then, that traditional names and naming practices would also carry spiritual meaning. ${ }^{20}$ The author concludes:

by virtue of the cultural knowledge which is embedded and conveyed through them, Niitsitapi personal names provide a powerful means of establishing, maintaining, and communicating perceptions of individual as well as social and cultural (ethnic) identity. (p. 49, emphasis added)

She further asserts that "a falling away from traditional personal naming practices would most likely exacerbate the language loss and erosion of cultural identity" (p. 49). And indeed, what I find particularly fascinating is that they call their Niitsitapi names their "real names," and likewise, that the name of the language itself, Niitsi'powahsin, means "the Real Language" (p. 43). This implies that the "real," "true" - or, to return to the term

\footnotetext{
${ }^{20}$ See Moore (1984) for an interesting analysis of male and female names among the Cheyenne, relating naming practices to their traditional understanding of cosmology and the natural world (including spirits, plants, birds and animals).
} 
used by Searles (2010), "authentic" - Niitsitapi identity is best (and perhaps only) expressed in the ancestral language.

\subsubsection{Thematic trends in language and identity studies}

In considering the studies presented here, a number of important themes emerge in relation to language and identity. These include land/territory, authenticity, new emergent identities (particularly in urban contexts), pride, shame, names and naming practices, spirituality, social mobility and the dominance of English, and the polarisation of labels (such as Welsh vs. English, Inuit vs. Qallunaat, Navajo vs. White, tradition vs. modernity). This is by no means an exhaustive list of traits that always or inevitably play a role in cultural identity construction, nor are they necessarily discrete categories; indeed, there may be significant overlap between them. The themes of both land and names, for example, combine in the work of Basso (1996), an ethnolinguist who examines the socio-cultural value and functions of topographical naming practices among the Western Apache in Arizona. He finds that Apache clans' "names for themselves are really the names of places"21 (p. 18) and that discursive "place-making is [...] a way of constructing social traditions and, in the process, personal and social identities" (p. 7). These themes do, however, offer guidance and serve as an anchor for the study of language and identity here at hand. I use the knowledge gained from these and other studies to situate my own research and to stay attuned to the possibility of these same themes emerging in my own data. Nevertheless, I also remain open to encountering new themes or issues that arise for my specific participants.

\footnotetext{
${ }^{21} \mathrm{He}$ means this literally, citing an Elder who, in telling a story about the origins of Apache clans, recounts: "This earth is part of us! We are of this place, Juniper Tree Stands Alone. We should name ourselves for this place. We are Gad 'O'ááhn [Juniper Tree Stands Alone People]. This is how it shall be" (p. 21).
} 
As valuable as the abovementioned studies are, they still tend to generalise to the communities in question, rather than offering detailed analyses of participants' personal "trajectories" and thereby attempting to account for possible factors influencing their attitudes. This is the area of research to which my study aims to contribute, as I provide detailed individual participant profiles to help contextualise their perceptions of language and cultural identity. Before proceeding to the details of this particular study, however, it is important to first situate my research within the historical context of Aboriginal peoples in Canada - the topic to which we now turn.

\subsection{Language and Identity in an Aboriginal Context in Canada}

Indigenous peoples in Canada have endured a difficult history of discrimination, marginalisation, social and economic oppression, and other hardships that have deeply affected their communities (e.g. Aboriginal Healing Foundation, 2009; Alfred \& Corntassel, 2005; Lawrence, 2003, 2004; Miller, 1996; Weaver, 2001). Not least among these issues is that of traditional language loss: of the approximately 61 Indigenous languages still spoken in Canada, only three - Cree, Inuktitut and Ojibwe - are considered to have a reasonable chance of survival over the next few generations (Kinkade, 1991; Task Force on Aboriginal Language and Culture, ${ }^{22} 2005$ ). Given the preceding discussion regarding the role of language in the construction of cultural identity, the endangerment of the vast majority of these languages may be cause for serious concern.

It is simply not possible here to offer a detailed and comprehensive overview of the history of Indigenous peoples in Canada; such a monumental task would require

\footnotetext{
${ }^{22}$ Henceforth TFALC.
} 
several textbooks to even remotely do it justice. Instead, I aim to present a brief summary of the principal ways in which Aboriginal languages and identities have been impacted by colonialism. Before doing so, however, a note regarding terminology: I use the term Aboriginal as it is intended in the Canadian Constitution Act (1982) to be inclusive of Inuit, Métis and First Nations. I also employ the terms Indigenous (people), Native (people) and First Peoples interchangeably with Aboriginal. In doing so, I recognise and adhere to protocols regarding capitalisation and grammatical usage, ${ }^{23}$ identified by Retzlaff (2005a, 2005b, 2008) as markers of respect for the status of Aboriginal groups as “distinct peoples/nations" (2008, p. 351). Indeed, on this point I understand a nation to be "a human group conscious of forming a community, sharing a common culture, attached to a clearly demarcated territory, ${ }^{24}$ having a common past and a common project for the future while claiming the right to self-determination",25 (Guibernau, 2007, p. 11). It is in this sense that I refer to Aboriginal nations, though legally and politically they remain situated in the framework of the nation-state of Canada.

Kinkade (1991) attributes the decline of Aboriginal languages in Canada to a number of factors since the sixteenth and seventeenth-century arrival of European colonialists. These include the physical decimation of Native populations by foreign disease $;^{26}$ the forced dislocation of whole communities and their placement on reserves with members of other Aboriginal nations who did not share the same language or

\footnotetext{
${ }^{23}$ That is, using such terms as modifiers rather than nouns, as in "consultations with Aboriginal people" and not "consultations with Aboriginals" (Retzlaff, 2008, p. 350).

${ }^{24}$ I would point out, however, that in this "attachment" to territory should be loosely interpreted, being in some cases more symbolic than physical given the current urbanisation of more than half the Aboriginal population in Canada (Patrick, 2008).

${ }^{25}$ The notion of self-determination is addressed later in this section.

${ }^{26}$ Notably smallpox, but also malaria, measles, and other kinds of disease (p. 157). Both Kinkade (1991) and Lawrence (2003) note that in addition to (primarily) accidental exposure, occasionally these diseases were actually deliberately introduced into the Aboriginal population as a means of physical extermination.
} 
traditions; ${ }^{27}$ the removal of Native children from their homes in order to attend residential schools where they were humiliated for, and prohibited from, using their mother tongue; and in modern times, the dominance of English and French in most arenas of social life, including education, modern media and technology. The broader underlying cause for the disappearance of Aboriginal languages, however, was related to the colonial attitude of disdain for the original inhabitants of the territory - Miller (1996) cites "assumptions of racial superiority by Euro-Canadians" (p. 185) - and the desire to stake a claim to that land for their own purposes. In fact, the damaging effects of this philosophy eventually permeated all aspects of life: the government adopted a policy of assimilation, or what Tschanz (1980) calls an "ideology of replacement" (p. 1), targeting the traditional cultures, languages, religious beliefs, territories and lifestyles of Indigenous nations (including the outright prohibition of cultural practices such as the Potlatch on the West Coast and the Sun Dance on the Plains; Lawrence, 2004).

The Indian Residential School (IRS) system mentioned by Kinkade (1991) was just one of these policies; it was, however, an extremely powerful and effective one. A network of schools and missions, largely operated by religious orders, began to grow in the late nineteenth century with the aim of "civilising" the Aboriginal population (Trudel, 1996). Miller (1996) offers a detailed and informed account of the institutionalised racism that permeated this system, and its devastating results. The author relates from an interview with a Saulteaux woman who attended such a school in the 1930s that:

At school she was taught that all the things she had learned at home were 'ugly' and 'meant for the devil,' with the result that she 'became ashamed of being Indian.' At school she learned to hate, not simply the people who oppressed her, but herself and her race as well. (p. 205)

\footnotetext{
${ }^{27}$ In such cases English usually became the only common language, as well as being the necessary medium of communication with government officials (p. 157).
} 
Children endured all manner of abuses at the schools, including the psychological trauma of being far removed from their families and communities. If they were caught speaking their traditional language, they were (often physically) punished and humiliated. ${ }^{28}$ Perhaps most disturbing is the fact that the imposition of shame and self-hatred was openly acknowledged and indeed, promoted, as one of the aims of the so-called "civilisation" process. A major church figure is reported as claiming, in 1876, that:

In leaving our missions, these children will have nothing left of being savage but their blood; they will have forgotten their natural language so completely that the savage life will no longer be possible for them, we will instill in them a pronounced distaste for the savage life, so that they will be humiliated when they are reminded of their origins. (TFALC, 1986, p. 35, emphasis added)

This shocking statement is but one example of the appallingly racist and destructive rhetoric of the period, clearly demonstrating the way in which the IRS system served as "a technique for destroying Indian [Aboriginal] identity" (Miller, 1996, p. 216).

Other ways in which Aboriginal identity was manipulated, regulated and oppressed was through political legislation, most notably the Gradual Enfranchisement Act (1869) and the Indian Act $(1876)^{29}$ and its amendments. Aboriginal scholar Bonita Lawrence (2003) provides an excellent, thorough review of the history of these policies and the colonial discourses that have shaped - and continue to influence - the conceptualisation of Indigenous identity in Canada and the United States. She explains that after a period of warfare between Britain and France as they fought over the territory now known as Canada, in 1763 the British defeated the French and then acknowledged a

\footnotetext{
${ }^{28}$ It should be noted that a small portion of schools and missions did not engage in such punishment; in a few, Native languages were actually encouraged. Generally, however, this was due less to any genuine respect for Aboriginal people as equals than to a desire for the children to better understand and acquire the language, religion and culture of colonialists - thus still serving the purpose of assimilation.

${ }^{29}$ I use the term "Indian" to refer to Aboriginal peoples only in the legal sense in which it appears in official legislation, and in relation to the notion of "status" bestowed upon individuals by the Indian Act.
} 
"nation-to-nation relationship" (p. 6) with First Peoples (see also Patrick, 2003, pp. 3334). While many groups did not cede their territories, the quest to gain land nevertheless continued as agents of the British Imperial Indian Department proceeded to bribe, cajole and coerce Aboriginal nations into turning over their territories while the number of White settlers continued to increase, and at the same time, the Native population was being utterly destroyed by disease and alcohol (Lawrence, 2003).

The creation of Indian reserves in 1850, whereby Aboriginal people were moved onto designated land allotments (often not their original, traditional territories), represented the continued push for land gains by the settlers. Indeed, the colonial need to define and regulate Indigenous identity was aimed at eventually gaining territorial control and assimilating the Indigenous population, as part of "a policy of paternalistic control and gradual removal of Native people from the path of white settlement" (Lawrence, 2003, p. 7). The Gradual Enfranchisement Act of 1869, which was merely a precursor to the Indian Act (1876), marked the first distinction between status and non-status Indians, thus defining "Indian-ness" in order to "make it a category that could be granted or withheld, according to the needs of the settler society" (p. 7). This was achieved in part by the concept of blood quantum measurement, by which "half-breeds" and "mixedbloods" were segregated out, often regardless of ancestry or personal identification. Loss of status meant loss of band membership and the right to remain on designated reserve land; Lawrence notes that, by 1985, "legislation ensconced in the Indian Act had rendered two-thirds of all Native people in Canada landless" (p. 6).

Both the Gradual Enfranchisement Act and the Indian Act also revoked status from women - but not men - who married non-status (Native or non-Native) individuals. Conversely, White women who married status Indians gained status. This overt gender 
(and racial) discrimination remained in effect until 1985, when Bill C-31 was passed, finally allowing some of these displaced individuals to regain their status. ${ }^{30}$ Regardless, the policies that had been in place for over a century had already taken an irreparably disastrous toll on Aboriginal individuals and communities alike:

The cultural implications of this social engineering process for Native people $[\ldots]$ are extremely significant. Taking into account that for every woman who lost status and had to leave her community, all of her descendants also lost status and for the most part were permanently alienated from Native culture, the scale of cultural genocide caused by gender discrimination becomes massive. (Lawrence, 2003, p. 9)

This "cultural genocide" is indeed the terrible legacy of the assimilationist policies embodied in legislation such as the Indian Act and institutions like the residential schools.

Note that the legislative policies described above in relation to "Indians" do not apply to Inuit, who are regarded as distinct from First Nations and who have a rather different history in terms of government legislation and control. Bonesteel (2008) recounts that despite long-term contact with European explorers, whalers, fur traders and missionaries, most Inuit continued to engage in traditional patterns of a nomadic (or at least semi-nomadic) land-based lifestyle until midway through the twentieth century. Nevertheless, like First Nations, Inuit identity has most certainly been influenced by colonial forces. They, too, were subjected to patronising and paternalistic efforts to Christianise, educate (in missions and residential schools), and "civilise" them according to Euro-Canadian standards with no regard for their age-old spiritual beliefs, complex social and kinship networks, and traditional forms of knowledge. Around the midtwentieth century, many Inuit were relocated (sometimes forcibly) by the government

\footnotetext{
${ }^{30}$ This amendment to the Indian Act was only achieved after a Maliseet woman from New Brunswick, Sandra Lovelace, appealed to the United Nations Human Rights Committee, which in 1981 found Canada to be in violation of the International Covenant on Political and Civil Rights. Her victory was the culmination of thirty years of struggle by Native women who had been fighting the Act's gender discrimination since 1951 (Grammond, 2009; Lawrence, 2003).
} 
under the pretext of better hunting and living conditions, but often with the agenda of asserting Canadian political sovereignty in the High Arctic (Bonesteel, 2008); in this way, like First Nations, they too were treated as pawns in the dominant society's quest for land. Alia (2007) notes that over time, Qallunaat "have studied and observed, praised and criticised, confused and distorted, regulated and registered, revised and amended Inuit social structures, families, identities and names" (p. 44). The government adopted an attitude of "keeping track" of Inuit in its implementation of social programmes, including census information, medical and police records, and certificates of birth, marriage and death. But the identification systems used were largely incompatible with Inuit culture:

Census takers relabelled children who were full family members in Inuit society 'boarder', 'step' or 'adopted'. They issued birth certificates with precise times and locations for births that were never recorded, for people who travelled widely and identified time and place in non-southern ways. (Alia, 2007, p. 58)

These kinds of inconsistencies are not insignificant as they can affect individuals' access to services such as healthcare and social assistance; for example, Alia (2007) reports instances of elderly Inuit not receiving pension cheques when they should, due to incorrect birth certificates.

A significant example of this imposition of European frameworks is the repeated renaming of Inuit. These include Christian names brought by nineteenth and early twentieth-century missionaries; the E-discs ${ }^{31}$ assigned to Inuit in the 1940 s for recordkeeping purposes but which essentially reduced individuals to four-digit numbers; and Project Surname (1968-72) in which all Inuit were told to adopt a family surname though the notion of first and last names was not a part of their culture. Traditional Inuit

\footnotetext{
${ }^{31}$ The E here stands for "Eskimo," an outdated and derogatory term for Inuit (Bonesteel, 2008).
} 
naming practices reflect complex networks of kinship and community responsibility, and are intimately linked to spiritual beliefs. ${ }^{32}$ The result was that

Project Surname created new identities and destroyed old ones, sometimes overnight. Not everyone had a say in the renaming, and the result was a tangle of inaccuracies and affronts to tradition. [...] Wives received husbands' surnames - created on the spot - overnight. Children were renamed while they were asleep or away at school. (Alia, 2007, p. 100)

While traditional Inuit naming practices did continue underground in many communities, these acts of renaming served as an assimilationist tool; as Alia (2007) notes, "renaming is universal. Immigrants, people who experience 'contact', women who marry, conquered subjects may be colonised in different ways, but renaming is almost always part of their colonisation" (p. 66, emphasis added).

Despite the trauma of past and present struggles, in more recent times Aboriginal people in Canada have mobilised in an attempt to reclaim control over their own identities through political autonomy and land claims. After World War II, international discourse on Indigenous rights, including land and language, partly contributed to such mobilisation (Patrick 2007, 2008). In 1969 the federal government produced the Government Policy Statement in Respect to the Native People of Canada, also known as the White Paper, which essentially advocated revoking the Indian Act entirely and giving Aboriginal peoples the same status as other Canadian citizens (Tschanz, 1980). Unfortunately it was merely a thinly-veiled attempt to return to the previous hundred years of assimilationist policies, and prompted an angry reaction on the part of the Aboriginal community. Tschanz (1980) explains that "the White Paper was instrumental in uniting Native People in opposition [...] and in giving impetus to Native organizations concerned with gaining a voice in the policies which directly affect their own lives" (p. 3). This mobilisation also

\footnotetext{
${ }^{32}$ A more detailed discussion of these traditional naming practices is provided in chapter 4 .
} 
contributed to the negotiation of land claim agreements such as those that resulted in the four Inuit territories of Nunavik (1975), ${ }^{33}$ Inuvialuit (1984), Nunavut (1993) and Nunatsiavut (2005) (Bonesteel, 2008). As Patrick (2007) observes, "cultural and linguistic revitalization remains bound up with the continuing political and social struggles reflected in the hundreds of still unsettled land claims and other kinds of 'unfinished Constitutional business' in the country" (p. 43). Aboriginal people's ongoing drive to settle this "unfinished business" is nothing less than the pursuit of their right to self-determination, an important term that is briefly discussed below.

Young (2004) asserts that the current mainstream conception of self-determination as "sovereign independence, where the self-determining entity claims a right of nonintervention and noninterference" (p. 177), is inadequate for understanding the claims of Indigenous groups to self-determination. She notes that Indigenous people rarely want to actually form separate states, but rather seek to increase their autonomy in "an institutional context of nondomination" (p. 187). Thus she proposes a relational interpretation of self-determination that more realistically accounts for the interdependence of social groups, whereby all peoples have both the duty and the right to "acknowledge the legitimate interests of others as well as promote their own" (p. 187). This view is shared by Whitaker (1999), who argues that self-determination "is not an absolute, not a zero-sum of authority; it is something that can, and should, be shared, without one people triumphing over another" (p. 86). These interpretations are further supported by the report of the Royal Commission on Aboriginal Peoples (1996), for whom self-determination is an expression of sovereignty - "the natural right of all human

\footnotetext{
${ }^{33}$ This land claim, called the James Bay and Northern Québec Agreement (JBNQA), also provided for the creation of a Cree territory in Northern Québec; one of my study participants grew up in this territory.
} 
beings to define, sustain and perpetuate their identities as individuals, communities and nations" (p. 108) - but can take place in cooperation with federal and provincial governments and does not necessarily require secession and the formation of an independent state. It is therefore within this framework of interpretation that I use the term self-determination in the present paper, unless noted otherwise.

Despite increased autonomy and recognition of Indigenous rights, Aboriginal identity and group membership - which has been so controlled and manipulated through centuries of colonial, assimilationist policies - continues to be a site of conflict and controversy for many Aboriginal communities and individuals alike, who may struggle with notions of authenticity. ${ }^{34}$ This struggle is demonstrated in the poignant reflections of filmmaker Tracey Deer (2005) in her documentary film, Mohawk Girls:

They called me an apple: red on the outside, but white on the inside. And it made me wonder if they were right. Was I less Mohawk because I wanted to make it in the outside world? It was easy to think this way, because being Native isn't only about how you feel. It's calculated by others.

These powerful words illustrate what she later refers to as "the secret ugliness of belonging" (Deer, 2008) - that is, the painful struggle of defining Indigenous identity and community membership, as so many aspects of contemporary Aboriginal identity have been forcibly imposed upon this country's First Peoples. Her mention of identity being "calculated by others" is also reflected in Lawrence's (2003) observation that, "for Native people, individual identity is always being negotiated in relation to collective identity, and in the face of an external, colonizing society" (p. 4, emphasis in original). Weaver

\footnotetext{
${ }^{34}$ Recall Searles' (2010) study of Inuit identity and the discussion surrounding the perceived "authenticity" of traditional land-based lifestyles versus urban or "town" lifestyles.
} 
(2001), too, describes these processes as three distinct types of identification: self, community, and external ${ }^{35}$ identifications.

Indigenous scholars Alfred and Corntassel (2005) advocate rejecting colonial definitions of Aboriginal identity - and especially those "narratives of 'victimization' and 'grievance"' (p. 606) - while instead embracing a new conceptualisation of identity on the terms of Indigenous peoples themselves. They describe such an identity as a "dynamic and interconnected concept" (p. 609) and claim that "our true power as Indigenous people ultimately lies in our relationships with our land, relatives, language, and ceremonial life" (p. 605, emphasis added). Indeed, they conclude that one of the keys to reclaiming Indigenous identity is to recognise that:

Language is Power - our people must recover ways of knowing and relating from outside the mental and ideational framework of colonialism by regenerating themselves in a conceptual universe formed through Indigenous languages. (p. 613, emphasis in original)

Unfortunately, despite such reconceptualisations of Indigenous identity, the fact remains that due to the history of cultural oppression and marginalisation discussed above, intergenerational transmission of Aboriginal languages has in many cases been interrupted or stopped altogether. For numerous communities in Canada, language loss has come to symbolise loss of collective cultural identity, and the dominance of English or French represents a continued push towards assimilation, as well as a power imbalance that places Aboriginal peoples at the bottom of the social hierarchy. More and more people - from professional linguists, to Elders and leaders of Indigenous communities, to individual community members - are expressing a serious sense of urgency when it

\footnotetext{
${ }^{35}$ Whereby members of an out-group (attempt to) define the identity of the individual. This is problematic, as stereotypes can influence out-group members' perceptions of that identity. And it gives rise to issues of authenticity: does an outsider have the right to decide who is an Indigenous person? (Weaver, 2001).
} 
comes to Aboriginal language maintenance and revitalisation. Anishinaabe scholar Basil Johnston (1998) feels that with language loss, "no longer will [Aboriginal people] think Indian or feel Indian. [...] They will have lost their identity which no amount of reading can ever restore. Only language and literature can restore the 'Indian-ness"' (p. 100). Indeed, many voices in current Indigenous discourse draw connections between language and cultural cornerstones such as land, traditional lifestyle, ecological and medicinal knowledge, the sacredness of oral history, spirituality, and psychological wellbeing (e.g. Alfred \& Corntassel, 2005; Battiste, 2000; First Peoples' Heritage, Language and Culture Council, ${ }^{36}$ 2010; Johnston, 1998; McCarty \& Zepeda, 1999; McLeod, 2001, 2007; Nettle \& Romaine, 2000; Pecos \& Blum-Martinez, 2001). Language is seen as a vehicle of culture and thus the preservation of Aboriginal languages would amount to a means of cultural "survival." Accordingly, some feel that losing one's traditional language is tantamount to losing one's Aboriginal identity entirely:

The Elders have told us that without our language we might survive, but we will not be whole and we will be cut off from our knowledge, spirituality and our true identity forever. Some Elders have said that if effective action is not taken soon, we, as people, will also become extinct. (Fontaine, 2000, as cited in Retzlaff, 2008, p. 337, emphasis added)

Abley (2003) relates another example in the Mohawk community of Kahnawá:ke in the words of a mother to her son:

I talk to you all the time in Mohawk and you always answer me in English. Son, you're going to live in two worlds. I encourage you to know English - but don't forget your Mohawk. Because the way things are going, you're going to lose your language. And if you lose your language, you have no business saying you're a Mohawk. (p. 182, emphasis added)

Similar sentiments are felt among other Indigenous peoples, as can be seen in the words of Apache scholar Bernadette Adley-Santa Maria's grandmother: "If you do not sing the

\footnotetext{
${ }^{36}$ Henceforth FPHLCC.
} 
songs - if you do not tell the stories and if you do not speak the language - you will cease to exist as 'Ndee' (Apache)" (as cited in Alfred \& Corntassel, 2005, p. 609). Nettle and Romaine (2000) cite Maori leader Sir James Henare, who said "the language is the life force of our Maori culture and mana ['power']. If the language dies, as some predict, what do we have left to us? Then, I ask our own people who are we?" (p. 23). Bunge (1992), too, feels that "a people who lose their language, and the view of the universe expressed by that language, can no longer survive as a people, but only as rootless individuals" (p. 380). These examples illustrate the widespread tendency of Indigenous discourse to essentialise the link between language and identity.

Clearly, then, a connection is indeed perceived between language and cultural identity by a significant portion of Aboriginal people, and as a result there is a persistent call for programmes and initiatives to maintain, protect and revitalise Aboriginal languages in the face of rapid language shift. Concerns over language loss and the need for such endeavours may become even more urgent for the growing population of Aboriginal people living in towns or urban centres away from their traditional communities (Patrick, 2008; Patrick \& Tomiak, 2008). However, as mentioned earlier, language maintenance initiatives (including bilingual education programmes) need to be planned and developed within the framework of a speech community's attitudes towards their ancestral language (Bradley, 2002). In what ways is the language valued? Is there a strong desire among non-speakers and partial speakers to learn it? How is it perceived by individuals? The study of individual perceptions is crucial to understanding not only the beliefs and attitudes themselves, but also the complex processes that help shape them.

In addition, the essentialisation of the link between language and identity cannot be assumed to reflect all individuals' views; it may raise difficult questions regarding 
authenticity for those Aboriginal people who do not know their traditional language, or whose language has already disappeared or is seriously endangered. What does language loss mean, personally, for these individuals? Might there be other ways of maintaining an Aboriginal identity without the ancestral language? More generally, to what extent do individuals' lived experiences, and their resulting attitudes and beliefs about language and identity, correspond to the trend in Indigenous discourse just mentioned - and what factors might be at play? It was questions such as these that led me toward the current study on language and identity in an Aboriginal context, the methodological details of which are outlined in the next chapter. 


\section{Chapter 3: Methodology}

In this chapter I describe the research questions, ethical considerations, research site and recruitment procedure, participants, data collection processes, data analysis techniques, and study limitations. While individual interviews serve as the primary source of data, I also make use of a focus group discussion as well as participatory observation to further shape and inform my approach.

\subsection{Research Questions}

As indicated in the literature review, this study is framed by the debate over the importance of a specific language for a specific identity, and I explore this issue in the context of Aboriginal people in Canada. Beyond prominent Aboriginal discourse generally emphasising the importance of maintaining Indigenous languages for cultural continuity (e.g. Alfred \& Corntassel, 2005; Battiste, 2000; Bunge, 1992; FPHLCC, 2010; Johnston, 1998; TFALC, 2005; see also Patrick, 2007), I am interested in how the presumed language/identity link is perceived at the individual level. By investigating each participant's attitudes towards her traditional language, whether or not she is proficient in that language, I hope to gain insight into perceptions of identity and, more generally, to test the hypothesis that language is fundamental to cultural identity (e.g. Fishman, 1991; Nettle \& Romaine, 2000; Skutnabb-Kangas \& Dunbar, 2010). Thus my research questions are as follows:

1. Is heritage language a salient aspect of participants' respective Aboriginal identities?

2. If so, in what way(s) is this language experienced as salient by each individual? What similarities and differences exist among these individual experiences, and what social, political, geographical or other factors might account for them? 
3. To what extent do these personal, individual experiences correspond to or diverge from theoretical perspectives on language and identity? Do participants emit essentialist discourses, or deny linguistic rootedness, or something in between?

\subsection{Ethical Considerations}

I recognise that the topic of (cultural) identity is very personal and, in some cases, a highly sensitive issue. I do not take this matter lightly and constantly strive to maintain cultural sensitivity in my approach. There can be challenges and ethical issues with conducting research among minorities, particularly when one is not an "insider" of said group (Lawrence, 2004; Oliver, 2010; Ytrehus, 2004). As Smith (1999) notes,

the outside 'expert' role has been and continues to be problematic for indigenous communities. As non-indigenous experts have claimed considerable acceptability amongst their own colleagues and peers, government officials and society on the basis of their research, indigenous voices have been silenced or 'Othered' in the process. (p. 139)

For this reason, though I do not presume to count myself among the "experts" she refers to, as a non-Aboriginal novice researcher I have made every effort to seek the guidance and collaboration of Aboriginal organisations and individuals. I have taken the initiative to meet with university staff, cultural liaison officers and local Aboriginal Elders, and to engage in numerous social, political, cultural, and educational activities within the Ottawa/Gatineau Aboriginal community that are continuously informing my research practice. As a result of these and other ongoing experiences, which will be elaborated upon in the following sections, I feel that I am capable of the cultural sensitivity and understanding necessary to undertake this type of research.

\subsection{Research Site and Recruitment Process}

This research was conducted at Carleton University. Before beginning recruitment, I discussed my project with three cultural liaison officers at the university's 
Centre for Aboriginal Culture and Education (CACE), with staff at the university's Aboriginal Enriched Support Program (AESP), and with local Elders Paul Skanks (Kanien'kehá:ka/Mohawk), Willy Bruce (Anishinaabe), and Cle-alls (John Medicine Horse Kelly) (Haida). ${ }^{37}$ Their insight proved invaluable, as they offered suggestions regarding terminology, literary sources, human resources and methodology. Perhaps most significantly, they advised against using a questionnaire - a format that I had been considering - due to the highly personal and culturally sensitive nature of my research questions and the importance, in Aboriginal traditions, of establishing interpersonal relationships before broaching such topics. They felt it imperative that I take a personal approach to recruitment in order to provide potential participants the opportunity to get to know me and to trust that whatever information they chose to share would be used in a respectful manner. ${ }^{38}$ Lawrence (2004) makes a similar point in describing her own approach to research involving other "mixed-blood" urban Native people:

For ethical reasons, I wanted to interview people to whom I had some kind of relationship; this would ensure that in writing about their lives I felt a personal obligation to present the stories in the sense that they had been told to me - not to make their life stories simply 'grist for an academic mill.' (p. 252)

Heeding this advice and guidance, I approached two classmates as well as one of my own students from the conversational French class I was instructing at the time. ${ }^{39}$ In addition, with CACE's permission and approval I spent a lot of time in the Aboriginal Student

\footnotetext{
${ }^{37} \mathrm{I}$ am grateful for the opportunity to have met these individuals through the Canadian Studies Department's weekly "Visiting Elder" programme and in the context of Dr. Allan Ryan's Canadian Studies 5101 course.

${ }^{38}$ Incidentally, some studies on language attitudes research show that "additional familiarity with the researcher" may result in participants providing "more valid data regarding [...] intimate attitudes" (Alderfer, 1968, as cited in Garrett et al., 2003, p. 31).

${ }^{39}$ This individual was of course assured that her decision to participate (or not) would have no bearing whatsoever on her standing in my class, nor on our teacher-student relationship. This was also mentioned in my application to the Ethics committee before undertaking this study, which received full clearance.
} 
Lounge in Tory Building T-27, getting to know students and discussing my study in an informal manner. Here I established friendly connections and was able to recruit two additional students, for a total of five study participants.

In order to be eligible for the study, participants had to be Carleton students over the age of 18 and self-identify as First Nation, Métis, and/or Inuit. Because my focus is on individual perceptions of personal identity, the key factor is that participants self-identify as Aboriginal; the possession or lack of "status" under the Indian Act was therefore not a condition for eligibility. As Lawrence (2004) points out, "to rely on other definitions [besides self-identification] of Nativeness - for example, Indian status or blood quantum - [is] to use the same colonial logic as the Canadian or American governments" (p. 251). At five participants, the sample size is admittedly small. This is partly due to the scope of an MA thesis, and so reasonable expectations must be set regarding the amount of data it is possible to process, analyse and report upon. However, a smaller group of participants also allows for a much richer, more in-depth and detailed investigation of individual language attitudes, cultural practices and identity construction. This aspect of the approach can thus be characterised as micro-analytic, and operates in combination with considerations of (more macro-analytic) socio-political and historical contexts outlined in the literature review. Finally, I wish to remain open to a variety of Aboriginal voices and so have chosen not to limit this study to a specific nation. I recognise that the communities that make up the Indigenous population in Canada are unique and culturally distinct; as such, notions of a single "pan-Indian” (e.g. May, 2008; Retzlaff, 2008) identity are avoided. Nevertheless, Aboriginal communities do have in common a shared colonial history and have engaged in similar social, political, cultural and economic struggles in Canadian society. 


\subsection{Participants}

Of the five participants I recruited, four identify as First Nations (specifically Shuswap, Ojibwe, Chippewa/Ojibwe,${ }^{40}$ and Cree) and one as Inuk; there are no Métis participants. Thus the Aboriginal language groups represented include the top three most viable in Canada, as well as a language in serious decline (Shuswap ${ }^{41}$ ). Participants have a range of ability in their respective ancestral languages, from non-speaker to partial speaker to fluent speaker. All are female, all are Carleton students between the ages of 26-42, all happen to have official status under the Indian Act (with the exception of the Inuk participant, to whom this legislation does not apply; she is, however, an enrolled beneficiary of the Nunavut Land Claims Agreement), all have lived in urban or "town" settings for at least 10 years, and four have children. In addition, all happen to be of mixed ancestry, though they strongly identify as Aboriginal: four participants have an Aboriginal and a non-Aboriginal parent. While the remaining participant's parents are both Aboriginal, they are from different nations, and in fact her father was adopted by a non-Aboriginal family at a young age and grew up isolated from his Native culture.

Due to the detailed, micro-analytic nature of my investigation, it is important to outline each individual's background to contextualise their experiences; thus participant biographies are provided in Appendix A (all names are pseudonyms ${ }^{42}$ ). However, Table 2 below offers a summary of participants in terms of pertinent demographic factors; this is also meant to serve as a reference chart when the findings and discussion are presented in

\footnotetext{
${ }^{40}$ Chippewa is an alternative pronunciation of Ojibwe; both terms refer to the nation whose traditional name for itself is Anishinaabe. Thus participants Della and Winona are both Anishinaabe but employ these terms rather flexibly and interchangeably. For consistency and out of respect for the traditional name I use "Anishinaabe" in my own writing, but maintain participants' original usage in all citations/paraphrases.

${ }^{41}$ According to the FPHLCC (2010) Report on the Status of B.C. First Nations Languages, only $4 \%$ of the Shuswap population are fluent speakers of the language (with an additional $13 \%$ who are partial speakers).

${ }_{42}$ Pseudonyms for participants and their families throughout this thesis are assigned in the same language as their real names; that is, English or Aboriginal pseudonyms reflect actual English or Aboriginal names.
} 
the next chapter. Of note is the category "language proficiency"; participants were asked to report their ability in their respective Aboriginal language in terms of the four main skills of speaking (S), listening comprehension (L), reading (R), and writing (W). The five options provided for the rating of each skill were none, a few words/phrases, basic ability, intermediate, and advanced/fluent. In the following table, where only one rating is listed, it applies to all four language skills.

Table 2 Participant data summary

\begin{tabular}{|c|c|c|c|c|c|}
\hline $\begin{array}{c}\text { Participant } \\
\text { name } \\
\end{array}$ & Age & $\begin{array}{l}\text { Aboriginal } \\
\text { affiliation }\end{array}$ & $\begin{array}{c}\text { Language } \\
\text { proficiency }\end{array}$ & Location of upbringing & Other ancestry \\
\hline Jade & 42 & $\begin{array}{c}\text { Shuswap } \\
\text { (Neskonlith } \\
\text { Indian Band) }\end{array}$ & None & $\begin{array}{c}\text { Okanagan Valley, BC } \\
\text { (mainly Kelowna) }\end{array}$ & $\begin{array}{c}\text { Father is non- } \\
\text { Shuswap First } \\
\text { Nation }\end{array}$ \\
\hline Victoria & 30 & Inuk & $\begin{array}{l}\mathrm{L} \text { : intermediate } \\
\mathrm{S}, \mathrm{R}, \mathrm{W} \text { : a few } \\
\text { words }\end{array}$ & Iqaluit, NU & $\begin{array}{l}\text { Mother is } \\
\text { English }\end{array}$ \\
\hline Della & 26 & $\begin{array}{c}\text { Anishinaabe } \\
\text { (Chippewas of } \\
\text { Nawash) }\end{array}$ & $\begin{array}{c}\text { R: basic } \\
\mathrm{S}, \mathrm{L}, \mathrm{W}: \text { a few } \\
\text { words }\end{array}$ & $\begin{array}{c}\text { Ottawa, } \mathrm{ON} \text { and } \\
\text { Cape Croker reserve, } \mathrm{ON}\end{array}$ & $\begin{array}{l}\text { Father is Italian- } \\
\text { Canadian }\end{array}$ \\
\hline Winona & 31 & $\begin{array}{l}\text { Anishinaabe } \\
\text { (Ojibwe) }\end{array}$ & $\begin{array}{l}\text { S, L: basic } \\
\text { R, W: none }\end{array}$ & $\begin{array}{l}\mathrm{ON}, \mathrm{BC}, \mathrm{AB} \\
\text { (urban areas) }\end{array}$ & $\begin{array}{l}\text { Father is } \\
\text { Persian }\end{array}$ \\
\hline Sophie & 32 & $\begin{array}{l}\text { Cree (Eastern } \\
\text { James Bay) }\end{array}$ & $\begin{array}{l}\text { Advanced/ } \\
\text { Fluent }\end{array}$ & Chisasibi, QC & $\begin{array}{l}\text { Mother is } \\
\text { Québécois }{ }^{43}\end{array}$ \\
\hline
\end{tabular}

It is important to acknowledge the number of participant variables present in this study. The most significant are (a) the Aboriginal nation with which participants identify, (b) their traditional language proficiency, (c) their location of upbringing, and (d) their mixed ancestry. As mentioned above, I wanted to remain open to all Aboriginal voices to get a sense of how language and identity are perceived by a variety of individuals; it may

\footnotetext{
${ }^{43}$ Note that because grammatical gender does not exist in English, in this text I use the generic term Québécois for concepts and people that in French would be distinguished as masculine or feminine.
} 
be that in some Aboriginal cultures, language is considered more fundamental to identity than in others. On the second point, due to the present state of endangerment of the majority of Aboriginal languages in Canada, it was not reasonable to select (nor easy to find) solely fluent speakers, as this would not be a just representation of the reality of most Aboriginal people. Furthermore, the inclusion of both speakers and non-speakers serves as an important point of comparison regarding language attitudes; for example, do speakers have more positive language attitudes than non-speakers? Do speakers and nonspeakers perceive the language/identity link in similar ways? Do non-speakers rely more on non-linguistic symbols of identity, and if so, what might these be? Do non-speakers identify with the language at all? Of course, such questions can only be addressed in the context of this small sample size, so generalisations beyond this population will be avoided. Nevertheless, degree of language proficiency is a significant variable to consider in accounting for individuals' language attitudes.

Regarding location of upbringing, Jade, Della and Winona all grew up in relatively urban areas. As a child, Victoria remembers Iqaluit (the capital city and largest community in Nunavut) as being very small, but the population grew significantly during her youth. It is now estimated at more than $7,250 .{ }^{44}$ Thus while admittedly small by southern standards, Iqaluit is a town and is therefore somewhat "urban." Indeed, according to Searles' (2010) study discussed in chapter 2, life in Iqaluit is "surprisingly familiar to life as lived in southern parts of Canada" (p. 160) and is considered to be the site of a developing urban Inuit identity (regardless of whether such an identity is recognised or deemed "authentic"). In addition, Victoria has lived in several other cities

\footnotetext{
${ }^{44}$ This information is available at http://www.city.iqaluit.nu.ca/i18n/english/demo.html, the website for the City of Iqaluit.
} 
since the age of 20 . Sophie was the only participant raised entirely in a rural area;

Chisasibi now has a population of just over 4,000 (http://www.chisasibi.org/). ${ }^{45}$ However, it should be emphasised that Sophie has lived in Ottawa for over a decade and thus also engages in an urban lifestyle. Therefore all participants have had significant (albeit very diverse) urban experiences, which likely play a role in their perceptions of their Aboriginal identities.

Finally, in terms of heritage, it should be repeated that all participants self-identify as Aboriginal and that it is this aspect of their identity that is the focus of the present study. Nevertheless, it is important to consider any other cultural affiliations participants may feel in order to better contextualise their attitudes towards their respective Aboriginal language and identity; thus individuals' identification with mixed-heritage (as well as Canadian) cultures is also discussed in the findings and analysis. These differences (in terms of Aboriginal nation, language proficiency, location of upbringing and mixed ancestry) represent precisely the kinds of social, political, historical, geographical, and other factors that influence identity construction. It is for this reason that an understanding of participants' personal "trajectories" is so important; such variables have been kept in mind during the data analysis and are addressed throughout the discussion of findings.

\subsection{Data Collection}

I have taken a mixed-method, ethnographic approach to both the collection and analysis of data. The following subsections describe the three methods of data collection - ongoing participatory observation, a focus group, and individual interviews - as well as the transcription of the latter two phases. It should be emphasised here that the personal

\footnotetext{
${ }^{45}$ See Appendix A (Sophie's biography) for additional information on the demographics of Chisasibi.
} 
interviews constitute the primary source of data for this study; the other two methods serve as a means of gaining background knowledge and improving my own understanding of the most salient topics and issues related to Aboriginal identities.

\subsubsection{Participatory observation}

Johnstone (2000) identifies participatory observation as a central tool in any ethnographic approach to qualitative sociolinguistic research, allowing us to "focus an ethnographic eye on sociolinguistic phenomena" (p. 81). Echoing the advice of the CACE cultural liaison officers, AESP staff, and individual Elders, she stresses that this kind of research "crucially involves building rapport and being accepted as an equal" (Johnstone, 2000, p. 90), which can be achieved in part by undertaking meaningful social and cultural events alongside members of the target population. Beginning in September 2010 I began a type of exploratory fieldwork by engaging with the local Aboriginal community through participation in a wide range of educational, social, cultural, and linguistic activities; this involvement has continued throughout my research process and is ongoing at the time of writing (Appendix B presents a list of the various kinds of participatory observation undertaken). Due to the scope of this study as well as ethical concerns regarding the need for individual consent, it was not practical to make audio or visual recordings of such events. However, throughout my participatory observation I systematically took written notes on these interactions. ${ }^{46}$

Note that by highlighting these experiences I do not mean to imply that I have earned any claim to "insider" expertise regarding Aboriginal languages or identities; it simply shows that I am not approaching this topic from a purely theoretical background

\footnotetext{
${ }^{46}$ At such times when I felt that note-taking was inappropriate to the situation - for example, during certain ceremonies or traditional teachings - I was careful to record my thoughts and observations as soon as possible following the event.
} 
but rather am attempting to incorporate real-world, experiential knowledge earned through relationships and shared experiences with Aboriginal individuals. Through these learning opportunities I was able to gain insight into particular social, cultural and/or linguistic events, and some of these observations serve as supporting evidence in the analysis of my data. To illustrate the applicability of this participatory observation, I offer a brief example here. At one point during her interview, Winona describes how "looking Native" can contribute to one's acceptance and inclusion, even by strangers, at a community event: "if you're at a pow-wow or something, and you look Native, someone's probably gonna be like, hey what's up, man? Like, laughing or pointing with their lips or something, right? [laughs]." The phrase pointing with their lips refers to a specific facial gesture used by many First Nations people for several purposes (including taboos regarding finger-pointing). Here it is used to extend an unspoken greeting, a query as to who this person might be, like a friendly "hey, you! What's your story?" indicating at the same time a sort of camaraderie or complicity between the two individuals.

All this I had already learned in the course of my involvement in Ottawa's Aboriginal community, both implicitly (through observation) and explicitly (in actual conversation about this particular mannerism). Without this insight, I would not have understood this culture-specific reference and might have overlooked it, or had to interrupt the participant to enquire about its meaning, thus breaking the flow of her commentary. This is just one small example of how an ethnographic kind of engagement can enrich research. I hope my participant observation will ultimately serve to situate my approach, reflect my cultural sensitivity, and lend legitimacy to whatever conclusions my findings may lead to; this being particularly important in my case, as a non-Aboriginal researcher. 


\subsubsection{Focus group}

A focus group involving four of the participants took place in early February 2011 for a period of approximately two hours; unfortunately, due to a scheduling conflict Winona was unable to attend this discussion. ${ }^{47}$ I asked a series of guiding questions relating to language attitudes and practices, culture, and identity in order to initiate and facilitate the group discussion (see Appendix C). Other than this general framework, the discussion was allowed to develop freely without much intervention on my part. Participants were invited to ask each other questions as well, in order to create a more dynamic and spontaneous exchange.

The purpose of the focus group was threefold. First, it was an opportunity to gather demographic and biographical information by having participants introduce themselves and thus contextualise, to a certain extent, their experiences and perspectives (personal "trajectories" were followed up in greater detail during interviews). Second, by allowing participants to meet each other and know they were not alone, I hoped to make them feel more comfortable broaching certain topics - of a personal and sometimes sensitive nature - in a safe space. ${ }^{48}$ Finally, this dynamic group discussion served to reveal participants' general attitudes regarding language, culture and identity; I was then able to follow up in greater detail (in interviews) on the issues raised by each individual.

\footnotetext{
${ }^{47}$ In her case, we planned for a longer personal interview where I asked the same questions from the focus group. Although it was unfortunate she was not able to contribute to the richness of the group discussion, I was still able to compare her responses to those of the other four who attended the focus group.

${ }^{48}$ I also felt that a group discussion was appropriate to research on Aboriginal cultures, which often traditionally make use of Talking Circles and consensus problem-solving methods, and which tend to place great value on community (W. Bruce, personal communication, December 7, 2010).
} 


\subsubsection{Individual interviews}

The five interviews, which lasted approximately 90 minutes each and which were conducted on campus, allowed me to delve deeper into the attitudes of each individual; they were semi-structured, whereby I brought a number of pre-prepared questions yet remained open to the flow of conversation. In designing these questions I was careful to keep in mind three common pitfalls identified by Garrett et al. (2003); that is, I avoided using hypothetical questions, leading or "strongly slanted" questions (which might push a respondent to answer a certain way due to "loaded" terms), and multiple/compound questions. ${ }^{49}$ Due to the variation among individual participants, it would not be practical to include here all the questions asked of each person; however, I have included a general list of questions/topics covered (see Appendix D). Finally, I contacted participants again by email with additional questions and requests for clarification; all five responded to these follow-up questions.

\subsubsection{Transcription}

The focus group and interviews were digitally audio-recorded with participants' consent; audio files were kept on a password-protected personal laptop and subsequently transcribed. The focus group recording of 1 hour 56 minutes resulted in a transcript of 31 single-spaced pages. The interviews amount to a combined duration of 7 hours 28 minutes and have been transcribed over a total of 165 pages.

\footnotetext{
${ }^{49}$ The authors give an example of such a question from MacKinnon's (1981) survey: "Should children in any part of Scotland be able to learn Gaelic at school if they or their parents want it?" (Garrett et al., 2003, p. 28, emphasis added). They note that this "conflates children and parents [...] making the interpretation of answers difficult" (p. 28).
} 


\subsection{Data Analysis}

As mentioned above, the participatory observation data was not audio-recorded or transcribed (other than via personal note-taking) and is not subject to a systematic analysis. The focus group was roughly transcribed shortly after taking place, and general topics were noted in order to help focus the personal interviews. Excerpts from the focus group are presented where they offer important insight into participants' views. As for the interviews, I adopted a bottom-up, mixed approach using discourse analysis (DA) to examine the data. As explained in the literature review, DA can be approached in a variety of ways; I felt it important to seek out the best method of making sense of my particular data set, rather than trying to make the data fit into a pre-conceived theory or framework. Thus I first made use of coding to identify emergent themes in each interview, followed by an examination of various linguistic features of participants' discourse; these processes are explained below.

\subsubsection{Thematic coding}

Coding involves identifying themes and sub-themes as they emerge in the data and comparing them within and across participants' discourse. Themes may appear in the form of just a few phrases, or several paragraphs of transcribed text, or something in between; there is no pre-established size for a unit of analysis. In some ways this resembles grounded theory, where "we create our codes by defining what we see in the data" rather than following "quantitative logic that applies preconceived categories or codes to the data" (Charmaz, 2006, p. 46, emphasis in original). The problem with grounded theory, however, is that it implies that research can be conducted free of personal bias, assumptions and subjectivity. As Charmaz (2006) herself has noted, such 
complete objectivity is impossible: "we are not scientific observers who can dismiss scrutiny of our values by claiming scientific neutrality and authority. Neither observer nor observed come to a scene untouched by the world" (p. 15). Thus it is only reasonable to rely on previous literature to help interpret the new data; by keeping in mind themes that arise in other studies (mentioned in the literature review), I approach the coding process with more of a structural framework than a grounded theorist. That said, given the specificity of the contexts within which all such studies are conducted, it is important as well to remain open to encountering new themes and categories, which I certainly do in this case. Finally, a further distinction is that Creswell (1997) conceives of grounded theory as involving 20-30 interviews in order to "saturate' categories and detail a theory" which is "grounded in data from the field" (p. 65). It should be emphasised that the scope of this thesis is necessarily much more limited than the type of research he describes, and that I do not in fact expect to develop a fully-formed theory about general Aboriginal language attitudes and identity per se. ${ }^{50}$ Rather, I aim to examine the similarities and differences among my five participants' language attitudes and perceptions of identity, while taking into account their individual "trajectories" or personal backgrounds.

\subsubsection{Linguistic analysis}

Unlike the themes, six discursive devices were determined beforehand based on the literature pertaining to DA, and identified in the interview data where appropriate. As Fairclough (2001) explains, "the set of formal features we find in a specific text can be regarded as particular choices from among the options (e.g. of vocabulary or grammar)

\footnotetext{
${ }^{50}$ Indeed, as stated earlier, I recognise the danger of referring to a single "Aboriginal identity" and other variations of pan-Indianism, as there is great diversity among the First Peoples of Canada.
} 
available" (p. 92), and these choices can represent significant "ideological differences" (p. 94) that may have bearing on language attitudes and perceptions of identity.

\section{Lexicon}

This refers to choices about naming, that is, the terminology used by participants. Sheyholislami (2011) notes that "names not only identify but they could also define things and people; they not only indicate the degree of intimacy with but also distance from people, places, and things" (p. 188). An example would be the term "Indian" as it is used by different participants in relation to their own and others' identities. Generally this label "is not value-free but rather negatively connoted" (Retzlaff, 2005b, p. 610). Sophie uses it ironically or sarcastically to highlight stereotypes held by non-Aboriginal people, such as when she mockingly poses the question "do you speak Indian?", implying a misconception that all Native people speak the same language. Winona, however, appears to embrace the term, originally imposed by outsiders but now appropriated and used by Aboriginal people themselves as cultural insiders. Retzlaff (2005b) observes that this may reflect a "counteracting practice, where the 'Indian' is used to show pride and solidarity with the in-group ('we Injuns') despite external definitions and categories" (p. 614). Thus participants' vocabulary choices can have implications for both attitude and identity.

\section{Pronouns}

Pronouns have "relational values" (Fairclough, 2001, p. 106) whereby they can serve to "position" speakers in regards to the people and things they talk about, either in alignment or in opposition - as in we and they, respectively (Johnstone, 2008). Analysing choices regarding personal pronouns has been an important feature of identity studies, as pronouns can act similarly to lexical items in terms of indicating intimacy and distance 
(Sheyholislami, 2011). Consider the way Jade aligns herself with the greater collectivity of Aboriginal people in direct contrast to those she refers to as "European people": "this is what, um, sort of European people see as another wrong thing with us, is we're too permissive with our kids. We're not punishment-oriented, you know, we don't control them." Here the pronouns we, us and our serve to position the speaker in solidarity with other Aboriginal people along the lines of certain behaviour (that is, child-rearing philosophies), while distancing her from non-Native people. In terms of identity, this can be seen as a manifestation of the Self/Other paradigm.

Modality

This concept is related to the speaker's authority "with respect to the truth or probability of a representation of reality" (Fairclough, 2001, p. 105). Modality can be expressed via tense and adverbs (such as possibly or probably), but more often takes the form of auxiliary verbs such as can, can't, may, might, would, should, must, etc; these verbs represent the degree of certainty or desirability of a proposition. An example arises from Victoria's interview in discussing Inuit Elders who are paid through cultural programmes to share their traditional knowledge, stories and other cultural teachings: "I think those aspects of culture, you shouldn't have to pay for them. And I think that they should be... something that you do in your family and - tradition, like that should be EXPECTED." The use of the modal should and shouldn't here indicates a judgement on the part of the speaker, and thus her underlying attitude towards the topic at hand. She does not view these cultural programmes in a particularly positive light, as her own ideology regarding "culture" is not in alignment with the current practices in her society. 


\section{Metaphors}

Lakoff and Johnson (1980) wrote a fundamental book on the all-pervasive role of metaphorical concepts in our lives, in which they state that "the essence of metaphor is understanding and experiencing one kind of thing in terms of another" (p. 5). Note that here the term "metaphor" is not restricted to its traditional definition as a poetic literary device, but is intended to be more inclusive of rhetorical concepts such as simile, personification, metonymy and synecdoche because their underlying conceptual systems are metaphorical. Since "different metaphors have different ideological attachments" (Fairclough, 2001, p. 100), the analysis of such imagery in discourse has implications for language attitudes and identity. For example, Winona describes how her ancestral language didn't simply gradually fall out of use; rather, it was "systematically blasted" as the residential school system waged "a very deliberate attack on the language." Her wording conjures up images of violence and warfare, as though language is a living organism that can be killed (similar to the views of scholars such as Skutnabb-Kangas), and shows that for her, language is a site of struggle.

\section{Presuppositions}

A presupposition is something that is presupposed, or assumed, beneath the surface of discourse; it is "an assertion that is implied rather than explicitly and overtly stated" (Sheyholislami, 2011, p. 190). Fairclough (2001) points out that presuppositions can have ideological functions in that they are revealing of speakers' background knowledge and interpretations of the world around them. Recall the excerpt from Jade's interview that was used as an example of pronouns; we might look at the same few phrases again from another perspective: "this is what, um, sort of European people see as 
another wrong thing with us, is we're too permissive with our kids. We're not punishment-oriented, you know, we don't control them." The phraseology here, which draws a sharp contrast between certain perceived "European" and Aboriginal values, presupposes that European people $d o$ value punishment and control as a means of raising their children. Thus Jade aligns herself in opposition to these negative characteristics, again as part of the Self/Other paradigm.

\section{Intertextuality}

Bazerman (2004) defines intertextuality as "the explicit and implicit relations that a text or utterance has to prior, contemporary and potential future texts" (p. 86). According to him, "we create our texts out of the sea of former texts that surround us, the sea of language we live in" and so intertextual analysis is the study of "the relation of a statement to that sea of words, how it uses those words, how it positions itself in respect to those other words" (pp. 83-84). Thus the choices we make about which voices to incorporate can be revealing of certain attitudes or ideologies. Consider the following excerpt from Della's interview:

There's actually - oh, it's great, it's by Ignatia Broker - and she, she wrote this book called "Night Flying Woman." And it's an autobiography of her experiences growing up. [...] And there's a great quote she has, she's like, i- it's about the preservation of language and the roles that we have, and it talks about the Seven Generations.

She goes on to paraphrase the writer's words and state that she herself holds similar views. Here, then, is an explicit reference to an Anishinaabe author ${ }^{51}$ upon whose work Della draws to support and lend authority to her own views; this frame of reference is

\footnotetext{
${ }^{51}$ Indeed, Della does point out the fact that the author is Ojibwe.
} 
significant in that she is situating herself within the greater Anishinaabe community by citing other Anishinaabe individuals.

Note that the analysis of these linguistic devices is not meant to stand apart or separate from the thematic coding; rather, the two are complementary. That is, the themes emerge in part through the use of features like metaphor, lexicon, pronouns, etc. The next chapter is structured to reflect this relationship by presenting themes, and incorporating discussions of key linguistic devices as they appear.

\subsection{Study Limitations}

I acknowledge that, as with every study, there are a few limitations to consider. In terms of the data itself, I have already demonstrated the importance of taking into account the variables among participants; if recognised and handled with sensitivity, these variables may still add to the richness of the analysis by allowing for key comparisons to be made. Nevertheless, I will be limited in terms of looking for common trends or patterns within a single Aboriginal nation, as participants are not from the same communities. Thus my focus is necessarily on the individual's experience of any language/identity connection(s) she may perceive, and where applicable, any common trends that seem to appear across nations among this participant group (while being careful to avoid any over-generalisations).

In regards to method, previous language attitudes research has shown that in the direct approach (that is, interview format) social desirability bias, or the tendency to give “socially appropriate responses," may influence participants' answers regarding attitudes (Garrett et al., 2003). Indeed, the reliance on self-reporting in general may have a weakness; Garrett (2007) cautions that "because attitudes are a mental construct, there 
can be uncertainty whether our research data truly represent the respondent's attitudes" (p. 116). Nevertheless, since these "mental constructs" cannot be directly accessed, the interview approach is one of the most effective means at our disposal for understanding language attitudes and enquiring into perceptions of identity (Garrett et al., 2003). Furthermore, this is where the power of DA becomes evident; it attends not only to speakers' explicit statements, but also to more implicit, underlying attitudes and beliefs, which they may or may not be aware of conveying (such as the example of presupposition given above).

A final challenge in this study consists of managing my own bias. While I am not Aboriginal myself, I have genuine concerns regarding the decline and disappearance of Indigenous languages and sympathise with communities whose language faces these conditions. As a Canadian citizen, I also harbour feelings of regret and responsibility for past injustices that First Peoples had to endure under colonialism, and are still faced with today. I have been continuously aware of this emotional involvement with the subject matter, and have attempted to account for it when analysing the data. Recognition of one's own bias and subjectivity is crucial; as Fishman (1991) points out, language shift (and its reversal or non-reversal due to beliefs about culture and identity) is ultimately and necessarily a "value issue" (p. 33) in relation to which we position ourselves, and claims of total objectivity or neutrality remain highly implausible. 


\section{Chapter 4: Analysis and Findings}

Based on the thematic and linguistic analyses described in the methodology, in this chapter I present the principal themes emerging in participant interviews in relation to language and identity. These themes represent various ways in which traditional language may be significant to the construction of some (though not necessarily all) participants' respective Aboriginal identities. As stated previously, while my approach is certainly grounded in theoretical literature and previous case studies identifying possible key elements in the presumed language/identity connection (such as pride, shame, spirituality, land, and others), I did not attempt to rigidly impose these same categories and remained open to new themes throughout my analysis of the data. As an example, the notion of spirituality is not a particularly salient feature of participants' discourse in relation to language itself (with one exception, which is duly noted); however, it does appear in the context of personal names, and thus is treated as an aspect of naming practices.

I identified a number of larger categorisations or "super-themes," most of which are further broken down into sub-themes. They consist of the following (sub-themes are listed in parenthesis): social mobility and cultural continuity; pride and shame (pride/belonging and shame/alienation); names and naming practices; land (language and land, rural vs. urban, and tradition vs. modernity); and additional modes of identification (non-linguistic, non-specific Aboriginal, and non-Aboriginal). This final thematic category, which admittedly appears contrary to the study's focus of Aboriginal language and Aboriginal identity, is nevertheless important. It serves to contextualise participant perceptions of the role and relative importance of their traditional language by situating their discourse within the "bigger picture" of cultural identity. For example, a participant 
who identifies as First Nation but not Canadian presumably has a different perception of her Aboriginal identity (and perhaps language) than a participant who identifies as both. Finally, linguistic analysis of discursive devices (lexical choices, pronouns, modality, metaphors, presuppositions and intertextuality) is intended to enhance the thematic analysis and thus does not appear separately; rather, it is integrated throughout the text as supporting evidence.

While these themes are necessarily treated as separate for the purposes of analysis and explanation, readers are cautioned that they do not consist of truly discrete categories and in fact may overlap and interconnect in quite complex ways for different people in different circumstances. Yet this might be said to apply to most kinds of human experience anyway; and indeed, a central tenet of discourse analysis - and of qualitative research in general - is that everything is relational, and everything is contextual. Furthermore, since "sociolinguistic work is always "interpretive,"' (Johnstone, 2000, p. 36), I acknowledge that these thematic categorisations are influenced by my own personal perceptions, and that the same data could be interpreted within a different yet equally valid framework. However, within the framework I do adopt, I make generous use of quotes in the hopes that each unique voice may be heard, in order to best and most accurately convey these individuals' experiences of language and identity.

Finally, a note regarding citation conventions: unless specified otherwise, participant quotes are drawn from their individual interviews. Notes from participatory observation are indicated as such, and focus group citations are marked in parentheses as FG. Personal communications (based on follow-up questions) are noted in parentheses as PC, followed by the date. 


\subsection{Social Mobility and Cultural Continuity}

Perceptions vary among participants regarding the social and cultural value of their ancestral languages. These first two themes are intended to provide a general sense of each informant's overall discourse; but as will be shown in subsequent themes, their views are neither simple nor straightforward, as there are a number of underlying complexities and contradictions. On the surface, however, participants' attitudes towards their traditional languages are manifested in two different types of discourse: one relating to social mobility, and the other to cultural continuity (including, for some, the notion of self-determination). Additionally, they seem to be conceptualised by participants in two distinct ways; the first view in the form of "usefulness" and the second in the form of "struggle" (and in fact, participants often make use of this same terminology). While social mobility and cultural continuity are admittedly not inherently mutually exclusive, they are quite consistently manifested in the data along oppositional lines, at least in terms of language. For example, while Winona does briefly acknowledge the usefulness of knowing English in today's world, her overall discourse is overwhelmingly focussed on the value of Anishinaabemowin as a vessel of cultural knowledge and tradition. Thus it seems reasonable to present preliminary impressions of participants' language attitudes in terms of these two more or less opposing themes.

\subsubsection{Usefulness: A discourse of social mobility}

Participants Victoria (Inuk) and Jade (Shuswap) both adopt a stance emphasising the social and economic "usefulness" of language. They value the linguistic currency of English and French, and do not appear to attach great sentimental or symbolic value to their respective Aboriginal languages. They see proficiency in the dominant language(s) 
as a means of survival in mainstream Canadian society, as a tool that can help them gain upward social mobility. This is demonstrated in excerpts such as the following, from the focus group discussion:

Jade: I'm like, well, we have to survive in this environment, this is where we are. And um, so... you know, you gotta learn English, you gotta go to school, you know, and all this stuff.

Jade: I was thinking, sitting here thinking, um... I'd really rather learn French right now [than Shuswap]. [laughs] 'Cause it would be useful to me. I'm from out West and trying to find a job here without being able to speak French is really difficult.

Victoria: I never really felt Inuktitut was, that... I wasn't very sad that I didn't know how to speak it. And I'm still not, like "Oh no, I wish I could speak, speak it perfectly." [...] It's not something that is important for me to make my daughter learn. I would rather her learn English and French, I think that right now those languages are more useful to her in terms of having the freedom to live and work wherever she wants.

Victoria: I don't think it's [Inuktitut's] that important because it's very, um... it's not used. The government of Nunavut is trying so hard to put emphasis on Inuktitut and use in the workplace but still the main, the main language of um, you know, business or anything right now is still English.

These participants thus seem to view the importance of language mainly in terms of employment, education, business, government and modernity. In this paradigm, the Aboriginal language is not "useful" and so learning it is not a significant drive for these individuals; at one point Jade explicitly notes that for her, learning Shuswap "never seemed like a top priority." This is perhaps not unexpected given the serious decline of the Shuswap language, but the above comments by Victoria are somewhat surprising as Inuktitut is one of the most vibrant Aboriginal languages in Canada and considered to have an excellent rate of survival (TFALC, 2005). Indeed, in her interview she states that she often needs to use her basic Inuktitut skills at her place of employment in Iqaluit; in this way Inuktitut does have currency in terms of employment and business. This is one 
of many contradictions, more of which will be discussed in later sections, that appear in Victoria's testimony.

In this discourse, then, the instrumental aspect of language is emphasised over its symbolic value. It is seen primarily as a tool for social mobility, and is thus distanced from the subject of personal or cultural identity. In fact, any sort of cultural value attributed to language (specifically Inuktitut) is dismissed by Victoria in the face of far more pressing social concerns:

We have SO much unhealthiness and it's so... like, I find like the government concentrates on stupid, you know, minute things such as culture - like speaking Inuktitut and stuff when we have serious problems like mental illness, um, addictions and, you know, just serious problems in the homes! People are not healthy right now. (FG)

The lexical choices "stupid" and "minute" serve to trivialise the heritage language and culture in direct opposition to what she perceives as more "serious" (and by extension, important) issues. In both her interview and focus group contributions, a very real feeling of frustration can be sensed on the part of this participant regarding perceived government inaction in addressing social and economic hardships faced by Inuit, including physical and mental health problems, housing conditions, overpopulation, poverty and domestic violence. This does not mean that she does not value Inuit culture at all; in fact, she holds some traditional Inuit practices and innovations in high regard, as will be shown later. However, concerns about language, culture and identity here are not seen as being on the same scale of these other more "serious" matters.

Thus in the "usefulness" analogy, languages are seen as currency that can have more or less value in terms of their ability to allow mobility within mainstream Canadian society; English and French are considered high-value while Aboriginal languages are not "useful." In the sense of broader social well-being that concerns Victoria (in regards to 
the problems plaguing Inuit communities), language is even less of a concern. At first impression, then, these two individuals seem to perceive language as (at best) a tool for material ends rather than a rallying point of cultural identity. However, the full picture is actually more complex than this, as will become clear through the examination of other themes. For now, I turn to an alternative discourse: that of "struggle."

\subsubsection{Struggle: A discourse of cultural continuity}

Contrary to Jade and Victoria, the other three participants portray a very different image of their respective traditional languages. Sophie (Cree), Della and Winona (both Anishinaabe) see their languages as symbolic "flags of allegiance" (Rajagopalan, 2001, pp. 21-22) that are intimately tied to culture and identity. That is, while the others view language as a tool for social mobility, these participants see it as a tool in the struggle for maintaining or reclaiming their cultural identities. This linguistic struggle seems to take place both internally and externally, and is conceived along three axes: the nature of the language itself, language's "reverse relationship" with biological identification, and language reclamation as a symbol of self-determination; these are explained below.

First, these participants conceptualise the nature of Aboriginal languages

themselves as having inherent cultural value, as exemplified in the following passages:

Sophie: The language contains so much of that- that LIFE, life knowledge, life view... like, the Cree view of life. It contains that... it's the map to the culture, you know? Like, to the practices, to the traditional ways.

Winona: 'Mother tongue' means, to me is like, that's the language that was given to my people. And it contains, like, everything, all our teachings and all our values. [...] It like, holds all the power, it holds everything. [...] It's a part of your epistemology, right?

Della: Our language, it gives us a place of being. It- it grounds us in this world, like it really does. [...] It provides a sense of identity and placement 
within culture. [...] I think they [language and culture] are the same thing. You can't- I think you can't have one without the other.

Metaphors become a rich resource in this kind of discourse. In the above excerpts Aboriginal languages are likened to maps, sacred gifts, ${ }^{52}$ containers or vessels, and roots or perhaps a kind of anchor ("grounding" people in a virtual "place of being"). This kind of imagery serves to emphasise the perceived inextricability of language and culture in what some might call an essentialist framework. In the case of Winona and Della, the first-person singular and plural pronouns also place the speakers within the larger collective that is the Anishinaabe nation (such as my people, our teachings/values, our language $[\ldots]$ grounds us). By thus positioning themselves, the language-culture connection becomes a rallying point for collective identity.

Secondly, this perceived cultural value of language causes them to see it as a tool in the struggle to establish (cultural) identity. The personal need for such an identity struggle seems to stem from their biological heritage and the fact that they are of mixed ancestry. Both Sophie and Della have one White parent and make mention several times of their physical appearance and the fact that with their relatively Caucasian features, they don't look "stereotypically Aboriginal" (Della, FG). As a result, they have occasionally encountered tension within their own communities and have felt the need to justify or somehow prove their identities as Cree and Anishinaabe, respectively - and language is a major part of that. For Sophie, being a more or less fluent speaker, her Cree skills were a way of "securing a spot in the community" (FG); but even so, as a child she remembers being criticised by her peers for mispronouncing words or having relatively more limited

\footnotetext{
52 The concept of language as a gift is common in many Indigenous cultures (Watahomigie, 1998; McCarty et al., 2006); this is further explored in the theme of names and naming practices, with supporting evidence from my consultations with a local Elder.
} 
linguistic knowledge. ${ }^{53}$ This was sometimes pointed out alongside taunts of "you're a White girl!" which brought further attention to her biological heritage, making her Cree language proficiency all the more important for "performing" Cree-ness. Indeed, this external process of identity negotiation became deeply internalised for her as a youth:

I clinged [sic] to my Cree heritage, you know, and kind of wanting always to distance myself from the French side of me. You know, or the WHITE side of me. ${ }^{54}[\ldots]$ I was resentful at times of who I was and, you know, struggled with identity and trying to fit in. [...] It was an internal struggle, you know, it was an internal thing that I- I battled with, with myself.

Thus her traditional language plays an important role in both the external and internal manifestations of Sophie's identity struggle. An additional "internal" aspect of her language use is the fact that she sings to her children in Cree, often draws or doodles using Cree syllabics, has occasional dreams in Cree (including images of words written in syllabics), and even swears in Cree. She notes that "there's still a strong tie that binds me to the language because, you know, to me that- that's my identity" (FG). Here, then, the Cree language serves as a veritable emblem of Cree-ness.

Della, too, speaks of having to similarly justify her Anishinaabe identity because of her physical appearance, though she still finds this problematic due to her current lack of language proficiency:

I just feel like it's constantly along the language, like I have to almost [say] 'I grew up on the reserve!' like, 'I paid my dues!'” [...] I've always kind of felt, in a way, that if I could speak the language, then that, maybe that could be sort of my acceptance. (FG)

Not being a speaker, then, seems to lead Della to find alternate forms of justification such as a link to the reserve territory (even though she was only there during the summer

\footnotetext{
${ }^{53}$ Recall that although Cree was and remains the primary language of her community, Sophie's mother is francophone and so she learned French first and continued to use it in the home, growing up.

${ }^{54}$ Note that participants' mixed heritage is addressed in the final theme of additional modes of identification. For now we are concerned with her Cree identity and attitudes to the Cree language.
} 
months growing up). However, she seems to believe that language proficiency would somehow be a more acceptable or valid form of "proof" of her Aboriginal identity. She sometimes feels that in the eyes of others, lacking this "is the one barrier against me that doesn't prove me as being an authentic Aboriginal person - or AS authentic." Language, then, is perceived as a vessel of cultural authenticity. For both Della and Sophie, language has a sort of "reverse relationship" with biology in terms of counteracting assumptions and discrimination on the part of other community members based on physical appearance, and serving to "prove" one's Aboriginal identity via linguistic competence.

For her part, Winona is not concerned with proving her Anishinaabe identity to others. Although she, too, has faced discrimination from other Native people due to her mixed ancestry, she passionately asserts that "that's on THEM, I don't really give a shit 'cause I know where- where I grew up and how I grew up and what my identity is." However, while she is clearly confident in her Indigeneity, certain aspects of it - namely language - nevertheless remain sites of struggle for her on an internal level. She longs for a deeper connection to her traditional language, saying of fluency in Anishinaabemowin that "if there was one thing that I could EVER have in my WHOLE life [...] it would be that." Since she perceives the language as a vessel of cultural teachings and spirituality (the latter of which is addressed later), she feels that linguistic competence would serve to bring her closer with her own culture's values, traditions and epistemology.

Finally, Aboriginal languages are also seen as a tool for struggle in terms of reclaiming the broader collectivity's identity in the face of post-colonial mainstream society; this view is put forth by Della. She considers the revitalisation and use of Anishinaabemowin to be an act of "reclaiming that identity" in the sense that: 
It [the language] has kind of been taken away from us. So it's something I want back, you know? [...] It's about self-determinacy as well, and it's about that sort of authenticity, I guess, that has sort of, kind of been taken away on our reserve. (FG)

Here the phrase taken away is significant as it conveys a certain agency and intent on the part of the Other - in this case, "White Euro-colonial standards/institutions of power" (Della, PC, June 24, 2011). Rather than saying that language and cultural "authenticity" were lost or have disappeared, she evokes instead notions of intentional theft or robbery, implicitly calling attention to assimilationist policies. Indeed, when asked to elaborate on her use of the term "authenticity," she explains that her reserve was "whitewashed" in the sense that the powerful effects of assimilation-based programmes (such as residential schools, Indian Agents, child Welfare, the Army, etc.) resulted in the suppression of traditional Anishinaabe culture, including language. It is for this reason that Della's own grandparents - and most other Elders of their generation on her reserve - refuse to speak the language, though most remain fluent to this day. She believes that the reclamation of Anishinaabemowin "allows for us to become self-determinate people, which will promote self-confidence" and will eventually lead to greater autonomy and self-governance.

Thus the traditional language is a source of political power, insofar as reclaiming it constitutes a symbolic act of self-assertion on the part of the greater collectivity of Anishinaabe people. Della attributes the development of her views in part to an Indigenous Studies course, which acted as a catalyst for self-discovery and growth in understanding the historical struggles of her people. She also cites the much earlier influence of her mother, who after a long period of not identifying as Aboriginal (again, due to assimilationist forces), finally began her own path to personal self-realisation. When Della was a child, her mother took an Anishinaabemowin course and then began 
teaching words and phrases to her children, telling them: "these are our words. This is what we're supposed to be speaking." Here the possessive our, as well as Della's use of the phrase "taken away" (see above), indicates that the language belongs to the people, like a possession that can be both stolen and reclaimed. The phrase we're supposed to might be interpreted on two levels. First, it may imply a certain responsibility on the part of Anishinaabe people themselves to maintain the language in the home, rather than placing the onus solely on governmental or other authorities (though it doesn't exclude the possibility of such support). Second, the modality of duty or obligation emphasises that a specific traditional language - and not English - is the "rightful" form of expression for this specific cultural group.

We have seen here that the discourse of language as a tool for identity struggle is manifested on three distinct levels: internally within the individual, externally in relation to other Aboriginal community members, and externally in the broader framework of establishing Aboriginal peoplehood as distinct from mainstream Canadian society. This is reminiscent of Lawrence's (2003) observation, mentioned in the literature review, that "individual identity is always being negotiated in relation to collective identity, and in the face of an external, colonizing society" (p. 4, emphasis in original). Note that my emphasis here on the discourses of Sophie, Winona and Della is not meant to imply that Jade and Victoria do not similarly "struggle" with their identities (as will appear in other themes); it's just that in their case this does not appear to take place in terms of language, at least not overtly. Interestingly, both Jade and Victoria do acknowledge their traditional languages as sites of struggle for their fellow community members, but in doing so they still keep themselves at a distance. For example, Victoria notes that: 
I know Inuit are very proud of their language and their culture and that it's something that, you know, they feel is worth fighting for and, and trying to keep. And... but there's a lot of, you know, other things that we need to take care of first, I think, before we go into those, um, those things.

Here through repeated use of third-person plural pronouns, Victoria completely removes herself from those Inuit who are "very proud" of their language and culture, but includes herself again within the greater Inuit society by suddenly switching to we when she refers to the "other things" that need to be addressed - meaning, as mentioned above, the high rates of poverty, addictions, disease, mental illness, and so on.

The above discussion has shown how the themes of usefulness and struggle represent two very different discourses regarding the value of language; the former in terms of social and economic mobility, and the latter in terms of cultural identity and selfdetermination. We now turn to the themes of pride and shame, and the ways these are manifested in relation to Aboriginal language, culture and identity.

\subsection{Pride and Shame}

It is not surprising that, when considering something as personal and emotional as identity, the themes of pride and shame are particularly salient in this data; recall that this was also the case in McCarty et al.'s (2006) study of Navajo youth, for example.

However, while pride and shame are personal, private emotions, they give rise to distinct kinds of "positioning" of the individual vis-à-vis the group, at least as they are manifested here; this is therefore reflected in my expansion of the theme titles to "pride and belonging" and "shame and alienation." 


\subsubsection{Pride and belonging}

Given the above discussion of language as a tool for establishing cultural identity, both internally and externally, it is evident that pride is another closely-linked theme in participants' discourse. When one's traditional language is seen as a gift, as a vessel of cultural knowledge, as an aspect of self-determination and as a symbol of collective identity, these positive constructions can lead to self-confidence and a sense of pride in one's (linguistic) heritage. Sophie speaks of her fluency in Cree as a badge of honour, an emblem of her Cree identity of which she is very proud. Although Winona and Della both long for better fluency in Anishinaabemowin, they do show pride in their current linguistic ability and what they are able to understand. For example, Della is proud of having recently learned the traditional names for certain plants and medicines from her grandmother (particularly as her grandmother has been resistant to speaking

Anishinaabemowin, which is still a struggle) $;^{55}$ she also shows passion and pride for the language in terms of reclaiming it as a step towards self-determination. Winona reacts positively to social situations in which she is able to participate in the language:

I feel really good, like I- I feel really good when I can understand things. [...] When I understand things in the community, like, it makes me feel good, especially when I can laugh. You know, I've been in things where Elders are saying things and I can laugh because it was, what they were saying was funny... like that really means a lot to me. ${ }^{56}$

Thus interaction in the traditional language is a means of social inclusion within her Aboriginal community, instilling in her a sense of belonging. She also recounts a meaningful linguistic experience when she attended her friend Christine's wedding in

\footnotetext{
${ }^{55}$ Della explains that she had to "harass" her grandmother repeatedly to convince her to share these words.

${ }^{56}$ This passage also brings up the topic of humour, which has been named as a common and important feature of Aboriginal discourse and identity (Retzlaff, 2005a, 2006); however, it did not happen to be a salient overall theme in the results of the present study and is therefore not explored in depth here.
} 
Oklahoma. Christine's father is Kikapu, and when he spoke (in Kikapu) at the ceremony to bless his daughter's marriage, Winona was amazed and proud to be able to understand much of his speech. This unexpected linguistic connection (she later found out that the Kikapu and Anishinaabe peoples are historically linked) created a sense of belonging and peoplehood on a broader scale, their shared Indigeneity being expressed in the symbol of a common (or at least very similar) language.

Thus linguistic pride serves to construct a sense of belonging for these individuals; their community is "imagined" in part through the traditional language associated with their cultural group. While pride was also a theme for Victoria, it was not manifested in terms of language. In fact, she actually sees linguistic - or more specifically, dialectal pride as a barrier to the social and economic "usefulness" of Inuktitut: "until they can get over their pride in their dialect and [...] standardise it, I think that there won't be any movement forward" (FG). She sees standardisation as a key step in giving value to Inuktitut in education, business and government, explaining that:

They think their dialect is the best and we can't have, it's not, like fiscally, or, like, financially possible to cater to, you know, all the different dialects. It's just not, you know, you can't do that. So... ah, but it's a very, like it's a very - people take lots of pride in their dialect. If I was to have my own dialect it would probably be a South Baffin dialect. (FG)

Again, use of third-person pronouns allows her to distance herself from those Inuit who feel pride in their language. Interestingly, the conditional modality of the final sentence presupposes that she does not identify as having her "own" dialect, despite the fact that she does have basic speaking skills (and intermediate comprehension) in Inuktitut. Thus while pride is manifested linguistically for Sophie, Winona and Della in combination with their discourse of language as a component of identity, in Victoria's case linguistic (or at 
least dialectal) pride is actually perceived as oppositional to her discourse of language as a tool for social mobility.

In terms of a more general sense of cultural pride, however, Victoria describes a life-changing experience in the form of Nunavut Sivuniksavut (NS), an eight-month college programme in Ottawa intended for Inuit youth from Nunavut to "prepare for the educational, training, and career opportunities that are being created by the Nunavut Land Claims Agreement (NLCA) and the new Government of Nunavut"

(http://www.nstraining.ca/). She states that before attending the course several years ago, "I knew nothing of my culture and territory" (PC, June 17, 2011), and it was through this experience that she gained a deeper knowledge of, and pride in, her Inuit heritage:

It gave me a lot more respect for Inuit culture, especially like the, the historical, um... component of the course. Because we studied in-depth, like, you know, what did- how did Inuit survive for four thousand years up there? What kind of things did they have and use ${ }^{57}[. .$.$] Inuit are$ absolutely... amazing. And one of the things I remember where it, like, sparked my interest, when I was like, wow! Inuit culture is so cool! is when I learned about this invention of the toggle head harpoon. ${ }^{58}$

Thus knowledge of the past and of traditional Inuit practices led to self-reflection and a coming-to-terms with her identity. She recounts this transformation in the same words she spoke at her graduation ceremony: "Before this I always just considered myself Victoria, I didn't consider myself, you know, Inuit or whatever. And, you know, I'm proud to say that I'm Inuk."

Finally, Jade too seems to be experiencing an ongoing process of transformation similar to that described by Victoria. In terms of language, Jade relates that in her

\footnotetext{
${ }^{57}$ While I recognise Victoria's continued use of the third-person pronoun here, which in previous citations has served to distance her from Inuit in general, I interpret this particular passage differently. Because she is speaking in broad historical terms (the past "four thousand years") it is plausible that she is using they simply to refer to people in the past. Admittedly, this itself may indicate a division in her understanding of past or "traditional" Inuit and modern-day Inuit.

${ }_{58}$ The toggle head harpoon will be explained and further discussed in the following subsection on tattoos.
} 
experience there has been no "sense of pride and WANTING to teach children [Shuswap]" due to the legacy of residential schools and other assimilationist policies, although this is gradually changing with a grassroots movement for cultural and linguistic preservation (c.f. FPHLCC, 2010). Notions such as pride and cultural belonging are things that she is working towards, but does not yet seem to have fully internalised. Having grown up mainly in suburban British Columbia with very little connection to her reserve, she feels somewhat displaced (particularly here in Ottawa) and still struggles with personal identity: 'it's hard to remember who you are if no one taught you who youwho you are, you know. [pause] And... I've pretty much spent my entire life trying to figure that out."

Like Victoria, this journey of self-discovery has been assisted by formal education as well as a lot of personal research and reading. Through her studies, Jade has come to terms with many unanswered questions about her past and the difficulties of her childhood; understanding this history has been like a healing process. She explains: "I'm so glad because I understand so much more, even like on a broad level, like, why so many Aboriginal people are in prisons or, you know, have alcohol problems, and then right down to, kind of, my own problems." Thus the knowledge she gains contributes to her self-awareness and self-empowerment (particularly in terms of understanding and solving her "own problems"), which may eventually lead to an increased sense of pride in her Aboriginal identity. Interestingly, the social networking site Facebook has also turned out to be an important tool in this process as she engages in online friendships with many people from her reserve and from the greater Shuswap nation:

What I found interesting is that, um, being connected - like, most of these people I don't even KNOW, but I know that I'm related to a lot of them. 
[...] But um, it gives me a great sense of comfort and belonging. Which

I really like, and if I had known I would have set it up a long time ago.

Given her geographical dislocation, this method of long-distance communication is very important for establishing ties to her Aboriginal community. She finds Facebook "reinforcing" in terms of motivating her to continue striving for self-improvement and healing, in the sense that 'it's like I should probably just be okay with the fact that I've made it to where I am and, you know, that- that's enough. But at the same time, it's not." Thus, while pride itself is not a particularly salient theme in Jade's discourse, the drive for self-understanding, self-confidence, and presumably pride in her cultural identity certainly is.

\section{Visible markers of pride: Tattoos}

One particularly interesting manifestation of linguistic and cultural pride - and of identity more generally - among participants is embodied in tattoos; as Johnson (2006) notes, "forming an identity is important to young and old, and for some, tattoos can be a symbolic part of this identity" (p. 48). Della and Winona both have tattoos of words/phrases in Anishinaabemowin. Della's consists of an expression about love and laughter; she notes that this symbolises "a way of keeping positive." Winona has several tattoos. One is a word relating to the fact that she was born with a large birthmark, which in her culture is believed to be very significant: Winona explains, "they say that when you're born with that $[\ldots]$ that you brought, like, a part of the spirit world with you." In addition, she has tattoos of the Seven Grandfather Teachings written in Anishinaabemowin, which correspond roughly to the English notions of courage, 
honesty, respect, humility, love, wisdom, and truth. These are considered time-honoured, sacred moral teachings meant to guide Anishinaabe people. ${ }^{59}$

Both Victoria and Sophie have plans to eventually get tattoos as well, and were able to describe and draw exactly what they have in mind. Sophie envisions a stylised sun in the shape of a Canada goose with wings outstretched. Below it are drawings of two different spaces: to the east (where the goose is facing, in the direction of her home) is a scene depicting the beauty and calm of the natural world, and to the west is the image of a city. This represents the split she feels between her rural past and urban present (a dichotomy which will be explored further in a later section), and the yearning she feels for home. Interestingly, she also wants to incorporate Cree syllabics into the design, but has not yet decided how, or which word(s) to include. Victoria was inspired from what she learned at NS and visualises a tattoo of a toggle head harpoon, which was a key invention necessary to Inuit survival as its asymmetrical shape allows it to remain in an animal instead of simply entering and exiting like a spear. As she explains: "to me it's just like a symbol of survival and my whole life has been survival. So... I don't know, I can really relate to it." She also has plans for a tattoo of two snowflakes, representing her and her daughter, because they're "from the land of snow." Finally, Jade also happens to have a tattoo but it is not representative of her Aboriginal heritage.

My interpretation of these tattoos is that they constitute an outward display of stating one's cultural identity. Based on a six-month ethnographic study in the United States, Johnson (2006) finds that "tattoos are a way of connecting to that inner self that gets lost in the sea of the material world. Tattoos are a reminder of one's roots, one's ancestors, and the time when everything meant something or had a purpose" (p. 59).

\footnotetext{
${ }^{59}$ These teachings are also something that I have come across during my participant observation.
} 
Indeed, in discussing her birthmark tattoo, Winona explicitly states: "it is a part of my identity and it says a lot- tells a lot- and when I got it, there was a reason why I got it." One's body is arguably the most tangible representation of one's individual self, and the act of permanently etching words or images onto it is highly meaningful in that it portrays a certain message to others. As another tattoo researcher observes, "to do something permanent is to be unable to take it back - it is to live in truth for eternity" (Bell, 1999, p. 57). Sophie's desire to incorporate Cree syllabics in the design again shows an orientation to her heritage language that is consistent with her overall discourse. That Della and Winona have tattoos actually written in Anishinaabemowin similarly corresponds to their attitude regarding the symbolic value of their traditional language as a marker of cultural identity. The fact that they both have a strong desire for fluency may also play a role in their selection of tattoos (that is, words rather than images); it is as if they are trying to establish a physical link with the language despite their lack of proficiency. As for Victoria, I have already shown that linguistic pride does not seem to be an element of her particular cultural identity; instead, her choice of image symbolises the innovation and survival of Inuit. It should be repeated that the preceding points constitute my own interpretations, and that further investigation into participants' tattoos, specifically, would be required to substantiate these impressions.

\subsubsection{Shame and alienation}

Alongside the theme of pride and belonging is its diametrical opposite - that of shame and alienation. This was highly salient both within and across participants' discourse, but interestingly it seems to take the form of two contrary notions: shame for knowing the traditional language, and shame for not knowing it (well). The first is rooted 
in the colonial history of assimilation, most notably residential schools, and usually arises when participants are discussing their parents' or grandparents' generations. This is exemplified in the following interview extracts:

Della: [regarding the first time she heard her grandmother acquiesce and speak in Anishinaabemowin] I- I imagine that moment must have been really difficult for HER, you know. 'Cause there's a lot of repression and that from years of, you know, inside the residential schools or just growing up in general and dealing with sort of this divided society, I guess.

Winona: [The language] was actually, like, systematically blasted. [...] People didn't want to speak their language in the schools because it was being like, like gibberish double-talk or something. Or speaking in tongues or something, like, yeah, that's a very deliberate attack on the language.

Jade: [The residential schools] also destroyed their, sort of, sense of- like, of themselves as Indian people. Like, one of the things that, that your religion is wrong, your language is wrong, the way you raise your children is wrong, your- the way you go about marriage is wrong. And this was like, hammered into children from the age of six and up.

The terms highlighted above illustrate the powerful imagery employed by these speakers in recounting the way Native children were indoctrinated by the residential schools to feel shame and self-hate. In addition, the repetition of the word wrong in the final citation evokes each "nail" being "hammered" into the minds and spirits of the children. Notions such as blasting, attacking, destroying and hammering constitute violent, war-like metaphors, revealing that participants view these assimilation policies as a terrible assault on their respective peoples. Thus many members of older generations are still haunted by the literal and figurative abuses of the past, and Jade acknowledges that to a certain extent, the resulting "feeling of shame has been passed on."

However, the other discursive manifestation of shame is interesting in that it seems to constitute a generational shift in perspective. Rather than feeling humiliated by 
their Aboriginal language and culture, participants of this younger generation instead express shame regarding a lack of linguistic knowledge:

Della: there's always a part of me that feels somewhat ashamed that I don't know it and so when I get asked, like "Oh, you- you're Aboriginal. Do you speak the language?" And I have to say no. [...] Most people will assume, "well if she's Aboriginal, then she should be able to speak her language."

[in discussing Winona's experiences at Anishinaabe cultural events]: Claire: And how about when you can't understand what's being said? Winona: I feel, like, shamed, kind of, like-Claire [overlapping]: $\quad$--Mmm.

Winona: I SHOULD be able to understand, you know.

Thus Della and Winona seem to have internalised certain expectations of themselves namely, linguistic competence - as Anishinaabe individuals. This corresponds with their discourse of language as a symbol of cultural identity, and with the pride they feel when they are able to participate in the linguistic and cultural practices of their communities. Their professed desire for fluency is likely in part a reaction to these internal selfexpectations, as gaining language proficiency represents a way to combat such feelings of shame. Particularly surprising is the fact that even Sophie, who considers herself fluent in Cree, imposes similar standards on herself, admitting at one point that she's "not where [she]'d like to be with the language in terms of [her] fluency." She talks about feeling "self-conscious," "shy," and "afraid of being criticised badly or, you know, being judged" in terms of her language skills, acknowledging that this likely stems from the teasing and occasional taunts of childhood peers (see section 4.1.2 above).

In addition, Sophie berates herself for not passing the Cree language on to her children as much as she would like. She compares herself to her father and states: "I'm the next generation and I have nothing to pass on in terms of that language. I- I mean, that- that's not true but, I feel like I have SO MUCH LESS than what my father has.” 
While she does briefly acknowledge her own abilities here, they are promptly brushed aside as she focusses on a perceived linguistic deficit between her own generation and the previous one. She further criticises herself when she exclaims:

I'm not even speaking Cree! How do I expect them [her children] to know the language? You know, we live outside of the- the community. I'm their only link to that language. [pause] I'm not doing, I'm not practising what I'm preaching. You know? It's- it's hard.

This is clearly a site of great personal conflict and pain, as at this point Sophie breaks down in tears and needs to take a break from her interview. This deeply emotional response adds further weight to her poignant testimony, showing that linguistic proficiency itself is not necessarily enough to alleviate language-related shame (as implied by Della and Winona's comments above).

Victoria and Jade also convey notions of shame in their discourse. This is particularly revealing in the case of Victoria, as it offers a more complex picture of her attitudes and feelings than what has been conveyed thus far, in terms of previous themes. Consider the following examples:

[Speaking Inuktitut]'s mostly like a confidence issue as well because [...] dialects and pronunciation are SO revered, like if you have really bad pronunciation, you're almost like, outcasted [sic]. Or you're like, you know, treated less than somebody who speaks the language well.

I don't feel comfortable speaking Inuktitut because it's something that is like, dissected and analysed on you and if you don't fit that, you know, kind of um, higher speaking profile then you're, then you're not thought of as, I don't know, you're not... taken as- as ah, seriously as someone else who speaks better. (FG)

Several times she mentions the humiliation of being scolded by Inuit Elders because of her pronunciation or dialect. This, then, offers much more insight into Victoria's relationship with her heritage language; although in her overall discourse she equates language with a tool for social mobility and claims not to be "sad" that she doesn't speak 
fluent Inuktitut, it would appear that she does feel an emotional connection to the language, albeit not necessarily positive. Her discomfort and fear of being stigmatised contribute to a general sense of shame - or at the very least, lack of confidence regarding her limited linguistic ability. In fact, later in her interview she confides that "I have, like, fantasies of going and spending maybe, like, four or five months in a community to pick up my Inuktitut again. And just for that, you know, experience of living in a small community." This suggests that although she downplays the importance of Inuktitut, on some level she does strive for improved language skills, perhaps as a way of combatting the stigma and discomfort she feels.

For her part, Jade does not express any such feelings of linguistic shame, per se. However, she does show a kind of shame in regards to her lack of cultural knowledge. At the time her children were born, which was before she began the studies which would set her on a path of self-awareness and healing, she decided to register them as members of their father's band, rather than her own: "I just kind of felt like I didn't have anything, soI didn't have anything to offer the kids." She often mentions a lack of connection to her culture and territory (something that Facebook has been helpful in changing; see above), and although she embraces the empowering knowledge she has since gained in studying Aboriginal history, it is no substitute for learning her own people's stories and traditional practices in the natural form of transmission from parents and community members. This becomes apparent upon analysis of her discourse in terms of intertextuality; she makes frequent references to what she has read yet conveys this information almost apologetically, as if it is simply an unfortunate reality. For example:

I only know what I've read from books, sadly.

It's funny but the only way I can say this is from what I've read. 
I have stuff around and I, you know, read about it myself. Sometimes I

burn smudge at home but I, I'm not - like, I hardly understand it.

Thus she appears to feel somewhat embarrassed by the fact that her cultural and historical knowledge comes from books rather than the experiential knowledge gained from relationships with other community members. There is a disconnect between reading about a tradition or philosophy, and incorporating it as a lived daily practice; hence Jade's comment about hardly (truly) understanding the purifying ritual of smudging.

This disconnect is reflective of a particular aspect of the shame felt by study participants: alienation. Just as pride is linked to a sense of belonging, shame can contribute to individuals feeling disconnected from their community, either in specific contexts or in a more general sense. While both Della and Winona generally express pride and belonging with their culture, they mention feeling alienated at specific events when they don't understand the language ("I feel really left out," Della, FG). ${ }^{60}$ Even Victoria admits to thinking, "language and that culture acceptance definitely do go, like, hand-inhand" (FG) - a statement which, again, appears to contradict her apparent overall attitude distancing language from (cultural) identity. However, when we consider her abovementioned account of feeling criticised or "outcast" by other Inuit based on her Inuktitut pronunciation, it is clear how a sense of alienation might arise. Jade speaks in more general terms of going to Aboriginal cultural events such as pow-wows: "I just always kind of felt like an outsider. Mostly just, I think, not having been brought up with it or IN it, so I sort of feel like a- a tourist." Finally, alienation per se seems absent from Sophie's

\footnotetext{
${ }^{60}$ It might be argued that anyone would feel alienated in an environment where they don't understand the language being spoken. While this is a valid point, I assert that here we are talking about a deeply personal kind of "cultural alienation" in which one may "feel like more of an outsider, when you're supposed to feel like you're part of, you're like you're an insider, you're part of the group" (Della, FG).
} 
discourse, except perhaps in terms of generational shift (the difference between her father's and her own) and geographical displacement; she notes that living in Ottawa for the past ten years has "taken a toll" and that she misses home. Although she is sometimes self-conscious and fears criticism in terms of specific language skills, as a fluent speaker she feels that overall "my language was my way of securing my spot in the community."

\subsection{Names and Naming Practices}

Names are arguably one of the most obvious manifestations of a connection between language and identity; names are necessarily in a language, often with special meaning, and we use them to refer to - indeed, to identify - ourselves and others (e.g. Edwards, 2009). It should come as no surprise, then, that names and naming practices are a highly salient theme in this study; personal and family names turn out to be significant for every participant. Jade notes that although her last name (Gracey) is European, “it's the only thing that actually links [her] to [her] reserve" (FG) and "is the only thing that sort of says [she's] FROM there." Thus for her, the name's value comes from its ability to connect her with her territory and kinship network. As mentioned earlier, Jade gains a sense of groundedness with her Shuswap community in part through the use of Facebook, and in this context her name is important for identifying and connecting with relatives: "whenever they have the same last name I send a [Facebook friend] request. [laughs] I'm like, they're related to me!" In this way, then, the fact that her name is in English seems to be of little import; it is not through the Shuswap language, but rather through kinship ties, that Jade strives to establish a link with her home community.

The other participants also emphasise the role of their names in contributing to a sense of community belonging, but in ways that are much more deeply intertwined with 
their respective Aboriginal languages and cultural practices. For example, both Della and Winona have European (first and last) names but attach special significance to the notion of an Anishinaabemowin spirit name. Of her first name, Della says that it "comes from absolutely nothing. [My mother] just wanted to be different, so... I was like, that- that sucks. I was hoping there was more meaning to that, Mum, thanks!" Her seemingly joking manner does not quite conceal her very real desire for a culturally meaningful name; she later reveals her plans to approach an Elder to request and "find" an Anishinaabemowin name. Her reasoning for this echoes her belief that language is key to cultural belonging and collective identity:

Claire: And what, ah, what's the significance of that to you? Like, if and when you do get that name, what do you think that will do for you? Della: [4-second pause] [quiet laugh] I don't know... [pause] I don't know, a sense of belonging, I guess. [...] Well in a way, um, I'm lack of a better word right now, but legitimise myself as, you know, an Aboriginal person. [pause] An Anishinaabe-kwe [Anishinaabe woman].

The hesitation and long pauses here are not at all characteristic of Della's overall speech pattern; this, along with the phrases "I don't know" and "I guess," seem to indicate some discomfort on her part. Perhaps she does not want to admit that naming is an ideological site of identity struggle for her; however, her phraseology implicitly asserts (presupposes) that she does not always feel a "sense of belonging" and "legitimacy," something that might be attained through an Anishinaabemowin name. Note that the lexical choice Anishinaabe-kwe is particularly meaningful in this sense; it would appear that the very notion of what it means to be a "legitimate" Anishinaabe woman is best expressed not in English, but in her ancestral language.

For her part, Winona has already obtained her Anishinaabe name, which for her carries great cultural and spiritual meaning, as opposed to her English name which she 
says "doesn't really mean anything" to her. The name was revealed in the vision of an Elder during a sacred ceremony, and she describes this vision in detail; it relates to the atmosphere and the surface of the water, whose movement is regulated by the moon. This name is Rhythm of the Water Woman, ${ }^{61}$ which Winona understands to mean "just a little space" where her "spirit is in between the water and the air." She notes that although this particular Elder is quite fluent in Anishinaabemowin, he was only able to relate this name in English, based on what he envisioned; Winona seems to have two conflicting reactions to this experience. On the one hand she recounts that she cried at the beauty of the vision, explaining that for her, "Native names are supposed to represent, like, who you are as a person. And so when you say those names, everybody who hears them is supposed to just know what type of person you are." On the other hand, she is troubled by the fact that she only knows the name in English and not in Anishinaabemowin, and tries to reconcile these two feelings by removing language from the equation altogether:

Not knowing it in my language, [pause] sometimes it feels like it, it just, invalidates the name, de-legitimises it. But at the same time, I don't think about it that way because those names weren't, that- that name wasn't spoken. That was something that you SEE, right? So it's like, kind of like, what- what language, it doesn't matter what language you know it in. Because that's a visual, that's your all-encompassing, that's your spirit, that's not a language, you know?

Thus she appears to conclude that the underlying meaning, or spiritual essence, of this name supercedes any special feature inherent to a particular language. Nevertheless, the first sentence of the above passage does imply that if and when she ever discovers the Anishinaabemowin word for her name, that this would somehow be more "valid" and "legitimate" than the English version. Furthermore, she also states that she doesn't tell others about this name, even in ceremony: "I know most of the stuff in Ojibwe, like when

\footnotetext{
${ }^{61}$ With Winona's permission I use her real Anishinaabe name here, as opposed to a pseudonym.
} 
you're introducing yourself and your clan. [...] But then all of a sudden, when I say my name in English, it would just, I don't know, be awkward." It seems, then, that naming for Winona remains a site of personal identity struggle, much like it does for Della.

Sophie's last name is Cree, and she takes pride in this as a symbol of her membership in her community, noting that it was something she "held close to [her] heart." This is not surprising, as it is consistent with her overall discourse of language as an emblem of cultural identity; and in fact, she would have also liked to have a personal name (that is, a first or middle name) in Cree. Growing up she recalls being envious that her brother was the only one of her siblings to receive such a name, after their greatgrandfather. For Sophie, "getting a Cree name comes from a special place," as she states: "that represented something special, you know, for- for them and for him, for my brother to be able to carry on that name." This is why she made a point of giving her own daughters personal Cree names, in addition to their European first names and Sophie's own Cree last name. She emphasises that despite a recent trend among some parents to choose their child's Cree name themselves, she undertook this practice in the traditional way, by asking an Elder to name the newborn: "it's the proper thing to do, is to ask an Elder to- to name your kid." Her use of the term proper indicates a respect for tradition and implies that non-adherence to this practice would thus constitute some form of impropriety. Her first daughter Miya was given the Cree name Ajuksh, ${ }^{62}$ meaning "star," by Sophie's father, as she was born on a clear night when the sky was full of stars. Sophie mentions a powerful dream that came to her before this naming, in which she envisioned Cree syllabics coming together to form Miya's Cree name, but could never quite see it clearly - as if the name was not yet ready to be revealed. Her second daughter, Hana, was

\footnotetext{
${ }^{62}$ At Sophie's request, I use her daughters' real Cree names, rather than pseudonyms.
} 
named Tikushinuuhkwaau, or "the woman who is arriving," by Sophie's great-uncle. This was particularly meaningful as she was born two days before Sophie's brother passed away, and as Sophie notes, "the significance I felt for her name is that, you know, sheshe arrived to, um, to bring something with her, you know? Like, in a difficult time." Thus Sophie, like Della and Winona, attributes certain spiritual value to names and naming practices in her heritage language.

Finally, Victoria's discussion of names contradicts her statements elsewhere in the interview and focus group discussion; while overall she appears not to link her Inuit identity to Inuktitut, she does value her Inuktitut last name ("it's very special to me and I'm- I would never change, like if I got married I wouldn't change my name. I would keep Iksiraq") as well as the one she received from her namesake as part of the complex system of Inuit naming practices. Before examining Victoria's comments it is important to briefly explain this system, which is one of the "deepest and most intricate" on earth (Alia, 2007, p. 17), and which has great spiritual significance similar to reincarnation:

Names are passed from one generation to the next, regardless of gender. $[\ldots]$ The namesake, or atiq, can continue her or his life through many people. When a child is named, he or she becomes the sauniq or 'bone' of all those who have shared that name. [...] People linked by names help each other in time of need and are bound together in a complex and permanent set of relationships. (Alia, 2005, p. 252, emphasis in original)

Perhaps even more important than the actual name passed on to the sauniq is the kinship role that it confers upon that individual; this is reflected in the way kinship terms (brother, sister, uncle, grandmother, etc.) are honoured and regularly used, often in apparent contradiction with actual biological relationships. To illustrate, "no child is only a child. If I give my grandfather's atiq to my baby daughter, she is my grandfather. I will call her ataatassiaq, grandfather. She is entitled to call me grandson" (Brody as cited in Alia, 
2005 , p. 252) ${ }^{63}$ In addition, one may receive several such names and thus play a variety of roles to different people; for example, the same individual may be known to different relatives or friends as sister, grandson, mother, and uncle - regardless of age or gender. It may be difficult for non-Inuit to fully grasp the complexity of this powerful custom that binds people to each other, and to the past, through names and kinship terms.

It is within this cultural framework that Victoria situates herself when she talks about her own namesake and, especially, her decision to name her daughter Elaina in this way. Elaina was named after Victoria's late grandmother, being given a slightly different form of her English name (originally Elaine) as well as her (unchanged) Inuktitut name, Malaya. She explains that, in keeping with the customs described above, friends and family members honour the kinship relationships of the original Elaine when interacting with young Elaina. For example, there are a few children named after Elaine's late husband, Suqualuk, and Victoria says "if bump into them at the store, the mother will always be like, oh, [regarding Elaina] there's your wife!" Similarly, Victoria's father calls Elaina "mother" (though she is biologically his granddaughter):

He ALWAYS calls her anaana [mother], he NEVER calls her by 'Elaina' or whatever. And he also calls her najakuluk, which is sister, because HIS namesake [laughs] was related to Elaine's namesake, the original Elaine. So it's really complicated but there's a lot of connections [...]. (FG)

One might be inclined to argue that it is perhaps the naming system itself that is important to Victoria, with its cultural implications of kinship and relational responsibility, rather than the Inuktitut language per se. However, consider carefully the point she makes here:

I asked what, what Elaine's Inuktitut name was. 'Cause the thing was, like, I said, okay, if I'm going to name her Elaine I don't wan- like, I wanted to name her after her NAME. 'Cause like 'Elaine' was her

\footnotetext{
${ }^{63}$ Indeed, "the ties between an Inuk and his or her namesake are so strong that kinship terms, dress, and behaviour often follow the relationship rather than the person's biological sex" (Alia, 2005, p. 253).
} 
Christian, given name, after she moved off the land. She was from, you know, nom- like, the nomadic Inuit off the land. She had her own name before, and THAT was her name.

Thus while a version of the original Elaine's English name was indeed passed on, it would appear that her Inuktitut name (Malaya) holds more importance for Victoria. Her stress on the word NAME at the end of the second sentence, and the phrases her own name and THAT was her name indicate that Victoria makes a distinction between the English and Inuktitut names. She seems to consider 'Malaya' to be her grandmother's "true" name, perhaps more reflective of her traditional, land-based lifestyle and her similarly "true" Inuk self, and it was this that Victoria wanted to pass on to her child. ${ }^{64}$ Here it is important to keep in mind the historical context in which Inuit names have been a site of struggle (recall the discussion in chapter 2 of Project Surname and other renaming processes); it would appear that holding onto an Inuktitut name is perhaps a way of maintaining a link with a more genuine or "authentic" conception of Inuitness. Furthermore, she explains that she was partly motivated by the fact that Elaina's last name (from her father) is English:

I just didn't want her to be too, too much on that side. Yeah, I wanted her to have some of her, um, Inuit- like, Inuit identity with... And- and I think that, like, name and identity are very, like, closely connected to each other.

In fact, she confides that she is now undertaking a process to change Elaina's last name to match her own Inuktitut one: “I'm really, really sad that, um, I named her after [...] a Southern [last] name, Jameson. I'm really, really regretful that I didn't name her Iksiraq" (FG). Additionally, she mentions that her own inherited namesake is in English rather than Inuktitut, and that she would have liked to have a personal Inuktitut name. Thus it

\footnotetext{
${ }^{64}$ Several Inuit that I have met during my participatory observation have expressed just such an opinion: that their personal Inuktitut names are indeed their "real" names.
} 
turns out that on some level Victoria does feel a strong attachment to the Inuktitut language, at least as far as names are concerned; and by her own admission, she makes a link between name and identity.

Given these accounts by participants, it is fair to say that they all attribute a relational function to names; that is, their names serve (in part) to relate or connect them to others, be it their specific home territory or community, their broader Aboriginal nation, or their ancestors and family members. Interestingly, the notion that names in an ancestral language somehow bring them closer to their "true" selves (as implied by Victoria, Della and Winona's statements) is reminiscent of Lombard's (2011) finding, discussed in chapter 2, that Niitsitapi names are often viewed as "real names" (p. 43). Indeed, for them, "carrying [Niitsitapi] names is the same thing as carrying your traditions, [showing] who you belong to. [...] Naming keeps our traditions, ceremonies, language, and people, alive" (p. 44). With the exception of Jade, participants also seem to feel that a name in their traditional language carries certain spiritual meaning. Winona speaks of receiving her Anishinaabe name from an Elder's vision in a sacred ceremony, something that Della is pursuing as well ${ }^{65}$ Sophie dreamed of her first daughter's name, and links her younger daughter's name to her fortuitous arrival at a very trying time; and for Victoria, her grandmother's spirit lives on through her own child. Both these notions of "realness" and spirituality associated with Aboriginal names is further supported in a consultation with Kanien'kehá:ka (Mohawk) ${ }^{66}$ Elder Paul Skanks, who notes that according to Haudenosaunee teachings, "when you come into this world, you come with a

\footnotetext{
${ }^{65}$ Note that Della speaks of "finding" an Anishinaabe name, rather than having an Elder "choose," "decide on," "come up with," or "give" one. This interesting verb choice fits with Winona's account of a spiritual vision, implying that the name is already connected to the individual and just needs to be revealed.

${ }^{66}$ The Kanien'kehá:ka, or Mohawk, are one of six Aboriginal nations that make up the Iroquois Confederacy, which is more accurately called Haudenosaunee, meaning "People of the Longhouse" (http://www.kahnawakelonghouse.com/).
} 
name" and "that's the only name we have. That's our REAL name. And that real name is the name that the Creator knows us by" (interview, March 28, 2011).

In fact, according to him not only are names a gift from the Creator, but so are Aboriginal languages themselves:

The language is important because, ah, it goes right back to Creation. Those languages were given to us as a gift. And then in, in that language, in the sound of those languages, and in the construction of that language, the natural world understands that. Because they were told that by the Creator when they were placed here. (idem)

He goes on to explain that this is why the traditional language is particularly important in spiritual ceremonies, because it connects speakers - in ways that English can't - to what lies "beyond this dimension" (idem). This notion of language as a sacred gift is shared by many Indigenous peoples (McCarty et al., 2006; Watahomigie, 1998), and as such may be perceived as "the only viable means for sacred communication" (Pecos \& BlumMartinez, 2001, p. 75; see also Retzlaff, 2005a). I mention this because it is particularly important to Winona who, beyond the above analysis of her attachment to spirituality and name, also sees a crucial link between spirituality and her specific language:

Like even in ceremony and stuff, you know, like I'd like to be able to express myself, in my language, in the language of, you know, the spirits and the ancestors and stuff like that. Because it's like, how do I even know that they understand English, like... [laughs] you know? Like, how do I know that my prayers are being heard?

In this way, then, she subscribes to a belief in the "inseparability of language and spiritual expression" (Pecos \& Blum-Martinez, 2001, p. 75) and is conflicted about the efficacy of praying in English. Theology aside (it is not my role here to question participants' religious beliefs), if one believes in the existence of spirits - and the possibility of communicating with them - then might not such communication be considered an instrumental function of language? As such, is not the traditional language required to 
adequately perform certain behaviours (in this case, praying) that are a part of this individual's cultural identity? If we accept this, then we understand Winona's concern that her lack of language proficiency in Anishinaabemowin is literally an impediment to her spiritual expression and, presumably, spiritual identity ${ }^{67}$

\subsection{Land}

As a broad categorical concept, "land" figures prominently in all participants' discourse. This is not unexpected, given the central role of territory and land in claims to Indigenous rights and peoplehood, and its resulting salience as a theme in Aboriginal discourse (e.g. Alfred \& Corntassel, 2005; Patrick, 2007, 2008;TFALC, 2005; Tsosie, 2003). However, it is manifested in several overlapping and intersecting ways, depending on the participant. Most notable are the themes of language and land, rural versus urban, and tradition versus modernity; these layers of meaning are explored below. Note that the overall theme of land generally consists of a non-linguistic index of identity; however, as language is indeed involved at times for some participants, I include it here as a possible means through which language may be experienced as salient for identity. Additional non-linguistic aspects of identity are discussed below in section 4.5.

\subsubsection{Language and land}

Sophie subscribes to a rather essentialist linking of traditional language to land and to land-based cultural practices such as hunting. She repeatedly emphasises the inextricable nature of this relationship, and notes particularly that the Western post-

\footnotetext{
${ }^{67}$ I considered a separate theme of "spirituality" for this analysis, but it is manifested in the data overwhelmingly in relation to name; Winona seems to be the exception in making this additional connection with the language as a means of communicating with the spirits. Thus while this final observation may stray slightly from the core theme of names, I feel it important to include here as an additional dimension of this particular participant's spiritual identity, offering a more complete picture of her beliefs and values.
} 
colonial educational setting - so sterile and removed from experiential land-based learning - is inadequate for total language acquisition:

The language is very much part, COMES, you know, from... a life that's been led out on the land, you know. That's where it comes from and, um, I think with, you know, certain research and even, just, the Elders know this, that you cannot teach a kid to be fluent in the classroom. ${ }^{68}$

She is pleased with the Cree language initiatives in her home community that are specifically aimed at taking children out on the land through "culture camp" programmes, noting that "there's so much teaching IN that setting. There's so much that can be taught about the language, about the culture. You know, about the culture THROUGH the language." This view seems to be consistent with her community's broader cultural discourse; indeed, Jacobs (2001) notes that the Cree of Chisasibi continue to value "the tradition of learning by apprenticeship," that is, active learning through life experience (p. 312). Thus Sophie believes that when engaged in trapping, hunting, putting up a tipi, and so forth, one gains not only the context-specific vocabulary that is part of performing that activity, but also a deeper cultural insight, or what she calls a worldview:

The words used to describe what is used to make a tipi and what happens in a tipi, it- it's rich in that! That Cree worldview. You know, and again, I can't verbalise how, specifically, that is but I know it's in there.

Although she admits here to difficulty in explaining precisely how such knowledge is encoded in the language, the structure of her phrases convey her certainty that indeed it is (for example, the absolute negation of cannot above in the first block citation and the conviction of I know it's in there in the second). Several times she also supports her observations by referring to Elders and other community members who say the same, thus

\footnotetext{
${ }^{68}$ Indeed, she attributes her own (occasional) language deficiencies to the fact that she didn't grow up, at least to the same extent as some of her peers, "in the bush" and thus wasn't "fully immersed" in the language of that context (FG).
} 
situating herself in the wider Cree collective that subscribes to this philosophy linking language and land (including land-based activities), as also noted by Jacobs (2001).

In addition, however, Sophie cites the work of linguistic ethnographer Keith Basso (1996), who studies the socio-cultural significance of Western Apache place names (which are often associated with stories conveying morals about social behaviour); Sophie feels that the linguistic description of landscape is very much a fundamental part of Cree culture as well. Specifically, she notes that "stories are associated with certain places. And of course that plays into knowing the land and knowing how to navigate the land [...]. And it kind of embeds that- that knowledge even more." She says that Cree uses land-descriptive words and offers an example from an Elder who was asked to explain certain vocabulary that is no longer commonly used (this was undertaken for a language preservation project): aashtihtaayaahtikw, meaning "the sunny side of the forest." This single Cree word embodies a concept requiring a multi-word translation to be adequately conveyed in English, indicating in her opinion a difference in "worldview." Again, she emphasises that the only way to learn to navigate the land, and to acquire this language and these concepts, is to be present and experience these things in person.

Thus it seems that the importance of land for Sophie's identity is centred on the language, traditional knowledge, cultural values, and worldview passed down through traditional land-based practices in connection with the natural world, illustrating the notion of TEK discussed in the literature review (Skutnabb-Kangas \& Dunbar, 2010). This kind of discourse, so central to Sophie's interview, does not appear salient for the other participants; one might speculate that this is perhaps because the others are not fluent in their respective heritage languages. However, land certainly does play an important role for them in other ways, as is shown below. 
4.4.2 Rural vs. urban ${ }^{69}$

I believe knowledge of participants' upbringing is crucial to understanding their views on language and land. I would venture that Sophie's views discussed above are greatly influenced by the fact that she grew up in the rural and isolated region of Chisasibi, where the dominant language and culture is Cree, and where land-based activities are still very much a part of community life (albeit not to the same extent as in the past). Indeed, Jacobs (2001) reports that many Chisasibi residents stress the importance of hunting, trapping and other bush skills in transmitting traditional Cree values such as sharing and reciprocity, honesty, self-reliance, hard work, and respect for others (particularly Elders). Along with Sophie's own childhood experiences of going into the bush from time to time, being told by Elders and community members (particularly her own father) that language, culture and land are indeed related has undoubtedly shaped her perspective. In addition, her fluency in Cree gives her access and insight into the language itself and its perceived connection to the land. Despite living in (urban) Ottawa for the past decade, she still sees her identity as being very much rooted in the culture, language and land of her true (rural) "home" of Chisasibi. ${ }^{70}$

Della, Winona, and Jade, however, did not share this kind of upbringing in a culturally and linguistically vibrant, rural Aboriginal community. Winona and Jade were raised mainly in urban areas, never living on reserve, and while Della grew up partly on reserve, she emphasises that her community's Aboriginal culture, and especially

\footnotetext{
${ }^{69}$ Note that while distinctions are often made between urban and reserve Aboriginal people, I use the term "rural" here to be more inclusive of the variety of non-urban Aboriginal communities from which my participants originate. Sophie and Victoria, for example, come from Aboriginal territories that are not technically classified as reserves, as they have been secured under official land settlements (the James Bay and Northern Quebec Agreement for the former, and the Nunavut Land Claims Agreement for the latter). ${ }^{70}$ Recall her plans for a tattoo reflecting this divide between the urban and rural parts of her life, and the symbolism of the goose facing east (towards home).
} 
language, "took a back seat" (PC, June 24, 2011) to assimilation and Westernisation processes. Growing up, then, these participants' identities developed in very different circumstances - specifically, in literal and figurative urban spaces - compared to Sophie. These diverse urban spaces give rise to identities that are negotiated and interpreted differently according to the individual. Jade, for example, notes that there is a significant "split between urban and reserve [Aboriginal] people" and that "I know [other] people who live in the city and we're all kind of displaced" (FG). She seems to associate community events such as potlucks and pow-wows - even those that take place in the city - with a rural/reserve lifestyle or mindset that is "separated" from her "daily life" and doesn't mesh with her urban reality: "it's such an out-of-my-normal thing. It's like an effort and then when I get there I feel awkward." ${ }^{, 71}$

Thus for Jade, the urban/rural pair is problematic in that she perceives these two kinds of Aboriginal identities as mutually exclusive, at least for the moment; she has not yet personally experienced a "coming together of the two lifestyles." This struggle can further be seen in comments such as 'I always call it my mum's reserve because I don't feel like it's mine, even though it IS." Nevertheless, it is that very feeling of awkwardness or alienation that seems to be partly motivating her recent and ongoing attempts to reconnect - mainly through the use of Facebook - with her Shuswap community and particularly her relatives (as described in section 4.2.1). Indeed, she tells me that she "would love to move back," but won't until her children are older, as all their ties are in Ottawa. It seems she hopes to eventually achieve a sort of merging of urban and rural by going back to her territory (Neskonlith Indian Band) and renewing her understanding of that rural/reserve life, thus presumably combatting the displacement she currently feels.

\footnotetext{
${ }^{71}$ She reports going to such gatherings only about once a year.
} 
Della and Winona seem to have already found just such a balance, as the cultural events and community gatherings that make Jade feel awkward or alienated, and which she associates with a rural/reserve lifestyle, are very much a natural and comfortable part of Della and Winona's urban lives (for example, Winona is a pow-wow dancer). In addition, they both feel that their Anishinaabe identity is able to be supported and constructed in this urban setting through their politics and their work. ${ }^{72}$ Both take part in conferences, student governments, political rallies, volunteer organisations, councils and boards, all of which are directly related to supporting Aboriginal people and their rights; and both have been and are currently employed by national Aboriginal organisations, as well as government agencies mandated to give services to First Peoples. ${ }^{73}$ In this way, then, Aboriginal people and issues - and by extension, reminders of their own Indigeneity - are very much connected to, rather than separate from, their daily life experiences. It is quite possible that this connection contributes to the development of their seemingly strong urban Anishinaabe identities; this hypothesis is supported by findings from Patrick and Tomiak (2008) emphasising the role of social networks and "institutional landscapes" (p. 64), such as Aboriginal organisations, in constructing a sense of urban Inuitness. Similarly, in the context of urban Native Americans in the United States, Lobo (2001) notes that "Indian organizations come to powerfully represent Indian 'space' or 'a place that is Indian' and are intimately tied to identity" (p. 76).

However, I notice that Della and Winona also engage in what I call "narrative rootedness" which seems to provide a foundation for these urban identities; this works to

\footnotetext{
${ }^{72}$ Incidentally, Jade actually commented, unprompted, that "if you go to work for an Aboriginal agency, you might have more of a- a sort of coming together of the two [rural and urban] lifestyles. But I haven't been able to get work in a place like that and in my field [corrections/security], probably won't."

${ }^{73}$ In the interests of protecting participants' anonymity I am unable to disclose the specifics of their employers, employment positions, and community involvement.
} 
harmonise their senses of self and further prevent feelings of displacement and awkwardness such as those Jade describes. By narrative rootedness I mean a discourse emphasising location of origin, as a way of maintaining a more or less symbolic connection with an original land base, despite one's well-established presence in an urban area such as Ottawa. For example, Winona notes the importance of being able to "tell a story and say, you know, my grandmother was from here and I KNOW where she was from," while Della explains that:

As long as you know where you come from [...] I think that's the most important part. As long as you don't forget that you're part of a culture, do you know what I mean? 'Cause like, once you get completely, I don't know, once you lose yourself in it you get stuck into, like the Western world and whatever. (FG)

My interpretation of these statements is that the participants' urban identities are able to remain distinctly Aboriginal - as opposed to morphing into something "stuck" in the "Western world" - by their ability to know, remember, and narrate their origins. Della's words in particular reveal an underlying fear of assimilation associated with an urban identity if that ability is not maintained. Thus urbanisation is seen as "acceptable," so to speak, as long as one remembers where she comes from, both literally (in terms of territory) and figuratively (in terms of community and culture).

This narrative rootedness, however, is not a particularly salient feature for the fifth participant, Victoria. This may be partly due to the fact that she spends a lot of time in Iqaluit for her job and therefore may not need to engage in a symbolic discourse of "remember where you come from," as it is still very much a part of her daily, lived reality ${ }^{74}$ In terms of the notion of land itself, Victoria appears to conceive of it

\footnotetext{
${ }^{74}$ This is unusual as many, if not most, Inuit who have relocated to Ottawa cannot easily afford the costly fees of returning to their home communities on a regular basis (Patrick, 2008; Patrick \& Tomiak, 2008).
} 
simultaneously along two different axes. On the one hand, she demonstrates a strong attachment to and pride in "the North" and in "Nunavut" rather than emphasising a link to a specific location, such as her parents' home community or even Iqaluit, where she herself grew up. Through repeated contrast of the terms "North(ern)" and "South(ern)," she lays claim to a Northern identity based on this rather broad conception of land and particularly the natural elements such as snow, ice, wind and cold; recall, for example, her plans to get a snowflake tattoo in honour of her origins in the "land of snow." other hand, she also distinguishes at one point between the nature of rural and urban locations, stating that she "fantasises" about spending a few months in a small northern settlement in order to rediscover the "small community mentality and, kind of, connectedness" that she feels is lacking in the urban settings of both Iqaluit and Ottawa. This in turn has implications for cultural identity, as she feels that a rural environment would allow her to "get reconnected" with Inuit culture and even the Inuktitut language (recall that this was also mentioned in section 4.2.2).

In addition, she refers to the relatively recent (1950s and 60s) shift of Inuit communities from a semi-nomadic to a sedentary lifestyle, which I interpret as a variation on the rural/urban dichotomy. In this context, the notion of land is problematised in terms of cultural identity as Victoria acknowledges the challenges that her grandparents and parents have had to face in adapting to certain radically different Qallunaat (EuroCanadian) systems and institutions, such as the concepts of mortgages and nine-to-five office jobs. She states for example that "I see my father as a displaced Inuk man" who is “definitely someone who's like, stuck in between two worlds because he's that gap, he's

\footnotetext{
${ }^{75}$ Granted, it might be argued that this discursive emphasis on the North constitutes a kind of implicit narrative rootedness of the kind described above; however, I contend that the difference lies in Victoria's lack of emphasis on a need to explicitly "know," "remember," and "tell a story about" that rootedness.
} 
that transition person" (FG). While she does not explicitly identify with this feeling of displacement herself (unlike Jade; see above), she does consider it "very important" to regularly take her daughter up North and to have her learn land-based cultural pursuits such as hunting, fishing, skidooing and so forth - the very kinds of activities that Victoria herself was unable to engage in as a child due to her parents' financial constraints at the time. This, then, further suggests that Victoria values a relationship with the land (including land-based cultural activities) as an aspect of Inuit culture and identity.

\subsubsection{Tradition vs. modernity}

As readers may have noted in the preceding subtheme, undercutting the discourse of rural versus urban (or in Victoria's case, nomadic versus sedentary) is also that of traditional versus modern. The tradition/modernity dichotomy is something that all five participants struggle with and react to in their own ways, as it intersects with land or language or both, depending on the individual; yet for all of them this struggle is centrally about maintaining their cultural identities. In keeping with her discourse linking land, language and culture, Sophie fears that modernisation (and especially, a disconnection from the land) will be harmful to traditional Cree language and culture:

My dad's generation is the last generation that had lived out on the land and had been born on the land, you know. And it's a very scary thing because, you know, after my dad's generation, you know, there's me, who hasn't had, lived that life, you know, very much. I grew up in the- in the modern, ah, modern Cree community. ${ }^{76}$

Winona, too, expressly values cultural practices such as sweat lodges, pow-wows, dances, spiritual ceremonies, learning and speaking Anishinaabe, and immerses herself in them as often as possible in order to hold on to tradition in the face of modernity. Thus just as

\footnotetext{
${ }^{76}$ Recall similar comments in section 4.2.2 where Sophie compares herself to her father's generation.
} 
engaging in "narrative rootedness" allows her to maintain a connection with her rural/reserve origins in an urban setting, engaging in tangible cultural practices is a way to preserve tradition in a modern setting. Interestingly, Della equates such practices with what she perceives as the philosophical and political metaphor of "going back to the land." She explains that growing up, she sometimes heard Elders' insistence that "Oh, we have to go back to the land, go back to the land," but in her opinion:

We need to do this, like, sort of compromise and be like, okay, we're not going to defeat capitalism, just give up on it. A lot of our lands are extremely eroded right now so we can't physically go back to the land. It's a state of mind, so I mean, you know - there is a point of pride in saying that yes, like, you don't want to lose those traditions and those issues because that's what holds onto the culture. (FG)

Expanding on this in her interview, she sees this "state of mind" as a form of philosophical and political self-determination in which Native people "reclaim what's rightfully ours" in terms of cultural traditions, and language in particular, thereby avoiding total assimilation into the modern Western world (her fear of which is noted in the previous subtheme). However, her mention of this need for "compromise," along with a subsequent comment that "we still need to be moving forward" (FG), shows that Della also orients herself to a kind of synthesis between tradition and modernity.

This orientation to modernity is much more overt in the discourses of Victoria and Jade, particularly in the context of resisting static or fixed identities based on stereotypes or past traditional practices that are no longer (perceived as) relevant. Victoria exclaims:

Inuit had a hard- hard way of life, you know? A really hard way of life and there's so much glorifying of the old days, 'Oh! Before White man came, blah blah blah,' you know? But it's like, no! I don't want to be in an igloo at minus 60! [laughs] And I do enjoy having, you know, heat and Internet and, you know, hot showers in the morning. (FG) 
The dismissive phrases "glorifying of the old days" and "blah blah blah" reveal her frustration regarding expectations and stereotypes - held by both Inuit and non-Inuit about traditional land-based Inuit identity that are incompatible with Victoria's own sense of self in the modern, urban world. Similarly, Jade notes that

there's just this idea that, kind of, the way an Aboriginal person lives, or the way an Aboriginal person speaks, I mean... and I think, to me - for one thing I can't live that way, 'cause I wasn't taught how to, and for the other thing, too, it's not useful for me. (FG)

This reference to the perceived "usefulness" (or lack thereof) of traditional conceptualisations of Aboriginal identity is reminiscent of both women's overall discourse of linguistic social mobility presented at the beginning of this chapter. In fact, Victoria feels that the Inuktitut language would have more relevance and socio-economic value in the modern world if concerns about traditional language and dialectal pride were put aside to allow for linguistic standardisation. In discussing disagreements over dialectal differences, as well as the pressure or stigma she personally feels from other (generally older) Inuit in regards to speaking Inuktitut "properly," she asserts:

I just think this is a very old way of thinking, and I think once these, like, you know, kind of bossy Elders get out of the way, [laughs] and let, you know, younger people kind of take control more about it. Because I think a lot of that stigma comes from that. Because like, if you've ever been kind of like, scolded, by an old Inuit lady, it's not a pleasant thing, so...

The lexical items very old, bossy Elders, stigma and scolded evoke a rigid, obsolete framework for valuing language (and arguably identity, by extension); and the adherence to these old-fashioned traditions is perceived as an impediment to the development of a modern, relevant and dynamic Inuit language (and identity) embodied by younger 
people. ${ }^{77}$ Furthermore, I recall a conversation with Victoria during my participatory observation in which she observed that the syllabic writing system only widens the gulf between Inuktitut and other languages; instead she advocates the use of roman orthography, which is more easily recognisable to speakers of other languages (notably English and French in Canada) and which she feels would facilitate more cross-cultural and cross-linguistic communication. Again, her focus here is on the socio-economic value of the language in a modern, global context.

Victoria and Jade's comments suggest a need for these participants to diverge from tradition (to a certain extent) ${ }^{78}$ in order to create new Aboriginal identities that converge with their orientation to modernity. Indeed, Jade notes that with every new generation “you get a kind of a hybrid, which is... I don't know, to me I think that's good, adapting is good" while Victoria similarly feels that "Inuit don't necessarily want to be single-faceted." While Sophie, Winona and Della's discourses do not necessarily exclude this notion of "new identities" in the modern world, they are certainly dominantly characterised by a desire to maintain a link to the past through traditional cultural practices. As Patrick (2005) observes, "although the focus on older, more 'traditional" cultural activities or values might seem for some people to be reproducing static - and even irrelevant - notions of culture, this focus can be meaningful and of great value for others" (p. 383). Thus while Jade and Victoria situate their Aboriginal identities in terms of adaptation and change, the other three participants seem to define theirs in terms of ties to the past. The division is not black and white, however, nor are these views mutually

\footnotetext{
${ }^{77}$ It is important to note the possibility, however, that were Victoria a fluent speaker of Inuktitut she might feel more attachment to a specific dialect and would be less inclined to advocate for such standardisation.

${ }^{78}$ Recall that both participants do value what might be considered "traditional" cultural ties, as demonstrated by Jade's ongoing efforts to reconnect with (and plans to someday return to) her reserve community, and Victoria's commitment to exposing her daughter to land-based activities up North.
} 
exclusive; each individual seeks to maintain her own personal balance between old and new, traditional and modern, ancient and innovative.

\subsection{Additional Modes of Identification}

The previous themes have demonstrated the principal ways in which participants report language as a salient marker of their respective Aboriginal identities. There is no question that all participants do indeed identify with their Aboriginal affiliations, as this was a condition of eligibility for the study; however, the nature and processes of these identities vary according to the individual. As such, this analysis would not be complete without keeping these findings in perspective by considering broader notions of cultural identity. That is, while the focus of my study is the presumed connection between (Aboriginal) language and (Aboriginal) identity, it is important to offer participants the opportunity to align themselves with non-linguistic aspects of that identity, ${ }^{79}$ and indeed with other kinds of cultural identities altogether. This contextualises each individual's discourse and thus provides a more complete and insightful profile of her perception of identity, including the salience of language where appropriate.

\subsubsection{Additional non-linguistic aspects of Aboriginal identity}

The aim of including this theme is to illustrate the relative importance of language for individual identity by looking at other, non-linguistic aspects of identity. Participants were asked what aspects or activities (besides language) defined them as Cree, Anishinaabe, Shushwap or Inuk, respectively. In addition to the salience of the two themes addressed above (rural vs. urban and tradition vs. modernity), all participants

\footnotetext{
${ }^{79}$ Some non-linguistic features have of course already been addressed in the form of land, specifically the themes rural vs. urban and tradition vs. modernity. However, as will be shown below, other non-linguistic indexes of identity arise as well.
} 
mention their biological heritage and their location of origin; this is not particularly surprising, considering the ethnic implications of kinship and bloodlines, as well as the previous themes illustrating the salience of land for each individual ${ }^{80}$ Sophie initially laughs and replies, "my first response, you know, if you asked me that any other day it'd be, I'd be inclined to respond, you know, my language!" Thus even when asked about other aspects of identity, she still feels the need to reiterate that for her, language is absolutely paramount - reflecting her fluency in Cree and her continuous discursive thread linking language and culture, which should be clear by this point. Della mentions her "politics and beliefs" and Winona her "epistemology," both explaining these terms as referring to their knowledge and understanding of the history of their people - another discourse of "remembering where one comes from" similar to that of the narrative rootedness discussed above. This is also reflective of the importance of oral history in many Indigenous cultures; beliefs and values are embedded in stories passed from one generation to the next, connecting the past with the present and allowing individuals to anchor themselves in collective memory (McLeod, 2001). Note that while both participants do have a strong desire to improve their fluency in Anishinaabemowin, believing it will enhance their cultural understanding, these acts of historical remembering can nevertheless take place in English.

Interestingly, only one person (Della) explicitly mentions status under the Indian Act as a marker of her identity - an "obvious one," according to her. It may be that this is more salient for her than for other participants due to her family history; under the rules of the old Act, her grandfather (and hence her mother) lost status when he joined the

\footnotetext{
${ }^{80}$ Specificity of location did vary, however; for example, Sophie names her Chisasibi Cree community, while for Victoria Nunavut and simply "the North" were again her points of reference.
} 
airforce ${ }^{81}$ but the family regained it through Bill C-31 in 1985 . Having her family apply to gain back their status - and all the rights and benefits it entails - likely increases its symbolic value for Della's Anishinaabe identity. Without ever having lost status, it is possible that the other participants take it more for granted - although at least one finds it problematic in terms of Aboriginal identity. Not in response to my question, but elsewhere in her interview, Winona notes that "you can't just go from status cards" in determining who is or is not Aboriginal. She talks about friends and acquaintances who for various reasons do not have status, nor the rights and benefits associated with it, such as subsidised post-secondary education. One friend was able to apply to an Aboriginal organisation for scholarship funding as a non-status individual, and as part of the process:

Winona: $[\ldots]$ they actually interview them, to say like, tell me about your connection-Claire [overlapping]: --Your story, yeah.

Winona [overlapping]: --tell me about your community, like... so that way, it- it's validation, right. And I think that's more important than... a piece of paper.

Again, being able to tell a story about one's origins and community - that narrative rootedness - is crucial for Winona, more so than any government recognition.

Finally, Winona also mentions pow-wow dancing as an important marker of her Anishinaabe identity; she started learning from her mother at the age of four and although she did not always keep it up continuously, today she still dances on a regular basis. This dancing is a link to the past, as something that is passed down from mother to daughter; it is a way of practising traditional culture in a modern, urban setting; and it carries spiritual value as an important aspect of ceremony (as noted previously, Winona has a strong sense of spirituality). As such, dancing is a physical celebration of her heritage and is arguably

\footnotetext{
${ }^{81}$ As Grammond (2009) explains, "when an Indian was enfranchised, his wife and children were automatically enfranchised as well" (p. 99).
} 
a form of empowerment, though she doesn't use this term herself, in the face of struggle which is another aspect of her identity that is presented in the following subtheme.

\subsubsection{Non-specific Aboriginal identity}

Thus far I have consistently emphasised the cultural diversity among First Peoples in Canada, being careful to avoid talking about a single, homogeneous "Aboriginal identity"; there is, however, a time and place for such a concept to indeed be addressed. The very existence of the Assembly of First Nations and of other national Aboriginal organisations demonstrates a certain solidarity and mobilisation among First Peoples. However, the degree to which individuals personally subscribe to a broader "Aboriginal" identity varies. Sophie does feel a connection to her "Aboriginal sisters and brothers" of other nations, but remains "first and foremost" firmly grounded in her specific Cree identity. Della identifies equally as both Anishinaabe and Aboriginal and does not see them as distinct concepts. Victoria seems to struggle with the notion of a broader Aboriginal or Native collective, describing a Canadian Studies class in which she engaged in discussion with several other Aboriginal students and was surprised to find that "it was the first time, ever, that I felt Native!" (FG). Thus her sense of Northern, Inuit identity does not inherently correspond to a feeling of overarching "Aboriginal" identity. We might plausibly attribute this to the fact that Inuit and First Nations culture are very different; that is, despite the diversity among First Nations, they generally have more in common with each other than with Inuit. This is also supported by comments by Jade and Winona, whose views are discussed next.

Indeed, Winona situates herself quite firmly within a broader First Nations identity that is distinct from Inuit, explaining that: 
I feel more connected to a FN [First Nation] culture whether Ojibwe, Cree, Mohawk etc than I do to an Aboriginal culture. I don't feel connected to Inuit nor Metis as much as I do FN however I do share a sense of solidarity and spiritual connection with the broader Abo[riginal] collective. (PC, June 28, 2011)

In discussing this solidarity with an Aboriginal collective during her interview, Winona appeals to a discourse of oppression. She talks about the hardships she has faced, growing up in poverty, fighting discrimination and racism, being placed in (sometimes abusive) foster care, and seeing her mother be unfairly targeted by police and the justice system. In this way, she feels her identity has been very much shaped by

my struggle as a Native person. And I know that doesn't apply to all Native people 'cause there are Native people who have lived with privilege. So it's not fair to say because I've struggled I'm Indigenous, but that's where I get a lot of the identity from.

While indeed acknowledging that this may not be the reality for all Indigenous people, she does feel that this kind of struggle and social oppression are so common, and are so "systemic" and "engrained" in society, that they form a strong foundation of shared experience and solidarity among Aboriginal people based on "the fact that we are oppressed." For her, then, Aboriginal identity (or at the very least, solidarity) is tied to a shared history of colonialism and social oppression.

Jade, however, has a very different interpretation of "Aboriginal identity," namely pointing to specific attitudes, behaviours and values that are distinctly Aboriginal. In fact, this is actually a very salient aspect of Jade's discourse in both the focus group and interview, but has thus far not been able to emerge in relation to previous themes. Interestingly, unlike the other participants, she actually identifies less with a specific Shuswap identity and more with a general Aboriginal identity:

I think that's probably most appropriate - "Aboriginal" - because um, like I was saying, a lot of people, Aboriginal people, do things differently here, 
like, as far as dances and ceremonies and stuff. But all of those underlying things that I was talking about are pretty much the same. So I would, yeah, classify as Aboriginal. Like, even Inuit, um, they do things vastly different than we do, but for the most part they have the same kind of attitude.

These "underlying things" she refers to include attitudes of non-interference and noncompetitiveness, child-rearing philosophies, and behavioural codes governing social interaction. She feels "really uncomfortable" in competitive environments, especially school (including post-secondary) where students are expected to outwardly display their knowledge, and is completely put off by what she describes as an attitude of "teacher, teacher, I know the answer, I'm so smart" (FG). Instead she prefers cooperative learning and "not one person just trying to dominate the whole thing" (FG). This notion of dominance in social settings does not coincide with Jade's cultural values:

A lot of, um, Aboriginal people aren't like that, you know. Everybody... like, we're not perfect, but it's, like, more of the norm for people to take turns to talk and if everybody knows that somebody has knowledge then they'll ask them and, you know, not just listen to the loudest person.

This last phrase indicates that talking for the sake of talking, without thoughtful reflection and appropriate turn-taking, is seen as superficial and does not earn the respect of fellow community members. She goes on to note that she never raised her children to be "really outspoken like that." Indeed, the domain of child-rearing is another in which Jade feels Aboriginal values conflict with the mainstream (readers may recall the following example from chapter 3): "This is what, um, sort of European people see as another wrong thing with us, is we're too permissive with our kids. We're not punishment-oriented, you know, we don't control them." Instead, she advocates allowing children to learn by experience and offering them tools to help them think for themselves and make their own choices. ${ }^{82}$

\footnotetext{
${ }^{82}$ In fact, Jade confides that this difference in views is a major source of tension between herself and her non-Aboriginal boyfriend, who she says is critical of her parenting techniques.
} 
Note that whether or not mainstream Euro-Canadians actually are competitive, dominating, punishment-oriented or controlling is not the point here; what matters is that Jade perceives them as such, and constructs her identity in opposition to them while simultaneously in alignment with other Aboriginal people, whose attitudes she feels are similar. Hence what emerges is a strong sense of Aboriginal identity that transcends (though by no means erases) her specific, local Shuswap identity and is manifested in generalised, non-linguistic attitudes and behaviours. ${ }^{83}$ Furthermore, she asserts that these Aboriginal attitudes were transmitted to her as a child "even though my parents didn'tnever spoke to us in the [Shuswap] language" (FG). She feels that her Aboriginal identity can absolutely be constructed and "performed," in a sense, through English - indicating that for this particular participant, traditional language is not crucial to her identity.

\subsubsection{Mixed heritage and Canadian identities}

In order to contextualise participants' perceptions of, and claims about, their respective Aboriginal identities, it is important to also consider what other cultural groups they may identify with. All participants were asked about the degree to which they associate themselves with the culture of their non-Aboriginal (or in Jade's case, nonShuswap) heritage, as well as whether or not they identify as Canadian (and if so, what kinds of things they do that they feel are "Canadian").

Winona, Jade and Della identify the least with their alternate heritage (Persian, non-Shuswap First Nation, and Italian-Canadian, respectively). Jade explains that her father was adopted by a White family, grew up off reserve with few connections to his

\footnotetext{
${ }^{83}$ Note that Jade's comments here might have been included in the preceding theme (non-linguistic aspects of identity). There, however, the question referred to participants' affiliations with their specific nation, and Jade does maintain that connection (albeit tenuous) through reserve-based kinship ties. I feel it important here to recognise her emphasis on certain attitudes being common to Aboriginal people in general, and the implications of this for her own identity. Admittedly this decision is also a matter of personal preference.
} 
culture, and never learned his ancestral language; thus this culture was not passed on to Jade as a part of her identity. Winona was raised by a single mother and never knew her Persian father; she says that "for a long time I suppressed the Persian side because I only, um, identified with the First Nations side. So I never even, like, acknowledged it." While she certainly acknowledges that part of her now, she does not connect or identify with it, because she didn't grown up with Persian culture. In her words, "I AM Persian, but I don't know what it's like to BE Persian." Della, though she does not repress or deny her Italian heritage, notes: "I focus more attention on my Aboriginal side than I do, say, my Italian side" and that sometimes, "I almost forget that I'm half." This tendency likely stems in part from the fact that her father has long been accepted into their Anishinaabe community and he himself "identifies with, you know, pseudo-Indian more than Italian!" Sophie and Victoria do identify more so with their non-Aboriginal cultures, but not without personal struggle. As a youth Sophie resented her White, French-Canadian heritage because it marked her as "different" in her Cree community, but with time she has come to embrace it. She identifies Québécois language, food, and television programmes as ways in which she relates to the culture, but emphasises that she does not identify politically as Québécois (and specifically, does not celebrate St-Jean Baptiste Day, which is the June 24 Québec "national" holiday). This reveals her desire to distance herself from the destructive actions and "conquering mentality" of the Québec government in terms of Cree people and their lands; she passionately writes,

When it came down to the land and its precious resources (minerals, lumber, water) we were simply not considered. We were squatters in our own homeland, pests to be left to rot in whatever filth that would be the residual waste resulting from the ravaging of our forests, waters, and sacred earth. (PC, July 18, 2011) 
Thus she makes a point of resisting a Québécois political and national identity because it conflicts with her Cree identity, while still relating to certain aspects of the culture that was passed down to her by her mother. Finally, Victoria is arguably the most embracing of her non-Aboriginal heritage. Her maternal grandparents are from the UK, and while her mother grew up immersed in Inuit language and culture, she also transmitted the English language and aspects of the culture (mainly in the form of cooking, says Victoria) to her daughter. Victoria notes that she spent a very long time

just thinking about Inuit and being Inuk and what it's like to be Inuk and stuff, and I totally neglected my other side of me. And then, and then I just came to this, like, self-realisation that, like, I'm half my mother and my mother's not Inuk. And I need to... I need to take, I- like, you need to give both sides your equal love and admiration and attention, you know.

This notion of duality also takes the form of a metaphor when she refers to herself as a "chameleon" who makes the best of both worlds through her ability to "mix in" with both Inuit and non-Inuit. She notes that "growing up in that, you know, two cultures has really helped me to become like that, like, just fitting in." This likely also accounts in part for her orientation towards modernity and new conceptualisations of Aboriginal identity, whereby she asserts that Inuit are not necessarily "single-faceted" (see section 4.4.3). In terms of identifying as Canadian, participant responses vary significantly. At one extreme are Winona and Della who definitely do not, at the other is Victoria who absolutely does, and the remaining two fall somewhere in between. For Winona, being an insider on the 'Canadian Club' means having to perform whiteness, pledge allegiance to the neo-capitalist regime and propagate Canadian 'myths.' Also, I may certainly locate myself in many Canadian institutions such as University, voting, shopping, mild forms of capitalism etc - I still do that under the auspices of my First Nations identity first. (PC, July 7, 2011) 
Della takes a similar tone when she says that "Canada is built on a nationalistic colonial ideology that has plagued turtle island ${ }^{84}$ for centuries" and as such, she does not identify as Canadian in terms of a "political, ideological and cultural category" (PC, July 11, 2011). Sophie and Jade are both far more embracing of a Canadian identity, although they remain conflicted given the negative impacts of both colonialism and modern mainstream society on Aboriginal people. However, Jade points out that

whether anyone wants to admit it or not, we [Aboriginal people] have contributed as much as any other group to the identity Canada has today. New work on this subject is always a welcome read for me and gives me a feeling of pride and of being Canadian. (PC, July 5, 2011)

Thus rather than dichotomising Aboriginal and Canadian identities, she brings them together, implying that she is Canadian by virtue of her Aboriginal identity (that is, through the contributions of First Peoples). Similarly, Sophie "love[s] this country" and takes pride in being Canadian, especially now that "the tides are changing" with the recognition (by individuals and the government alike) of past injustices as well as attempts at healing and reconciliation (PC, July 18, 2011). ${ }^{85}$ She is grateful for the freedom and opportunities available to her and her family by living in Canada, but acknowledges that many other Aboriginal people do not have these advantages, which saddens her. Although she embraces her Canadian identity, she nevertheless declares "I am Iiyiyiu from Iiyiyiu Aschii (Cree Territory of James Bay region). ${ }^{86}[\ldots]$ I wouldn't be me without first and foremost knowing that I am liyiyiu and identifying as such" (idem).

\footnotetext{
84 "Turtle Island" is a term commonly used by Eastern Aboriginal people to refer to North America and is derived from a creation story whereby the earth was formed on a turtle's back (Retzlaff, 2008). I often hear this term during my participatory observation.

${ }^{85}$ Interestingly, Sophie stresses that she does celebrate ("quite excitedly") Canada Day, in stark contrast to her comments about Québec's St-Jean Baptiste Day.

${ }^{86}$ Iiyiyiu is the Crees' name for themselves. This is the only instance in the data where Sophie uses it, thus I have employed the term "Cree" consistently throughout this paper in accordance with her own usage.
} 
Finally, Victoria stands apart from the others in that she actually identifies as Canadian "first before anything," listing the fact that she was born in Canada, has a Canadian passport, and engages in Canadian politics as markers of her Canadian-ness (PC, July 5, 2011). She asserts that this is a common sentiment among Inuit and refers to the late Jose Kusugak (former president of ITK $^{87}$ ) who said that "in accepting Canada, we shouldn't have to worry about losing our identity or believing in ourselves any less. Inuit are more than First Canadians, Inuit are Canadians first" (http://www.itk.ca/mediacentre/media-releases/first-canadians-canadians-first; see also Bonesteel, 2008). Victoria also mentions the popularity of hockey, the ubiquity of Canadian flags and the importance of Canada Day celebrations in the North as symbols of the fact that "most people around here are proud Canadians" (PC, July 5, 2011). She further states: "the True North Strong And Free - most people up here, are seriously northern, and definitely can relate and identify with Canadian culture, along with their own" (idem). It seems, then, that she experiences her Canadian-ness through, or at least concurrently to, her Northern-ness. This is in keeping with Patrick's (2008) observation that "Inuit have, historically, geographically, politically, and legally, been imagined and positioned - and imagined and positioned themselves - as a distinct Northern people inhabiting the Canadian Arctic" (p. 101). Thus while Victoria may identify first as Canadian, this does not occur at the expense of her Inuit-ness - in fact it is very much in line with popular Inuit discourse, at least as promoted by ITK. ${ }^{88}$

\footnotetext{
${ }^{87}$ ITK is the national Inuit organisation in Canada and stands for Inuit Tapiriit Kanatami, meaning "Inuit are united in Canada" (http://www.itk.ca/).

${ }^{88}$ Anecdotal evidence and personal experience from my participatory observation indicates that many other Inuit do identify as Canadian.
} 
This concludes the final section of the present analysis. This chapter has aimed to offer detailed and contextualised accounts of the ways in which these participants experience their heritage language as a salient feature (or not) of their respective Aboriginal identities. As noted at the beginning of this chapter, the themes presented here are not truly discrete categories but rather tend to overlap significantly. Consider that the theme of naming practices is related to that of pride, since most participants view a name in their Aboriginal language as a source of pride and a symbol of group belonging. Spirituality, while not treated as a theme in itself, is also intertwined with names and naming practices. Another example of such overlap is the way the theme of tradition vs. modernity is manifested in Victoria's discourse, being related to both land (she appreciates her modern, urban lifestyle and rejects the nostalgic "glorifying of the old days" when Inuit led a harsh life out on the land) and language (she sees entrenched traditional dialect loyalties as an impediment to the modern standardisation of Inuktitut). These interrelationships, along with the variation found among participants' orientations to each theme, reveal some of the complexities involved in individual cultural identity construction. This chapter has presented a microanalysis of individual experiences, and while some important discussion has already taken place throughout this analysis, what is still required is a broader discussion drawing these many elements together - particularly in light of the literature review and research questions. This is the purpose of the next chapter (following a brief summary of the themes presented here). 


\section{Chapter 5: Discussion}

The previous chapter offered a detailed and comprehensive analysis of study findings, while this chapter aims to put these findings into broader perspective; that is, to account for some of the possible reasons behind the similarities and differences among participants' attitudes towards language and identity. Therefore after a brief summary of the themes just discussed, I revisit the data in terms of participant profiles - the goal being to gain insight into each individual's experience of language as a salient marker (or not) of cultural identity. I then focus on what I deem to be the most novel findings put forth by this particular study, consider participants' overall cultural identities in terms of bicultural identity integration (BII), and show how my findings relate back to my original research questions and literature review.

\subsection{Summary of Themes}

This section briefly summarises the most salient themes (appearing below in italics) that emerge in the data in relation to Aboriginal language and identity. As indicated at various points in the previous chapter, most of these themes reflect those found in the case studies discussed in the literature review. Overall and at first glance, participants seem to position themselves at opposite ends of a polarity in regards to the value of language; these discourses also emerge in McCarty et al.'s (2006) work with Navajo youth. Victoria and Jade exhibit a general discourse of social mobility, emphasising the "usefulness" of English and French in terms of education, employment, business, government, and general functioning within Canadian mainstream society. Sophie, Della and Winona, on the other hand, extol the virtues of their ancestral languages in a discourse of cultural continuity or "struggle" which is manifested 
internally, externally toward other community members (particularly as a means of counteracting judgements about biological ancestry), and externally toward mainstream society (in the form of Della's "self-determinacy"). The theme of pride and belonging seems to follow this split between participants; the latter three speak of linguistic pride while the former two resist this connection to language, though they do feel a more general sense of cultural pride as a result of gaining knowledge of the history and traditional practices (but not language, per se) of their respective peoples. An interesting finding in connection with pride is the presence of tattoos (or concrete plans to get tattoos) symbolising participants' heritage - this is explored in greater detail in section 5.4. Next, shame and alienation are manifested in an apparent dichotomy along generational lines; this, too, is further discussed below as a relatively novel finding. While participants acknowledge parents' or grandparents' shame of their Aboriginal culture and language, largely due to the effects of residential schools and other assimilation-based programmes, they themselves express shame at a lack of cultural (for Jade) or linguistic (for the remaining four participants) knowledge and proficiency. While overall pride and shame are also both significant topics for McCarty et al. (2006), this unexpected manifestation of shame as well as the abovementioned tattoos constitute new emergent themes in my data, not previously encountered in my survey of the literature.

Similar to Lombard's (2011) work on Niitsitapi names, names and naming practices is another highly significant theme, with all participants attributing a relational value to their personal and family names. That is, they see their names as symbolic of their connections to other people, in terms of networks ranging from kinship to community to a broader cultural collective. Nearly all participants point to the importance of names in their Aboriginal languages (Jade being the exception here). Territory also 
proved key to identity, in keeping with the findings of Williams (2009) regarding Welsh, and Patrick (2008) and Searles (2010) regarding Inuit. The broad category of "land" is manifested in various ways, and while Sophie is the only one to really emphasise an explicit connection between language and land, all participants do experience their territorial origins as a salient feature of their Aboriginal identity, in terms of the themes tradition vs. modernity and, particularly, rural vs. urban. As Lobo (2001) notes in regards to Native Americans in the U.S.,

for many Indian people the urban areas are visualized more as an extension of home territory. [...] For those living in the city, even those a few generations removed from tribal homelands, these strong linkages to 'back home' are, for the most part, not broken. (pp. 76-77)

While participants vary in terms of the strength of their "linkages to back home" due to different upbringings and their current ability to afford the costs of travel (consider the difference between Jade and Victoria, for example), it is clear that maintaining that link, however tenuous it may be, is of utmost importance. Finally, additional modes of identification (non-linguistic, non-specific Aboriginal, and mixed heritage/Canadian) serve to position participants' stated views within the larger picture of "overall" cultural identity. On this front, participant responses certainly allow for a multiplicity of cultural identities, as in the case of Sophie and Victoria who, in addition to their Aboriginal affiliations, also embrace their non-Aboriginal ancestry and identify as Canadian (though not entirely without conflict; this is explored below in the discussion of bicultural identity integration). 


\subsection{Summary and Discussion of Individual Attitudes}

\subsubsection{Jade}

Jade displays the least attachment to, and interest in learning, her ancestral language; indeed, she notes that she is far more "inclined to FEEL more of a connection with English." She values the socio-economic status of English and French, denies the "usefulness" of Shuswap, does not exhibit feelings of linguistic pride or shame, does not expressly desire a Shuswap name (nor did she give her children Shuswap names), and makes no connection between language and land. There are a number of factors that come to mind in explaining these attitudes. First, it is crucial to note that Jade is the only participant representing a language group other than the top three most viable Aboriginal languages; as mentioned in chapter 3, only $4 \%$ of the Shuswap population are fluent speakers (FPHLCC, 2010). ${ }^{89}$ Since so few others speak it, her lack of linguistic proficiency could hardly be perceived as a barrier to acceptance or belonging in her community. Second, the immense geographical distance between Ottawa and the Okanagan Valley (and the fact that she cannot afford the exorbitant travel costs) heightens her feelings of physical and cultural displacement and brings to the fore issues of territoriality and community - hence attempts to reconnect with relatives and other community members, and establish ties to her specific band, are a bigger priority than language. Her emphasis on the role of Facebook in facilitating these efforts is significant; online social networking sites are recognised by scholars as empowering tools in the (long-distance) construction and reinforcement of collective identity among marginalised and/or minority groups (e.g. Danet \& Herring, 2007; Sheyholislami, 2012). Jade finds such communication validating and reassuring because she feels other Shuswap people

\footnotetext{
${ }^{89}$ While revitalisation efforts do occur in some communities, the prospect of full linguistic revival is bleak.
} 
"have the same kind of experiences and the same outlook." Finally, she points to several non-linguistic behaviours that clearly are highly salient aspects of her identity, including non-competitiveness, non-interference, norms for spoken interaction (especially in a group), and child-rearing philosophies. She feels that these attitudes are independent of language and attributes them to Aboriginal people in general, identifying herself in these broader terms as well. Indeed, these non-linguistic aspects of a general "Aboriginal" identity seem to be the closest thing to a cultural anchor that Jade holds onto as she tries to "survive" in a modern, urban environment.

This is not to say that she looks down on Aboriginal languages or revitalisation efforts. In fact, at one point she notes that occasionally people post things in Shuswap on Facebook, and that she's "glad that there are other people who know what they're saying"; this is hardly an expression of desire to reclaim that language for herself, however. Jade's personal trajectory, and the current displacement and alienation she feels, signal a very real need for the conceptualisation of "new identities" among urban Aboriginal populations (Patrick, 2007, 2008). Her language attitudes indicate that linguistic heritage need not necessarily be a focus or even an aspect of this new identity, and in this sense, she seems to be a prime example of Eastman's (1984) claim that language is merely a surface feature of ethnic/cultural identity, and of May's (2008) assertion that "there is no inevitable correspondence between language and ethnicity" ( $p$. 129).

\subsubsection{Victoria}

Victoria focusses on kinship, territorial connections, and land-based activities (particularly for her daughter) as salient aspects of cultural identity; these findings are in 
line with elements identified by Patrick (2008) and Patrick and Tomiak (2008) as important aspects of urban Inuitness. However, it should be noted that Victoria differs significantly from these scholars' respondents in terms of her unusual ability to regularly return home to her Northern community. Because of this, one might expect her - even more than solely Southern-based Inuit (who do tend to value Inuktitut, according to Patrick and Tomiak, 2008) - to emphasise the importance of Inuktitut as a form of cultural capital. However, this is where her views seem fairly incongruous. Indeed, her case is arguably the most contradictory of all five participants; more than the others, when it comes to language she appears truly caught between notions of tradition and modernity.

On the one hand she stresses the importance of French and English, ${ }^{90}$ is not concerned about her lack of fluency in Inuktitut, and criticises the perceived focus on "stupid" and "minute" things like culture and the Inuktitut language when Inuit are facing serious social problems. This is consistent with May's (2006) observation that dominant languages are often linked to modernity, development and wider communication while minority languages are associated with tradition and obsolescence, seen as "obstacles to social mobility and progress" and even leading to "ghettoization" (p. 263), even by minority language speakers themselves. Furthermore, Victoria denounces dialect loyalty and linguistic pride as old-fashioned and impediments to standardisation; this implies that she currently sees Inuktitut as "merely" a dialect, not standardised and not sophisticated enough for the modern world. This reflects Fishman's (1997) reference to the common perception "that the beloved language is not (or cannot conceivably become) a fit

\footnotetext{
${ }^{90}$ This is not meant to imply that urban Inuit respondents in Patrick's (2008) and Patrick and Tomiak's (2008) studies do not also value English and French; on the contrary, bi- and multilingualism are seen as important aspects of both Northern and Southern modern Inuitness. Unlike Victoria, however, this does not appear to come at the expense of also valuing Inuktitut for different but equally important purposes.
} 
instrument of modern pursuits and statuses" (p. 334). Taken alone, these attitudes indicate that Victoria associates Inuktitut with the past and does not see it as a salient feature of her modern, urban Inuk identity.

On the other hand, she does make fairly regular use of her Inuktitut skills at work, highly values Inuktitut names (both her own and her daughter's) and explicitly links them to identity, and cites that same linguistic pride on the part of others as a cause of discomfort and humiliation when it is directed at her as a criticism. It seems, then, that on some level her traditional language is important to her cultural identity, but that certain negative experiences have caused her to deny this. This is further supported by the fact that, while she repeatedly states that it's more important to learn English or French than Inuktitut, she has nevertheless enrolled her daughter at the OICC where Inuktitut is taught and celebrated. Furthermore, her comment that "there won't be any movement forward" (FG) until Inuktitut is standardised implies that if and when it is standardised (at least to her view), this will elevate it above the level of "dialect" to become a more sophisticated, modern, and "useful" language. One wonders whether such a transformation of the language in Victoria's mind might lead her to be more proud of her Inuktitut abilities and to see her traditional language as a more obvious emblem of her identity. These contradictions regarding language reveal that individuals may experience difficulties and "disconnects" in the construction of these new forms of Inuitness, or indeed, new Aboriginal identities in general. Note that one of these specific challenges - the criticism Victoria faces in terms of her Inuktitut proficiency - is addressed again in section 5.4. 


\subsubsection{Della and Winona}

Interestingly, Della and Winona have remarkably similar language attitudes - so much so that it makes the most sense to combine their profiles (while still accounting for individual differences). Their overall discourses regarding language are very similar, with the principal difference being Della's emphasis on self-determination and Winona's emphasis on spirituality. ${ }^{91}$ Both have limited linguistic knowledge but long for increased fluency in Anishinaabemowin; ${ }^{92}$ both bear tattoos as manifestations of their linguistic and cultural pride; both feel ashamed in certain cultural situations due to a lack of ancestral language proficiency; both view the notion of an Anishinaabemowin name as a powerful symbol of "true" or "legitimate" cultural identity; both engage in a discourse of "narrative rootedness" honouring their location of origin in spite of (or perhaps because of) their current urban setting; both hold on to symbols of tradition as a way to ground themselves in modernity; and both resist the notion of a Canadian identity. Of particular interest is the fact that these two participants did not meet during the focus group (recall that Winona was unable to attend), nor do I have reason to believe they know each other in another context. Thus there is no evidence of prior discussion of these views, so it seems that each theme arises independently and with fairly equal salience for both individuals.

How can these similarities be accounted for? The most obvious connection is the fact that both women are Anishinaabe; might there be some inherent aspect of Anishinaabe culture that instills in community members these values about language and

\footnotetext{
${ }^{91}$ Reasons for these differences are explored in the previous chapter. Della's activism stems from her mother's influence and from the political views she has formed since her first Indigenous studies class; Winona's spirituality can be attributed to the cultural practices she engaged in growing up, such as powwow dancing and sacred ceremonies, and the traditional beliefs that have been passed down to her (for example, that her birthmark represents something tangible from the spirit world).

${ }_{92}$ Significantly, I have learned that at the time of writing both individuals are registered in an Anishinaabemowin course to be offered in Ottawa this fall.
} 
identity? On the one hand, this seems plausible given that both participants come from different communities and had very different upbringings, ${ }^{93}$ so common cultural values might well explain these similar views. On the other hand, while it may indeed play a role on some level, this explanation strikes me as too simplistic, drawing dangerous generalisations based on only two individuals and implying a kind of group homogeneity that Edwards (2009), for example, warns against; furthermore, most of their views also correspond to those of Sophie, whose Cree culture is entirely distinct from Anishinaabe (though their languages are both in same linguistic family, Algonquian). Considering that all three women are highly committed to Aboriginal issues through their programmes of study as well as involvement with Aboriginal organisations, it is possible that their views about language and culture are significantly influenced by popular Aboriginal discourse surrounding healing and reconciliation, linguistic revitalisation, self-determination and empowerment, and community well-being (e.g. Aboriginal Healing Foundation, 2009; Johnston, 1998; Patrick, 2007; Retzlaff, 2005a, 2006, 2008; TFALC, 2005). ${ }^{94}$ Additionally, since both Anishinaabemowin and Cree are among the top three most viable Aboriginal languages in Canada, it may be that the very real possibility of linguistic maintenance/revival gives these individuals enough hope to emotionally invest themselves in the symbolic meaning of their respective languages; one wonders if Della and Winona would hold these same views if their language was in a state similar to Jade's (Shuswap). This is a case where in-depth familiarity with Anishinaabe culture and a broad-scale investigation into the views of a larger sample of (both urban and reserve)

\footnotetext{
${ }^{93}$ Della grew up with relative stability in a two-parent household alternating between Ottawa and her Cape Croker reserve, while Winona lived in various cities in three provinces, raised by a strong but struggling single mother and facing poverty, discrimination and the uncertainty and instability of foster care.

${ }^{94}$ A more detailed investigation into participants' social networks and political beliefs, as well as tracking the kinds of discourses they are exposed to (and their reactions to such discourses), would be required in order to confirm this hypothesis.
} 
participants would be highly revealing and would serve to further contextualise Della and Winona's responses.

\subsubsection{Sophie}

Sophie arguably represents the most straightforward and consistent example of one who experiences language and cultural identity as being fundamentally and inextricably linked - a poster child of sorts for the views espoused by Fishman (1991), Nettle and Romaine (2000), Skutnabb-Kangas and Dunbar (2010), and others. Her entire discourse revolves around the importance of the Cree language; its very nature as a vessel of cultural knowledge, its importance for "securing a spot in the community," its intimate connection to the land, and the necessity of transmitting it to future generations for the maintenance of Cree culture. As observed in the previous chapter, this attitude can be traced to the fact that she is a fluent speaker who grew up in a predominantly Cree community where similar beliefs are held by other community members, including wellrespected Elders and Sophie's own father (see also Jacobs, 2001). Such community attitudes or expectations may also be one of the factors contributing to her anxiety and distress at the thought of not being able to pass on as much linguistic and cultural knowledge as she "should" to her children. However, individual personality traits should not be overlooked here; Sophie refers to herself as a "very sensitive" person and clearly puts great pressure on herself, noting that this particular language issue "weighs very heavy" on her. Whether her fears are shared by others or indeed constitute a common trend in Cree communities would need to be substantiated by further large-scale research. Thus while many scholars and postmodernists denounce the "essentialist" claim that a specific language is fundamental to a specific ethnic or cultural identity, Sophie 
(along with Della and Winona) demonstrates that, theoretical concerns aside, it is most certainly possible to experience one's ancestral language as fundamental. In this particular case, however, there is an important distinction to be made - one that has not yet been discussed - between the nature of this experience for Sophie, on the one hand, and for Della and Winona on the other; this is explained in the following section.

\subsection{Beyond Instrumental and Symbolic: A Third Language Function?}

The need for the present discussion arises from the fact that while Sophie, Della and Winona's overall discourses are very similar in terms of linking language and identity, there remains one crucial and unavoidable difference: their actual language proficiency. Certainly, all three attach symbolic value to their heritage languages, as has already been made clear; but Sophie's fluency should surely result in some difference of substance in terms of the way she experiences her language, compared to Della and Winona (who are at best partial speakers). How can we distinguish between the two kinds of experience - or indeed, should we distinguish between them? I believe we should. Recall that Sophie sings in Cree, often draws or doodles using Cree syllabics, swears in Cree, and even has occasional dreams in Cree (including images of words written in syllabics). These are very personal and private functions that do not serve as outward displays of her linguistic or cultural identity, as they are not "performed" for the benefit of others. Some might argue that this merely constitutes a subcategory of language's symbolic function; however, a few scholars contend that there is indeed a difference. Sheyholislami (2010) identifies a "constructivist" (p. 290) function whereby one's identity is (re)constructed through personal use of the heritage language in the form of 
singing, writing, storytelling and similar activities. ${ }^{95}$ He notes that this kind of language use is "inevitably private, intimate, and individualistic" and as such, is "directed towards the self, to the soul, as it were, and the in-group" (J. Sheyholislami, PC, July 18, 2011). It would seem, then, that while one may align oneself symbolically with a language in which one is not proficient, it is not possible to use a language one doesn't know for constructivist purposes. However, this does not account for the fact that linguistic ability exists on a sliding scale and is not black and white; that is, at what point would one know a language "well enough" for it to serve a constructivist purpose?

Thus, although I introduced Sophie's case as a clear example of this third language function, this does not imply that without total fluency, Della and Winona are incapable of experiencing Anishinaabemowin as constructivist. ${ }^{96}$ On the contrary, I would argue that in Winona's case, for example, even her limited linguistic ability can be spiritually constructivist, as she mentions being able to "say my ceremony" in Anishinaabemowin. While this ritual may be performed in the presence of others, it is nonetheless highly personal and intimate. This example is useful because it demonstrates significant cross-over between language functions: symbolic, constructivist, and arguably even instrumental - recall my observation in chapter 4 that Winona's concern about being able to communicate with the spirits in a language they understand could constitute a kind of perceived instrumentalism. ${ }^{97}$ The point here is that these aspects of language are not fixed and discrete but rather fluid, overlapping, and intricately intertwined - and all may

\footnotetext{
${ }^{95}$ Joseph (2004) uses the term expression to describe a similar concept, "where what is expressed are the feelings, emotions and passions, usually of an individual, sometimes of an entire ethnicity or gender or other grouping" (p. 16). I prefer the label "constructivist" as it connotes that there is an underlying purpose to this type of expression: to (re)construct or give form to one's sense of self, one's identity.

${ }^{96}$ Victoria's attachment to Inuktitut names might also be construed as serving a constructivist function.

${ }^{97} \mathrm{I}$ offer this merely as an interesting line of thinking to consider. However, the instrumentality of language as it is discussed in the literature generally refers to the use of language for materialistic purposes: employment, education, voting, politics, and the like (e.g. Rubio-Marín, 2003).
} 
be important for identity. Indeed, together "all these instances and functions of language contribute to the construction of not only the self and in-group but the Other and the outgroups" (J. Sheyholislami, PC, July 18, 2011, emphasis added).

\subsection{Pride and Shame: New Twists on Old Themes?}

The purpose of this section is to follow up on two particular subthemes that appear relatively novel to my mind: tattoos as symbols of linguistic pride, and the generational shift in feelings of linguistic shame. Note that these were not notions I encountered in my research before undertaking this study or analysing the data; rather, they represent new, emergent topics that I was able to find by remaining open and flexible in my analytical approach. While the general themes of pride and shame are by no means new or surprising in studies of identity (including language and linguistic identity), these specific elements strike me as fresh perspectives and hence "new twists" on old themes; I briefly enquire into each of these below.

While there is no shortage of general literature on the history, meaning, and identity implications of body art, tattoos are not something that came up in my own research on language and identity in particular. A preliminary search reveals a number of sources on the historical practices of tattooing among Indigenous groups (e.g. Balvay, 2008; Krutak, 2007; Simmons, 1986; Thomas, Cole, \& Douglas, 2005) as well as studies on contemporary Western and Indigenous tattooing (e.g. Bell, 1999; Johnson, 2006; Pritchard, 2001, 2010; Sanders, 1988; Schildkrout, 2004). However, studies of linguistic tattoos (that is, tattoos of words or phrases) among Aboriginal peoples in Canada, specifically, do not seem to feature in the literature. Since the above scholars generally concur that tattoos are important forms of self-expression and as such, constitute markers 
of identity, a study of linguistic tattoos as forms of linguistic and cultural pride seems both warranted and significant. It would be fascinating to investigate the popularity of such contemporary tattoos among various Aboriginal communities, and to enquire into individuals' motivations for getting this kind of body art. For as Johnson (2006) notes,

The purpose of wearing this art on one's body rather than hanging it on a wall signifies a total commitment to what it stands for. It is the most permanent form of self-expression, with no escape from it. It is everywhere they go, they carry it with them, and it is a part of them. It is connected to one's mind and one's body for their time spent here on earth, and connected to their spirit, their inner essence forever. (p. 59)

While this may constitute a somewhat romanticised view of tattooing, it nevertheless emphasises the enormity of the decision to have permanent images (or words) marked on one's body; in this way, tattoos are powerful symbols. The fact that Della, Winona and Sophie all have or envision linguistic tattoos in their heritage language is very much in line with their relatively "essentialist" discourses grounding cultural identity in language. One therefore wonders whether other individuals (Aboriginal or otherwise) with such linguistic tattoos might share similar language attitudes. In assessing the significance of such tattoos it would be important to consider factors such as their popularity among the Aboriginal group in question, and the participant's total number of tattoos. That is, individuals who might otherwise not consider getting any kind of tattoo may be motivated to get one that is symbolic of their Aboriginal heritage if it becomes a common trend within their community. As well, if participants bear multiple tattoos and their Aboriginal tattoo is merely one among many (the others being non-Aboriginal), this may arguably reduce the symbolic weight they assign to the Aboriginal tattoo; conversely, if all of their multiple tattoos represent their Aboriginal heritage, this may indicate an increased emphasis on the cultural symbolism of this body art. All these lines of questioning likely 
have implications for cultural identity. There is obviously a plethora of factors influencing a person's decision to become tattooed and so the significance of an Aboriginal (linguistic or otherwise) tattoo would have to be considered in light of such variables. Lack of space prevents me from exploring these ideas in greater depth, however, I suggest that this topic shows promise as an area of future research.

The other topic of interest here is in fact the opposite of pride; quite unexpectedly, participants express feelings of shame in relation to a (perceived) lack of linguistic proficiency or continuity. I say perceived because even Sophie, a fluent speaker by her own admission, exhibits this in terms of (a) fearing judgement or criticism, based mainly on childhood experiences, and (b) not adequately passing on the Cree language to her children. As noted above, this may also be attributed to individual personality traits; however, when considered alongside the testimony of three other participants (Winona, Della and Victoria), a pattern seems to emerge. ${ }^{98}$ The fact that this trend spans three different Aboriginal nations and languages (among these particular participants) indicates that it may be related more to a generational shift - perhaps instigated by broader social and political factors - than to specific cultural values. I posit that two possible influential socio-political factors are Aboriginal discourses emphasising the role of heritage language revitalisation in contributing to strong, healthy cultures and communities (mentioned above in the profile on Della and Winona), and recent changes in mainstream Canadian attitudes on the part of both individuals and the government. The latter is symbolised for example by Prime Minister Harper's 2008 apology for the residential school system; as Sophie aptly puts it:

\footnotetext{
${ }^{98}$ Recall that Jade, too, feels something like shame regarding her lack of general cultural knowledge, particularly in terms of passing it on to her children; however, the focus here is linguistic shame.
} 
The tides are changing [...] because of the awakening of many Canadians that recognize the damages done, the injustices, and the wrongdoings of Canadian governments in their ideas of 'dealing' with the 'Aboriginal Issue.' (PC, July 18, 2011)

Although I do not deny the reality of ongoing discrimination towards Aboriginal people, this recognition that past paternalistic and assimilationist policies were harmful and wrongheaded seems to contribute to a revalidation and to some extent, de-stigmatisation, of Aboriginal identities. Thus it is gradually becoming seen as acceptable and indeed, desirable, to embrace one's Aboriginal culture (language included) with pride. However, those who lack or do not have access to the cultural capital necessary for cultivating this identity may be faced with issues of authenticity or inadequacy; hence Della and Winona's feeling that they "should" know Anishinaabemowin.

Here it becomes important to distinguish between two kinds of shame: internally generated and externally imposed. That is, Sophie, Della and Winona note that their shame comes more from within (internally generated) than from the direct comments or ostracism of other community members. ${ }^{99}$ Again, personality surely accounts for part of this; but I would point out that such feelings - and particularly their consistency among these three different individuals - do not occur in a vacuum. Rather, socio-political factors such as those just mentioned may have also played a significant role. Victoria, on the other hand, seems to resist those very discourses promoting heritage language revitalisation, at least in the face of what she perceives as far more serious and important social concerns, and so this seems to be a less plausible explanation in her case. Instead, her shame is externally imposed in the sense that she feels judged, criticised and scolded by other (older) community members because of her lack of skill in Inuktitut - including

\footnotetext{
${ }^{99}$ Although at one point Della does mention her perception that non-Aboriginal people often assume that she speaks - or, again, "should" be able to speak - her heritage language.
} 
general lack of proficiency, poor pronunciation and lower-status dialect. By her account, there is a linguistic hierarchy among Inuit that makes her feel stigmatised or "outcast."

It can be argued that to a certain extent, such stratification is an aspect of any speech community; according to Garrett (2007), studies in language attitudes have found that people judge language varieties in terms of superiority (prestige, intelligence, competence), social attractiveness (friendliness, trustworthiness) and dynamism (enthusiasm, liveliness). However, I would argue that given the complex social, cultural and political contexts surrounding (often endangered) Indigenous languages and identities, the phenomenon is not so easily explained away. Recall Searles' (2010) finding that lack of proficiency in Inuktitut, among other factors, has come to be associated with a lack of traditional cultural "authenticity"; might it be possible, then, that such scolding from Elders is intended, consciously or unconsciously, to motivate young people to keep up or improve their language skills - that is, in a sense, to shame them into speaking Inuktitut - and thereby reconnect with Inuit culture? ${ }^{100}$ Entertaining this notion for a moment, it would seem that such a goal was not achieved in Victoria's case, as she now does not feel "comfortable" speaking Inuktitut for fear of having her linguistic ability "dissected and analysed" (FG) by others. These negative experiences may in fact be part of the reason for her overall discourse of social mobility in which she denies the "usefulness" of Inuktitut. Of course, with the testimony of just one individual I can only offer conjectures at this point; and indeed, as preliminary searches did not reveal any literature on this particular "shame" phenomenon, I fully acknowledge the speculative nature of my comments here. I thus contend that it would be a worthwhile endeavour to

\footnotetext{
${ }^{100}$ While very different from Inuit historical and socio-political contexts, such practices have in fact been identified as a deliberate strategy of language maintenance used by Pan-Mayas in Guatemala, who "'shame' young families and youths into speaking or learning to speak Mayan languages" (Reynolds, 2009).
} 
investigate whether other adults or youth have had experiences similar to Victoria's, and if so, whether such shaming practices do in fact serve some kind of socio-cultural function.

\subsection{Sketching Cultural Identities in Light of BII}

In this section I explore in greater detail participants' additional cultural affiliations, that is, their orientations vis-à-vis their mixed ancestry and the notion of a Canadian identity. To do so I return to the framework of bicultural identity integration, or BII (Huynh et al., 2011), briefly discussed in the literature review. The authors describe an assessment questionnaire that has been developed to help create detailed BII profiles of respondents; as mentioned previously, since my study's focus was the link between Aboriginal languages and Aboriginal identities, specifically, such in-depth investigation of additional cultural identities was beyond its scope. Nevertheless, the detailed analysis of participant views in chapter 4 does provide some insight into their cultural orientations. Based on this available information I believe it is reasonable to propose an initial sketch of individuals' potential BII strategies.

First, both Della and Winona downplay their non-Aboriginal heritage and resist a Canadian identity; thus they do not actually appear to exhibit biculturalism. Instead they seem to employ another kind acculturation strategy, called separation, whereby individuals identify only or primarily with the "ethnic" (in this case Aboriginal) culture (Huynh et al., 2011). The other participants do seem to identify as bi- or multicultural, but this is manifested differently according to the individual. Recall that BII includes the two distinct components blendedness (vs. compartmentalisation) and harmony (vs. conflict), and biculturals "can have any combination of high or low blendedness and high or low 
harmony" (Huynh et al., 2011). I posit that Jade's cultural orientation as both Aboriginal (Shuswap) and Canadian is relatively more blended than compartmentalised, in the sense that she experiences her Canadian-ness by virtue of her Aboriginal-ness, stating that Aboriginal people have contributed in a fundamental way to what Canada is today. However, at the same time she experiences low cultural harmony (that is, high conflict) between the two, given the colonial history of Canada's oppression of Aboriginal people. She feels tension between the mainstream and her own cultural behaviours (such as noncompetitiveness and child-rearing philosophies), and notes that "police and military action against Aboriginal People bring up feelings of un-Canadianness" (PC, July 5, 2011).

Similarly, Victoria exhibits strong signs of blendedness among all her cultural affiliations, identifying simultaneously as Inuit, English and Canadian and using the metaphor of a "chameleon" to describe her ability to blend in with both Inuit and nonInuit culture. However, it is difficult to gauge, based on the information available, the degree of compatibility or clash (that is, cultural harmony or conflict) she perceives between them; I would venture, tentatively, that her apparent struggle between tradition and modernity may indicate more conflict than harmony. She seems at times to associate Inuit language and culture with an archaic past, incompatible with the more modern, urban English and Canadian cultures and the social mobility that French and English can provide.

For her part, Sophie seems to experience both low blendedness and low harmony. Regarding the former, she compartmentalises rather than blends her cultures, seeing herself first and foremost as a Cree who lives in Québec/Canada and not a "hyphenated" Cree-Québécois/Canadian individual. In terms of the latter, while she does embrace 
aspects of Québec culture passed down by her mother, she strongly resists a Québécois political identity due to the oppressive colonial history whereby Québec "was a major destructive force in the peaceful ways of the Cree" and has "always had a conquering mentality" regarding Cree land, resources, and people (PC, July 18, 2011). For Sophie, the degree of clash perceived between Cree and Québécois values or worldviews is too great for cultural harmony to be achieved. Interestingly, however, this raises the question of why she is proud to embrace a Canadian identity; certainly, the federal government has been an oppressive colonial force as well. More specific historical and political contexts likely play a role here; there was great tension during the 1970 s and 80 s between the James Bay Cree and the Québec government over a massive hydroelectric project, which succeeded in its first development but was defeated by the Cree in the second (Great Whale) development (Whitaker, 1999). Furthermore, Whitaker (1999) explains that Cree and other Aboriginal groups in Québec voted almost unanimously against the province's proposed secession from Canada during the two referendums, largely over concerns that they themselves will (paradoxically) not be recognised by an independent Québec as separate nations with the right to sovereignty and self-determination. These relatively recent conflicts with Québec, combined with Sophie's perception that "the tides are changing" in terms of Canadian individual and governmental recognition of past wrongdoings towards Aboriginal people, may help explain why she experiences more harmony with a Canadian identity than a Québécois identity.

Finally, while participants thus seem to demonstrate two kinds of acculturation strategies (separation for Della and Winona, and various forms of biculturalism for the other three participants), none appear to engage overall in the strategies of assimilation (identification with the dominant culture only) or marginalisation (identification with 
neither culture). I would emphasise again that the preceding discussion, while based on reliable information from the interviews, is nevertheless only a preliminary sketch of participants' cultural orientations. Additional investigation would be required to confirm these interpretations, including perhaps the assessment questionnaire described by Huynh et al. (2006) as well as observation of participants' behaviour in various bicultural contexts; the authors acknowledge that 'individuals' subjective experience of their identity and their behavior/competencies may not necessarily map onto each other" ( $p$. 830). It seems, then, that BII could constitute a rich area for further (ethnographic) research among these and other Aboriginal individuals.

\subsection{Return to the Research Questions}

This final section reviews the research questions in light of what has already been discussed and makes a few additional connections between this study's findings and theoretical discussions surrounding language and identity. My three central research questions are repeated below:

1. Is heritage language a salient aspect of participants' respective Aboriginal identities?

2. If so, in what way(s) is this language experienced as salient by each individual? What similarities and differences exist among these individual experiences, and what social, political, geographical or other factors might account for them?

3. To what extent do these personal, individual experiences correspond to or diverge from theoretical perspectives on language and identity? Do participants emit essentialist discourses, or deny linguistic rootedness, or something in between?

To answer the first question, yes, ancestral languages are a salient feature of four participants' cultural identities (Jade being the exception); I include Victoria here because despite her contradictory statements, evidence does point to her identification with Inuktitut on some level, particularly regarding personal names. Question 2 was addressed 
in the thematic analysis, and the participant profiles in this chapter demonstrate the degree to which language attitudes and beliefs are situated and contextual - like most aspects of identity, in fact. By tracing each individual's personal trajectory I have attempted to account for the wide range of views regarding language and identity that are manifested in the data. Also relevant to this question is the above discussion of a constructivist function of language, which provides a more nuanced understanding of the difference between the way Sophie and Della, for example, experience the salience of their heritage language. What does seem to be common to all participants, however, is the notion that their cultural identity is a site of struggle, whether in the form of language, cultural knowledge or skills, tradition vs. modernity, territoriality, kinship/community networks, considering mixed heritage or battling discrimination and oppression from the mainstream.

In regards to the final research question, participant discourses reflect and overlap with a number of theoretical positions and arguments. Sophie, Winona and Della's views seem to be in alignment with "essentialist" perspectives shared by Fishman (1991), Skutnabb-Kangas and Dunbar (2010), and others. As non- or partial speakers, Della and Winona's attitudes confirm that it is indeed possible to strongly identify with a language in which one is not proficient, as Skutnabb-Kangas (2008) suggests. Victoria and Jade's discourses are generally more reflective of notions such as social mobility, hybridity and the muti-faceted nature of identity. However, their efforts to maintain territorial links through Jade's use of Facebook and her hope of someday returning to her reserve, and through Victoria's regular travel to Iqaluit, her family ties there, and her general emphasis on her Northern origins - run counter to hybridity theory, which denies any and all forms of rootedness (May, 2008). In their case, then, some roots are valued and even necessary 
to maintain both a sense of individual self and an association with a cultural collective. In this sense these two participants reaffirm, arguably more than the others, Patrick (2007, 2008) and Patrick and Tomiak's (2008) call for reconceptualisations of what it means to be Aboriginal in modern and/or urban settings. ${ }^{101}$ The relatively micro-analytic approach I adopted allowed me to enquire into the highly situated, complex processes of identity construction on an individual level. The variety of attitudes revealed in this study leads me to agree with May's (2008) insight that a language "is crucial to our identity to the degree to which we define ourselves by it" (p. 135, emphasis added). This accounts for the presence in my data of both essentialist and more hybrid, "postmodern" conceptions of the importance of language for cultural identity. As Jade does not define herself by the Shuswap language, it appears to be more or less irrelevant to her identity; for Sophie, however, the Cree language is absolutely fundamental to who she is.

Overall these findings lead to two different conclusions. First, Sophie, Della and Winona's testimonies indicate that, in keeping with prominent Aboriginal rights discourses, there is a strong desire felt by some individuals to maintain Aboriginal languages and thus a need to continue implementing revitalisation projects and opportunities for language learning, especially in urban centres where people are separated from the speech community. As mentioned above, Della and Winona have both registered for an upcoming Anishinaabemowin course, an opportunity that Winona referred to as a "dream come true" (PC, July 27, 2011). Second, however, the very different viewpoints exhibited by Jade and Victoria suggest that prominent Indigenous

\footnotetext{
${ }^{101}$ This is not meant to imply that Sophie, Winona and Della are excluded from notions of "new identities"; on the contrary, their involvement with urban Aboriginal organisations and workplaces, and the "narrative rootedness" they have developed, certainly qualify. However, overall they subscribe to a more essentialist discourse and seem to focus more on tradition than do Jade and Victoria.
} 
discourses essentialising the link between language and identity do not correspond to the realities experienced by all Aboriginal people. This, then, becomes somewhat problematic: the very discourse relied upon to support the struggle for Indigenous rights and cultural continuity, if stressed too emphatically, may well risk alienating a significant portion of the Aboriginal population it is meant to protect. 


\section{Chapter 6: Conclusion}

There is nothing more important for native young people than to know their native language and the tribal lore and wisdom embodied in that language. It is the very heart of identity.

(Bunge, 1992, p. 379)

This and other statements by Bunge (1992) represent a view of language and identity that many theorists consider essentialist and thus incompatible with the flexible and dynamic nature of identity (Edwards, 2009; May, 2004, 2008). However, other scholars support such a view, believing that a specific language is indeed intimately linked to a specific cultural identity because of the unique worldview, TEK, and other kinds of cultural practices that are "encoded" in the language itself (Davis, 2009; Fishman, 2001; Nettle \& Romaine, 2000; Skutnabb-Kangas \& Dunbar, 2010). Certainly, as I showed in the literature review, this kind of view is apparent in contemporary Indigenous discourse as it has arisen in a specific historical and socio-political context whereby language has become embedded in claims to Indigenous rights, including struggles for land and self-determination (Patrick, 2007; TFALC, 2005). Despite the prevalence of this discourse, however, I questioned to what degree it reflected the real life experiences of Aboriginal people, on an individual level. Given the decline or "endangerment" of many Aboriginal languages today, I wondered how non-speakers and speakers alike might negotiate their cultural identities in terms of their traditional language. And, if that language was indeed important to individuals, I wondered in what ways, specifically, it was experienced as a salient marker of identity. Thus in undertaking this study I aimed to investigate individual perceptions of the presumed language/identity connection among Aboriginal people in Ottawa. 
In order to do so, I investigated participants' language attitudes by conducting a focus group discussion and a series of personal interviews. This kind of self-reporting on the part of participants is consistent with the "direct approach" in language attitudes research, and with the call in that domain for more nuanced, qualitative approaches to the study of such attitudes, "rather than relying so much on stimulus tapes and rating scales" (Garrett, 2007, p. 119). I applied the qualitative method of discourse analysis to my data, performing two levels of analysis to examine participants' attitudes not only in terms of their explicit statements (thematic analysis), but also in terms of the more implicit ideologies underpinning their discourse in the form of lexical choices, modality, pronouns, metaphors, presuppositions, and intertextuality. I also showed that a consideration of both broader historical contexts and personal "trajectories" or circumstances is important for situating individuals' attitudes and thus understanding their views.

Not surprisingly, I found both similarities and differences among participants' responses. Some (Sophie, Della and Winona) exhibit a discourse that closely mirrors that described above, joining a specific language and a specific culture. These three share the most similar attitudes and tend to experience the salience of language in much the same ways. These include seeing their Aboriginal language as a vessel of cultural knowledge, traditions and beliefs; a source of pride when spoken and understood, and of shame when not; an embodiment of spiritual power, particularly in regards to personal names; a form of identity validation in the face of judgements by others regarding their mixed ancestry and physical appearance; and, for Sophie, a social practice connected to land in terms of both navigating the actual landscape and engaging in traditional land-based activities. Overall, then, they see their heritage language as a powerful marker of both their 
individual and collective identities; in this way, their views seem to be very much in harmony with the widespread discourse advocating the maintenance of Aboriginal languages in order to protect and promote the cultural continuity of Aboriginal groups.

However, others (Victoria and Jade) position themselves very differently. Victoria arguably appears the most conflicted in terms of her relationship with her traditional language, alternating between a view that trivialises Inuktitut as useless, "minute" or "stupid," and one that seems to associate it with a "real" or authentic kind of (land-based) Inuit identity, specifically in terms of traditional naming practices, which also carry important spiritual meaning. The discomfort and shame she feels due to the way her Inuktitut language ability is "dissected and analysed" by other Inuit, and the fact that she "fantasises" about living in a small Northern settlement partly to improve her linguistic skills, contradicts her claim that lack of Inuktitut fluency does not bother her. Given these statements, she clearly does negotiate her identity at least partly in relation to her traditional language, even if that process of negotiation is a struggle and a site of conflict. Jade, on the other hand, does not appear to identify with her traditional language at all, even symbolically; learning Shuswap was never a "priority" and in fact she feels "more of a connection with English." She believes her cultural behaviours and attitudes can be expressed in any language, does not exhibit linguistic pride or shame, and does not remark upon a spiritual aspect of Shuswap or the significance of Shuswap names. Both Jade and Victoria emphasise social mobility, privileging French and English because these languages allow them to "survive"102 in modern society.

\footnotetext{
${ }^{102}$ Recall Victoria's assertion that "my whole life has been survival" and Jade's comment that she has to "survive in this environment."
} 
What this suggests is that there is a disconnect between the essentialist language ideology so prominent in Indigenous rights discourse, and the lived reality of some Aboriginal individuals. That is, discourses mapping traditional language onto cultural identity in a one-to-one relationship (language $=$ culture) may be inadequate for understanding some people's relationship with their Aboriginal language, and may not always be applicable to their particular identity constructions. This supports Patrick's (2008) call, for example, for a "reconceptualisation" of Aboriginal identity (in her case specifically Inuit, but given Jade's testimony I would argue that this is also applicable to other Aboriginal groups) in ways that allow for the use of other languages to also be validated as important aspects of that identity.

In addition to this finding, a number of other study results stand out as well. These include the significance of tattoos as a symbol of linguistic pride; the apparent generational shift in feelings of linguistic shame; in Jade's case, the role of social media such as Facebook in contributing to the construction of individual and collective Aboriginal identities; and a proposed distinction between symbolic and constructivist forms of identification with language. While these were addressed to some extent in the preceding chapter, in-depth analyses would require further investigation focussing specifically on these elements. I therefore propose that these four topics (tattoos, manifestations of shame, the role of social media, and a constructivist language function) would constitute worthwhile areas of interest in which to conduct future research.

\subsection{Further Research Directions}

In addition, it is important to note a few limitations that could also be followed up on in further research. First, my participants consist only of female university students. 
While this was in some ways an advantage, as it helped reduce the variables among an already diverse group, it also limits my findings to a specific gender and education demographic. It would be useful to extend this research to include male Aboriginal perspectives, as well as views from outside the university setting, to see what similarities and differences might arise in comparison with the present study. Second, four of the five participants represent the top three most viable Aboriginal languages in Canada; the one individual who does not fall into this category (Jade) turned out to be the one who identifies least with her language. This raises the question of whether attitudes and identification processes similar to hers may be more prevalent among communities whose language is in more serious decline. Thus it would be interesting to conduct a study of such language attitudes among a larger population sample of representatives from less viable Aboriginal language groups. Finally, I repeat here Johnstone's (2000) point that all sociolinguistic research is interpretive and that the study findings presented here have undoubtedly been influenced by my own background; that is, the same data might have been approached differently and resulted in alternative conclusions. In fact, there were other emergent topics that could have been analysed here but were unfortunately beyond the scope of this study - for example, those of education and biculturalism.

While education usually comes up in fairly general terms (as an "institution") in participant interviews, at times connections are made to language; in any case, it may well constitute a rich domain to be explored in the data, offering further insights into language and identity, language rights, mother tongue education, the negotiation of Aboriginal identities within educational institutions, and other concerns. ${ }^{103}$ Considering that many

\footnotetext{
${ }^{103}$ For example, Della mentions the perceived paradox or "double-edged sword" of attending university as an Aboriginal person: "it's such a Westernised way of assimilating the Indian into, you know, White man's
} 
arguments for minority language rights and mother tongue education appeal to "essentialist" discourses linking language and culture (e.g. Skutnabb-Kangas \& Dunbar, 2010), it would be interesting to see how participants' views measure up on this point. That is, do individuals who espouse more essentialist views of language and identity similarly support extended mother tongue education? And for those whose views do not correspond to this discourse, what position do they take regarding such education? What kinds of trends or inconsistencies may appear among participant views on this matter?

Another avenue to pursue is that of biculturalism, particularly in terms of the BII framework (Huynh et al., 2011). Although in the discussion chapter I did briefly assess the degree of participants' affiliations with other cultural identities in light of the basic constructs of BII, it nevertheless remains a very preliminary and speculative interpretation. Following up on this angle in greater depth would undoubtedly provide a more detailed and thorough understanding of these individuals' identities. Because all participants clearly self-identify as Aboriginal and the object of study was the presumed connection between a specific Aboriginal language and a specific Aboriginal identity, I remain confident in the integrity of my findings; however, I recognise that new insights could be gathered from further investigation. This might entail additional interview questions, but could also include more extensive ethnographic measures such as tracking participants' social networks, studying their daily interactions, and observing them in situations where they might have the opportunity to engage in cultural frame-switching (one of the possible aspects of BII).

\footnotetext{
world, by making them go to school. So they give it to us for free" (FG). At the same time, she feels she "owes" it to her family and community to "fight back and [...] STAY in school" (FG), using her education and skills for the good of her community in some way; this example indicates an important area to explore.
} 
Thus it should be noted that while the findings reported here are certainly the most salient in regards to language and cultural identity, they nonetheless represent only part of the wealth of data collected. While I had to limit myself to analysing only the most prevalent and pertinent themes for this thesis, additional topics certainly do emerge in the data and thus still constitute a rich resource for future research endeavours. In this thesis I have shown that actual processes of identity negotiation in relation to an Aboriginal language are highly situated, can vary significantly not only across but also within individuals, and do not necessarily match up with the discourses promoting Indigenous rights in terms of a bond between language and identity. If this disconnect is intense enough, it could alienate individuals who don't entirely relate to the discourse surrounding language maintenance efforts - such as Victoria, whose frustration is evident when discussing the detrimental social conditions faced by Inuit, which she feels should be a priority before all else (namely, language and culture). This frustration, along with other participants' emotional reactions at various points, is a telling sign of the difficulties and personal struggles associated with the negotiation and social positioning of their identities. Some of these struggles and contradictions have been demonstrated in the present study; but it would seem that even the numerous complexities that have been revealed in this analysis of individual identity represent only the tip of a very large iceberg. 


\section{References}

Aboriginal Healing Foundation. (2009). Response, responsibility and renewal: Canada's truth and reconciliation journey. Ottawa, ON: Aboriginal Healing Foundation.

Alfred, T., \& Corntassel, J. (2005). Being indigenous: Resurgences against contemporary colonialism. Government and Opposition: An International Journal of Comparative Politics 40(4), 597-614.

Alia, V. (2005). Inuit names: The people who love you. In D. Newhouse, C. Voyageur, \& D. Beavon (Eds.), Hidden in plain sight: Contributions of Aboriginal peoples to Canadian identity and culture (pp. 251-266). Toronto, ON: University of Toronto Press.

Alia, V. (2007). Names and Nunavut: Culture and identity in Arctic Canada. New York, NY: Berghahn Books.

Anderson, B. (1991). Imagined communities: Reflections on the origin and spread of nationalism $\left(2^{\text {nd }}\right.$ ed.). New York, NY: Verso.

Atwood, M. (1995). Marsh languages. In Morning in the burned house (pp. 54-55). Toronto, ON: McClelland \& Stewart.

Baker, C. (1992). Attitudes and language. Clevedon, UK: Multilingual Matters.

Balvay, A. (2008). Tattooing and its role in French-Native American relations in the eighteenth century. French colonial history $9(1), 1-14$.

Basso, K. (1996). Wisdom sits in places: landscape and language among the Western Apache. Albuquerque, NM: University of New Mexico Press.

Battiste, M. (2000). Maintaining Aboriginal identity, language and culture in modern society. In M. Battiste (Ed.), Reclaiming Indigenous voice and vision (pp. 192 
208). Vancouver: University of British Columbia Press.

Bazerman, C. (2004). Intertextuality: How texts rely on other texts. In C. Bazerman \& P. Prior, What writing does and how it does it: An introduction to analyzing texts and textual practices (pp. 83-96). Mahwah, NJ: Lawrence Erlbaum Associates.

Bell, S. (1999). Tattooed: A participant observer's exploration of meaning. Journal of American Culture 22(2), 53-58.

Bhatia, V., Flowerdew, J., \& Jones, R. (2008). Approaches to discourse analysis. In V. Bhatia, J. Flowerdew, \& R. Jones (Eds.), Advances in discourse studies (pp. 1-17). London, UK: Routledge.

Bonesteel, S. (2008). Canada's relationship with Inuit: A history of policy and program development. Ottawa, ON: Indian and Northern Affairs Canada.

Bonvillain, N. (2003). Bilingual communities. In Language, culture, and communication: The meaning of messages $\left(4^{\text {th }}\right.$ ed.) (pp. 336-369). Upper Saddle River, NJ: Pearson.

Bradley, D. (2002). Language attitudes: The key factor in language maintenance. In D. Bradley \& M. Bradley (Eds.), Language endangerment and language maintenance (pp. 1-9). New York, NY: RoutledgeCurzon.

Bucholtz, M., \& Hall, K. (2004). Language and identity. In A. Duranti (Ed.), A companion to linguistic anthropology (pp. 369-394). Oxford, UK: Blackwell.

Bunge, R. (1992). Language: The psyche of a people. In J. Crawford (Ed.), Language loyalties: A source book on the Official English controversy (pp. 376-380). Chicago, IL: University of Chicago Press.

Castellano, M. (2000). Updating Aboriginal traditional knowledge. In G. Dei, B. Hall, \& D. Rosenberg (Eds.), Indigenous knowledges in global contexts: Multiple 
readings of our world (pp. 21-36). Toronto, ON: University of Toronto Press.

Castells, M. (2004). Communal heavens: Identity and meaning in the network society (pp. 5-70). The power of identity ( $2^{\text {nd }}$ ed.). Malden, MA: Blackwell.

Charmaz, K. (2006). Constructing grounded theory: A practical guide through qualitative analysis. London, UK: SAGE.

Creswell, J. (1997). Qualitative inquiry and research design: Choosing among five traditions. London, UK: SAGE.

Cummins, J. (2000). 'This place nurtures my spirit': Creating contexts of empowerment in linguistically-diverse schools. In R. Phillipson (Ed.), Rights to language: Equity, power and education (pp. 249-258). Mahwah, NJ: Lawrence Erlbaum.

Danet, B., \& Herring, S. (2007). Multilingualism on the Internet. In M. Hellinger \& A. Pauwels (Eds.), Language and communication: Diversity and change. Handbook of Applied Linguistics 9. Berlin, Germany: Mouton de Gruyter.

Davis, W. (2009). The Wayfinders: Why ancient wisdom matters in the modern world. Toronto, ON: House of Anansi Press.

Deer, T. (Director). (2005). Mohawk girls [Motion picture]. Canada: National Film Board of Canada.

Deer, T. (Director). (2008). Club native: How thick is your blood? [Motion picture]. Canada: National Film Board of Canada.

Eastman, C. (1984). Language, ethnic identity and change. In J. Edwards (Ed.), Linguistic minorities, policies and pluralism (pp. 259-276). London, UK: Academic Press.

Edwards, J. (1984). Language, diversity and identity. In J. Edwards (Ed.), Linguistic minorities, policies and pluralism (pp. 277-310). London, UK: Academic Press.

Edwards, J. (2009). Language and identity: An introduction. New York, NY: Cambridge 
University Press.

Eggins, S. (2004). An introduction to systemic functional linguistics $\left(2^{\text {nd }}\right.$ ed.). New York, NY: Continuum.

Fairclough, N. (2001). Language and power ( $2^{\text {nd }}$ ed.). Harlow, UK: Pearson Education.

Fenton, S., \& May, S. (2002). Ethnicity, nation and 'race': Connections and disjunctures. In S. Fenton \& S. May (Eds.), Ethnonational identities (pp. 1-20). New York, NY: Palgrave Macmillan.

First Peoples' Heritage, Language and Culture Council (2010). Report on the status of B.C. First Nations languages. Brentwood Bay, BC: First Peoples' Heritage, Language and Culture Council.

Fishman, J. (1972). The sociology of language: An interdisciplinary social science approach to language in society. Rowley, MA: Newbury House.

Fishman, J. (1991). Reversing language shift: Theoretical and empirical foundations of assistance to threatened languages. Clevedon, UK: Multilingual Matters Ltd.

Fishman, J. (1997). Language and ethnicity: The view from within. In F. Coulmas (Ed.), The handbook of sociolinguistics (pp. 327-343). Oxford, UK: Blackwell.

Fox, J. (2005). Revisiting the storied landscape of language policy impact over time: A case of successful educational reform. Curriculum Inquiry 35(3), 261-293.

Gagné, R. (1979). The maintenance of the Native languages. In J. Chambers (Ed.), The languages of Canada (pp. 115-129). Ottawa, ON: Didier.

Garrett, P. (2007). Language attitudes. In C. Llamas, L. Mullany, \& P. Stockwell (Eds.), The Routledge companion to sociolinguistics (pp. 116-121). London, UK: Routledge.

Garrett, P. (2010). Attitudes to language. London, UK: Cambridge University Press. 
Garrett, P., Coupland, N., \& Williams, A. (2003). Investigating language attitudes:

Social meanings of dialect, ethnicity, and performance. Cardiff, UK: University of Wales Press.

Gee, J. (2011). An introduction to discourse analysis: Theory and method $\left(3^{\mathrm{rd}} \mathrm{ed}.\right)$. New York, NY: Routledge.

Geertz, C. (1973). The interpretation of culture. New York, NY: Basic Books.

Giddens, A. (1993). Sociology: Introductory readings. Oxford, UK: Polity Press.

Grammond, S. (2009). Identity captured by law: Membership in Canada's Indigenous peoples and linguistic minorities. Montreal, QC: McGill-Queen's University Press.

Guibernau, M. (2007). The identity of nations. Cambridge, UK: Polity Press.

Hall, S. (1996). The question of cultural identity. In S. Hall, D. Held, D. Hubert, \& K. Thompson (Eds.), Modernity: An introduction to modern societies (pp. 595-634). Malden, MA: Blackwell.

Harrison, K. (2007). When languages die: The extinction of the world's languages and the erosion of human knowledge. New York, NY: Oxford University Press.

Hassanpour, A. (2000). The politics of a-political linguistics: Linguistics and linguicide. In R. Phillipson (Ed.), Rights to language: Equity, power and education (pp. 33 39). Mahwah, NJ: Lawrence Erlbaum Associates.

Heller, M., \& Duchêne, A. (2007). Discourses of endangerment: Sociolinguistics, globalization and social order. In A. Duchêne \& M. Heller (Eds.), Discourses of endangerment: Ideology and interest in the defence of languages (pp. 1-13). London, UK: Continuum.

Huynh, Q., Nguyen, A., \& Benet-Martínez, V. (2011). Bicultural identity integration. In 
S. Schwartz, K. Luyckx, \& V. Vignoles (Eds.), Handbook of identity theory and research (pp. 827-842). New York, NY: Springer.

Jacobs, S. (2001). Building a community in the town of Chisasibi. In C. Scott (Ed.), Aboriginal autonomy and development in northern Quebec-Labrador (pp. 304 315). Vancouver: University of British Columbia Press.

Johnson, F. (2006). Tattooing: Mind, body and spirit - the inner essence of the art. Sociological Viewpoints 23, 45-61.

Johnston, B. (1998). One generation from extinction. In D. Moses \& T. Goldie (Eds.), An anthology of Canadian Native literature in English (pp. 99-104). Toronto, ON: Oxford University Press.

Johnstone, B. (2000). Qualitative methods in sociolinguistics. New York, NY: Oxford University Press.

Johnstone, B. (2003). Discourse analysis and narrative. In D. Schiffrin, D. Tannen \& H. Hamilton (Eds.), Handbook of discourse analysis (pp. 635-649). Malden, MA: Blackwell.

Johnstone, B. (2008). Discourse analysis (2 ${ }^{\text {nd }}$ ed.). Malden, MA: Blackwell.

Joseph, J. (2004). Language and identity: National, ethnic, religious. New York, NY: Palgrave Macmillan.

Joseph, J. (2006). Language and politics. Edinburgh, UK: Edinburgh University Press. Kinkade, M. (1991). The decline of Native languages in Canada. In R. Robins \& E. Uhlenbeck (Eds.), Endangered languages (pp. 157-176). Oxford, UK: Berg Publishers.

Krutak, L. (2007). The tattooing arts of tribal women. London, UK: Bennett \& Bloom. Kymlicka, W., \& Patten, A. (2003). Language rights and political theory. Annual Review 
of Applied Linguistics (23), 3-21.

Lakoff, G., \& Johnson, M. (1980). Metaphors we live by. Chicago, IL: University of Chicago Press.

Lambert, W., Hodgson, R., Gardner, R., \& Fillenbaum, S. (1960). Evaluational reactions to spoken languages. Journal of Abnormal and Social Psychology, 60, 44-51.

Lawrence, B. (2003). Gender, race, and the regulation of Native identity in Canada and the United States: An overview. Hypatia 18(2), 3-31.

Lawrence, B. (2004). 'Real' Indians and others: Mixed-blood urban Native peoples and Indigenous nationhood. Lincoln: University of Nebraska Press.

Lemke, J. (2008). Identity, development and desire: Critical questions. In C. CaldasCoulthard \& R. Iedema (Eds.), Identity trouble: Critical discourse and contested identities (pp. 17-42). London, UK: Palgrave Macmillan.

Lewis, M. (Ed.). (2009). Ethnologue: Languages of the world $\left(16^{\text {th }}\right.$ ed.). Dallas, TX: SIL International. Retrieved March 19, 2011, from http://www.ethnologue.com/

Lobo, S. (2001). Is urban a person or a place?: Characteristics of urban Indian country. In S. Lobo \& K. Peters (Eds.), American Indians and the urban experience (pp. 7385). New York, NY: Altamira Press.

Martin, J., \& White, P. (2005). Attitude: Ways of feeling. In The language of evaluation: Appraisal in English (pp. 42-91). London, UK: Palgrave MacMillan.

May, S. (2004). Rethinking linguistic human rights: Answering questions of identity, essentialism and mobility. In J. Freeland \& D. Patrick (Eds.), Language rights and language survival: Sociolinguistic and sociocultural perspectives (pp. 3553). Manchester, UK: St. Jerome Publishing.

May, S. (2006). Language policy and minority rights. In T. Ricento (Ed.), An introduction 
to language policy: Theory and method (pp. 255-272). Malden, MA: Blackwell.

May, S. (2008). Language and minority rights: Ethnicity, nationalism and the politics of language. New York, NY: Routledge.

McCarthy, M., Matthiessen, C., \& Slade, D. (2002). Discourse analysis. In Schmitt, N. (Ed.), An introduction to applied linguistics (pp. 55-73). London, UK: Arnold.

McCarty, T., Romero, M., \& Zepeda, O. (2006). Reclaiming the gift: Indigenous youth counter-narratives on Native language loss and revitalization. American Indian Quarterly 30(1/2), 28-48.

McCarty, T., \& Zepeda, O. (1999). Amerindians. In J. Fishman (Ed.), Handbook of language ad ethnic identity (pp. 197-210). New York, NY: Oxford University Press.

McLeod, N. (2001). Coming home through stories. In A.G. Ruffo (Ed.), (Ad)dressing our words: Aboriginal perspectives on Aboriginal literatures (pp. 17-36). Penticton, BC: Theytus Books.

Miller, J. (1996). The means of wiping out the whole Indian establishment. In Shingwauk's vision: A history of Native residential schools (pp. 183-216). Toronto, ON: University of Toronto Press.

Moore, J. (1984). Cheyenne names and cosmology. American Ethnologist 11(2), 291-312. Nettle, D. \& Romaine, S. (2000). Vanishing voices: The extinction of the world's languages. New York, NY: Oxford University Press.

Oliver, P. (2010). The student's guide to research ethics $\left(2^{\text {nd }}\right.$ ed.). Maidenhead, UK: Open University Press.

Patrick, D. (2003). Language, politics, and social interaction in an Inuit community. Berlin, Germany: Walter de Gruyter. 
Patrick, D. (2005). Language rights in Indigenous communities: The case of the Inuit of Arctic Québec. Journal of Sociolinguistics 9(3), 369-389.

Patrick, D. (2007). Indigenous language endangerment and the unfinished business of nation states. In A. Duchêne \& M. Heller (Eds.), Discourses of endangerment: Ideology and interest in the defence of languages (pp. 35-56). London, UK: Continuum.

Patrick, D. (2008). Inuit identities, language, and territoriality. Plurilinguisme et identités [Special issue]. Diversité urbaine 8, 91-108.

Patrick, D., \& Tomiak, J.-A. (2008). Language, culture and community among urban Inuit in Ottawa. Études/Inuit/Studies 32(1), 55-72.

Pecos, R., \& Blum-Martinez, R. (2001). The key to cultural survival: Language planning and revitalization in the Pueblo de Cochiti. In L. Hinton \& K. Hale (Eds.), The green book of language revitalization in practice (pp. 75-82). San Diego, CA: Academic Press.

Pennycook, A. (2002). Mother tongues, governmentality, and protectionism. International Journal of the Sociology of Language, 154, 11-28.

Phillipson, R. (1992). Linguistic imperialism. Oxford, UK: Oxford University Press. Phillipson, R. (Ed.). (2000). Rights to language: Equity, power and education. Mahwah, NJ: Lawrence Erlbaum Associates.

Picard, A. (2009, September 3). With more than 500 Aboriginal women missing, action is overdue. The Globe and Mail. Retrieved from http://www.theglobeandmail.com

Pritchard, S. (2001). An essential marking: Maori tattooing and the properties of identity. Theory, Culture and Society 18(4), 27-45.

Pritchard, S. (2010). Essence, identity, signature: Tattoos and cultural property. Social 
Semiotics 10(3), 331-346.

Rajagopalan, K. (2001). The politics of language and the concept of linguistic identity. CAUCE, Revista de Filología y su Didáctica 24, 17-28.

Retzlaff, S. (2005a). Tradition, solidarity and empowerment: The Native discourse in Canada - An analysis of Native news representations. Stuttgart, Germany: ibidem-Verlag.

Retzlaff, S. (2005b). What's in a name? The politics of labelling and Native identity constructions. The Canadian Journal of Native Studies 25(2), 609-626.

Retzlaff, S. (2006). Power over discourse: Linguistic choices in Aboriginal media representations. The Canadian Journal of Native Studies 26(1), 25-52.

Retzlaff, S. (2008). 'The Elders have said': Projecting Aboriginal cultural values into contemporary news discourse. In K. Knopf (Ed.), Aboriginal Canada revisited (pp. 330-359). Ottawa, ON: University of Ottawa Press.

Reynolds, J. (2009). Shaming the shift generation: Intersecting ideologies of family and linguistic revitalization in Guatemala. In P. Kroskrity \& M. Field (Eds.), Native American language ideologies: Beliefs, practices, and struggles in Indian country (pp. 213-237). Tucson, AZ: The University of Arizona Press.

Romaine, S. (2000). Language in society: An introduction to sociolinguistics $\left(2^{\mathrm{nd}} \mathrm{ed}\right.$.). Oxford, UK: Oxford University Press.

Rosen, N. (2008). French-Algonquian interaction in Canada: A Michif case study. Clinical Linguistics and Phonetics 22(8), 610-624.

Rosenberg, M., \& Hovland, C. (1960). Cognitive, affective, and behavioural components of attitudes. In C. Hovland \& M. Rosenberg (Eds.), Attitude Organisation and Change: An Analysis of Consistency Among Attitude Components (pp. 1-14). New 
Haven, CT: Yale University Press.

Royal Commission on Aboriginal Peoples. (1996). Report of the Royal Commission on Aboriginal Peoples (Vol. 2). Ottawa, ON: Minister of Supply and Services.

Rubio-Marín, R. (2003). Language rights: Exploring the competing rationales. In W.

Kymlicka \& A. Patten (Eds.), Language rights and political theory (pp. 52-79).

Oxford, UK: Oxford University Press.

Sanders, Clinton. (1988). Marks of mischief: Becoming and being tattooed. Journal of Contemporary Ethnography (16)4, 395-432

Schildkrout, E. (2004). Inscribing the body. Annual Review of Anthropology 33, 319-344.

Searles, E. (2010). Placing identity: Town, land, and authenticity in Nunavut, Canada. Acta Borealia, 27(2), 151-166.

Sheyholislami, J. (2010). Identity, language, and new media: The Kurdish case. Language Policy 9(4), 289-312.

Sheyholislami, J. (2011). Kurdish identity, discourse, and new media. New York, NY: Palgrave Macmillan.

Sheyholislami, J. (2012). Linguistic minorities on the internet. In K. St-Amant \& S.

Kelsey (Eds.), Computer-mediated communication across cultures: International interactions in online environments (pp. 235-250). Hershey, PA: IGI Global.

Skutnabb-Kangas, T. (2008). Bilingual education and Sign language as the mother tongue of Deaf children. In C. Kellett Bidoli \& E. Ochse (Eds.), English in international Deaf communication (pp. 75-94). Bern, Switzerland: Peter Lang.

Skutnabb-Kangas, T (in press). Mother tongue medium education. In C. Chapelle (Ed.), The encyclopedia of applied linguistics. Oxford, UK: Wiley-Blackwell.

Skutnabb-Kangas, T., \& Bucak, S. (1995). Killing a mother tongue: How the Kurds are 
deprived of linguistic human rights. In T. Skutnabb-Kangas \& R. Phillipson

(Eds.), Linguistic human rights: Overcoming linguistic discrimination (pp. 347370). Berlin, Germany: Walter de Gruyter.

Skutnabb-Kangas, T., \& Dunbar, R. (2010). Indigenous children's education as linguistic genocide and a crime against humanity?: A global view. Gáldu Ćála: Journal of Indigenous Peoples' Rights, 1. Guovdageaidnu/Kautokeino, Norway: Gáldu, Resource Centre for the Rights of Indigenous Peoples.

Smith, L. (1999). Decolonizing methodologies: Research and Indigenous peoples. New York, NY: St. Martin's Press.

Spielmann, R. (2009). How to learn Anishnaabe in two weeks or less! In Anishnaabe world: A (survival) guide to building bridges between Canada and First Nations (pp. 105-120). Sudbury, ON: Your Scrivener Press.

Spolsky, B. (2004). Language policy. Cambridge, UK: Cambridge University Press.

Task Force on Aboriginal Languages and Cultures. (2005). Towards a new beginning: $A$ foundational report for a strategy to revitalize First Nation, Inuit and Métis languages and cultures. Ottawa, ON: Task Force on Aboriginal Languages and Cultures.

Thomas, N., Cole, A., \& Douglas, B. (Eds.). (2005). Tattoo: Bodies, art, and exchange in the Pacific and the West. Durham, NC: Duke University Press.

Trudel, F. (1996). Aboriginal language policies of the Canadian and Quebec governments. In J. Maurais (Ed.), Quebec's Aboriginal languages: History, planning and development (pp. 101-128). Clevedon, UK: Multilingual Matters.

Tschanz, L. (1980). Native languages and government policy: An historical examination. London: University of Western Ontario Graphic Services. 
Tsosie, R. (2003). Land, culture and community: Envisioning Native American sovereignty and national identity in the twenty-first century. In D. Champagne \& I. Abu-Saad (Eds.), The future of Indigenous peoples: Strategies for survival and Development (pp. 3-20). Los Angeles, CA: UCLA American Indian Studies Center.

Watahomigie, L. (1998). The Native language is a gift: a Hualapai language autobiography. International Journal of the Sociology of Language 132, 5-7.

Weaver, H. (2001). Indigenous identity. American Indian Quarterly, 25(2), 240-255.

Wee, L. (2011). Language without rights. New York, NY: Oxford University Press. Weiss, G., \& Wodak, R. (2003). Introduction: Theory, interdisciplinarity and critical discourse analysis. In G. Weiss \& R. Wodak (Eds.), Critical discourse analysis: Theory and interdisciplinarity. New York, NY: Palgrave Macmillan.

Whitaker, R. (1999). Sovereignties old and new: Canada, Quebec, and Aboriginal peoples. Studies in Political Economy 58, 69-96.

Wodak, R. (2006). Critical linguistics and critical discourse analysis. In J. Östman \& J. Verschueren, Handbook of Pragmatics 2006. Amsterdam, the Netherlands: John Benjamins.

Young, I. (2004). Two concepts of self-determination. In S. May, T. Modood, \& J. Squires (Eds.), Ethnicity, nationalism and minority rights (pp. 176-195). Cambridge, UK: Cambridge University Press.

Ytrehus, L. (2004). Describing otherness: Ethics in research on ethnic minorities. In A. Paládi-Kovács (Ed.), Times, places, passages: Ethnological approaches in the new millennium (pp. 98-108). Budapest, Hungary: Akadémiai Kiadó. 
Appendices 


\section{Appendix A: Participant Biographies}

\section{JADE}

Jade is an upper-year undergraduate student and the mother of three. Now age 42, she was born in Kelowna, British Columbia, and grew up in the Okanagan Valley. Of mixed heritage, her mother is Shuswap ${ }^{104}$ from Neskonlith Indian Band (near Chase, BC) and her father is from a different First Nation but was adopted and raised by a nonAboriginal family with very little connection to his Native roots. As a result, he never learned his traditional language and while Jade's mother used to speak Shuswap, she hasn't done so for a long time; Jade herself was raised entirely in English and states that she has no language proficiency in Shuswap. Her early childhood was spent in rural (offreserve) areas as her parents were not financially stable and moved around a lot in search of work; however, she has lived in urban areas since reaching school age. She and her siblings had a troubled upbringing, due in part to their parents' alcoholism, and as a result they turned to substance abuse and other self-destructive measures. Jade dropped out of high school but went back several years later to upgrade her academic status in order to qualify for post-secondary education. Within her current field of study she is able to pursue her interest in "how people (especially Aboriginal) become dysfunctional/ criminal, with a special interest preventing child abuse/poverty" (personal communication, June 22, 2011).

\footnotetext{
${ }^{104}$ Shuswap is the English term for the Secwepemc Nation and their language, Secwepemetsin (http://neskonlith.org/). I mention this to acknowledge and honour their traditional language; however, in order to avoid confusion - as the participant herself uses the term Shuswap, and this appears throughout the focus group and interview transcripts - I continue henceforth using the English name.
} 


\section{VICTORIA}

Victoria is a 30-year-old Inuk woman who was born and raised in Iqaluit, Nunavut. Both her parents grew up in a small Nunavut community and speak fluent Inuktitut; her father is Inuk and her mother is Caucasian, originally from the United Kingdom, whose parents immigrated to the Canadian Arctic in the mid-1900s. ${ }^{105}$ Her first languages were both Inuktitut and English, but as she grew up she gradually lost her proficiency in Inuktitut and began speaking more and more English at home and at school (she was educated in the English-language stream from grade one onwards). Her selfreported language proficiency in Inuktitut rated as a few words/phrases in the domains of speaking, reading, and writing, and intermediate for listening comprehension. She also mentions returning for one week to her parents' community a few years ago for a family event and noticing, even in such a short time, a significant improvement in her Inuktitut abilities; thus it would appear that she retains a fairly solid passive knowledge of the language. She notes that as a child she didn't have the opportunity to pursue land-based Inuit cultural pastimes such as hunting and boating, as her family couldn't afford the high costs associated with such activities. Victoria is an undergraduate student, works parttime in a position that requires her to travel (at no cost to herself) regularly back to Iqaluit, and is the mother of a little girl who attends the Ottawa Inuit Children's Centre (OICC).

\footnotetext{
${ }^{105}$ Victoria notes that her maternal grandfather is now fluent in Inuktitut after immersing himself completely in Inuit culture, and that her grandmother understands the language, though she doesn't speak it.
} 


\section{DELLA}

Della is a 26-year-old graduate student from Cape Croker, Ontario, on the Saugeen (Bruce) Peninsula of Georgian Bay. She identifies with the (Anishinaabe) Chippewas of Nawash Unceded First Nation and grew up alternately between their reserve during the summers and Ottawa during the school year. English is her first and dominant language, but through her own efforts to actively seek out her traditional language she can speak, understand and write a few words and phrases in Anishinaabemowin (the Anishinaabe language), and has basic reading ability. She is of mixed ancestry with an Italian-Canadian father and Anishinaabe mother. Della's maternal grandmother is a residential school survivor and her grandfather was in the airforce, both of which she cites as key factors in her family's - and more broadly, her reserve's language loss and "Westernisation" due to assimilation policies in both institutions. She explains that on her reserve, her grandparents' generation was severely impacted by residential school experiences and as a result, most refuse to speak the traditional language although they are believed to be quite fluent. However, one community member is prominent Aboriginal scholar Basil Johnston, who is among the few Elders willing to actively speak, teach and promote the language, though he no longer lives on the reserve. Della has worked and volunteered for several national Aboriginal organisations and has been involved in many Aboriginal initiatives as a student leader. She does not have any children. 


\section{WINONA}

Winona is a 31-year-old Anishinaabe (Ojibwe) woman who has basic speaking and listening ability in Anishinaabemowin (she reports that she does not read or write it at all). She was raised entirely by her Anishinaabe mother, from the Gull Bay Reserve in the Thunder Bay District of Ontario, and never knew her Persian father. Born in Toronto, she spent her early childhood in Thunder Bay but then moved to several different towns in British Columbia and Alberta. Growing up, she and her family endured poverty, separation (several times she and her siblings were placed in temporary foster care), discrimination and sometimes violence. She finally returned to Ontario at the age of 12 when her family settled in Ottawa, where she has remained ever since. Although her mother, aunts and uncles are still fairly fluent in Anishinaabemowin, as children they attended English day schools where their traditional language was discouraged; as a result, they now speak mainly English and Winona's mother raised her children in English. Now a mother herself, Winona is currently pursuing an undergraduate degree while also working part time. Several of her past employment positions have been with national Aboriginal organizations and with Aboriginal-related branches of government departments; as she notes, "my work has been and probably always will be related to FN [First Nations] / Aboriginal issues" (personal communication, June 28, 2011). 


\section{SOPHIE}

Sophie is a 32-year-old graduate student, an Eastern James Bay Cree woman from Chisasibi (Québec) who is a fluent speaker and writer of Cree. Chisasibi is still a relatively new settlement, having been designed and constructed specifically for the 1980 relocation of 1,500 Cree people from the nearby island of Fort George - a move caused by the James Bay hydroelectric project that was expected to "engineer increased flows of the La Grande River and significant erosion of the island" (Jacobs, 2001 p. 304).

Chisasibi is $1,600 \mathrm{~km}$ north of Montreal, accessible by the Route de la Baie James, and is quite isolated; the closest town, Radisson, is $100 \mathrm{~km}$ to the east. Born to a Cree father and Québécois mother, Sophie grew up speaking mainly French in the home, along with some English with her father, but learned Cree from her peers as well as in school at both the primary and secondary levels. Cree was and remains the main language of daily interaction in her home community, and this is both reflected and supported by developments in literacy and education whereby Cree is now the medium of instruction from kindergarten to grade three, before then transitioning to English or French-medium instruction with Cree as a subject matter. Here in Ottawa/Gatineau, Sophie's main link to Cree society is through the Cree School Board and the Grand Council of the Crees. Her partner is also Cree but from a different region and does not know his dialect, so English is their main language at home and with their children. Nevertheless, Sophie actively promotes both French and Cree in the home and the family often returns to Chisasibi, where they are exposed to Cree language and society on a daily basis. 


\section{Appendix B: Participatory Observation}

Activities in connection with the Aboriginal community in Ottawa, undertaken by the researcher since September 2010, include but are not limited to:

- A Canadian Studies graduate course entitled "Aboriginal Peoples, Canada and the North" (CDNS-5101). This class covered a range of topics, including history, politics, language preservation, health care and the arts; and we were exposed to various guest lecturers from different Aboriginal nations.

- The Canadian Studies Department's Visiting Elders programme; weekly sessions whereby a local Kanien'kehá:ka (Mohawk) Elder shared stories, traditional teachings, and answered students' questions.

- Personal consultations with individual Elders from various Aboriginal nations.

- Time spent in Carleton's Aboriginal Lounge, socialising with other students.

- Social and ceremonial public events such as the 2010 Wakefield Harvest Festival, pow-wows, roundances, potlucks, Aboriginal Awareness week (January 2011), traditional throat singing, the 2011 Annual Inuit Spring Celebration, and a rally calling for government action in regards to the 500 missing and murdered Aboriginal women across this country (Picard, 2009).

- The 2011 Annual New Sun Conference on Aboriginal Arts at Carleton University.

- Inuktitut language classes offered by the Ottawa Inuit Children's Centre (OICC) in Vanier from September 2010 to March 2011.

- A regularly scheduled Inuit sewing circle through Tungasuvvingat Inuit (TI) ${ }^{106}$ in Vanier, where we were taught by Elders to make parkas and sealskin mitts, but which also served as an important intergenerational social gathering.

- A volunteer position at the Wabano Centre for Aboriginal Health in Vanier, where I have begun building connections with staff and patrons alike. It has also provided me with opportunities to participate in cultural workshops such as basket-weaving, Medicine Wheel teachings ${ }^{107}$ and a sweat lodge ceremony.

\footnotetext{
${ }^{106}$ Meaning "a place where Inuit are welcome" (http://www.tungasuvvingatinuit.ca/).

${ }^{107}$ As Retzlaff (2008) explains, "the Medicine Wheel is a teaching tool and a representation of traditional spirituality, philosophy, and psychology [standing] for the togetherness of people and nations, for unity and power, for spirit as well as for the cyclical nature of everything" (p. 338; see also Castellano, 2000).
} 


\section{Appendix C: Focus Group - Guiding Questions}

- Personal narratives: go around the circle, have each participant introduce herself and explain her level of proficiency in her heritage language. If she knows it: how did you learn it? If she doesn't know it: what factors account for this?

- How do you feel about your level of language proficiency? (i.e. if you speak your Aboriginal language, how do you feel about that? If you can't/don't speak your Aboriginal language, how does it make you feel?)

- What does "mother tongue" mean to you?

- In your opinion, are Aboriginal languages valued in Ottawa/Gatineau society?

- In your opinion, what is the \#1 reason to learn an Aboriginal language?

- Is your name important to you? If so, in what way(s) do you feel it is significant?

- As noted in the methodology, additional topics arose naturally in conversation and through the dynamic exchange between participants. Some of these include the legacy of residential schools; "western" versus "traditional" values; employment and upward social mobility; Aboriginal languages in the modern world; rural/reserve versus city life; belonging and alienation; physical appearance (due to mixed ancestry) and having to justify/explain Aboriginal identity; lack of awareness and stereotypes about Aboriginal people; and education. 


\section{Appendix D: Sample Interview Questions}

- Personal/demographic information (age; Aboriginal nation; other ancestry; brief family history; location of upbringing; current education/employment details; type of education institutions attended as a youth - public/private, religious, bandoperated, on/off-reserve, etc.; first language learned as a child; main language spoken in the home today; Aboriginal language proficiency in the 4 skills of speaking, listening comprehension, reading and writing; family members' Aboriginal language proficiency)

- What language do you feel defines you or that you associate with the most?

- Those who do not speak their Aboriginal language: Does this hinder your ability to communicate with any friends, acquaintances, or family members? Where, if anywhere, do you hear the language being spoken? How do you feel in these situations?

- Those who do speak their Aboriginal language: Is this important for your ability to communicate with friends, acquaintances, or family members? In what situations do you generally use the language? How do you feel in these situations?

- Are there any situations in which you experience discomfort or anxiety specifically related to your Aboriginal language?

- Do you see a relationship between language and culture? If so, how would you describe this relationship?

- Do you believe that preserving a community's language is necessary to preserving that community's culture?

- Here in Ottawa, what connections (if any) do you have with people or organisations affiliated with your Aboriginal nation and/or specific community? How important is it to you to have these kinds of connections? Do you find this difficult to maintain in an urban setting?

- How important is your name to your personal identity? Do you feel it matters what language your name is in?

- Language aside, what do you feel defines you as a (Cree, Inuk, Anishinaabe, Shuswap) person?

- Beyond your specific Aboriginal nation (Cree, Inuit, etc.), do you feel a broader sense of identity as an "Aboriginal" person? Please explain. 
- How do you perceive yourself in terms of your mixed heritage? Do you see yourself as having two cultures, or two identities? If yes, what kinds of things do you do that represent that other culture? If no, please elaborate.

\section{Follow-up questions}

- Do you identify as Canadian? If yes, in what way - that is, what kinds of things do you do that you feel are "Canadian"? If no, please elaborate on this point.

- Additional follow-up questions specific to each individual. 